\title{
Delaying child marriage through community-based skills- development programs for girls: Results from a randomized controlled study in rural Bangladesh
}

\author{
Sajeda Amin \\ Population Council \\ Johana Ahmed \\ Population Council \\ Jyotirmoy Saha \\ Population Council \\ Md. Irfan Hossain \\ Population Council \\ Eashita Haque \\ Population Council
}

Follow this and additional works at: https://knowledgecommons.popcouncil.org/departments_sbsr-pgy

Part of the Demography, Population, and Ecology Commons, Family, Life Course, and Society Commons, and the International Public Health Commons

How does access to this work benefit you? Let us know!

\section{Recommended Citation}

Amin, Sajeda, Johana Ahmed, Jyotirmoy Saha, Md. Irfan Hossain, and Eashita Haque. 2016. "Delaying child marriage through community-based skills-development programs for girls: Results from a randomized controlled study in rural Bangladesh." New York and Dhaka: Population Council. 


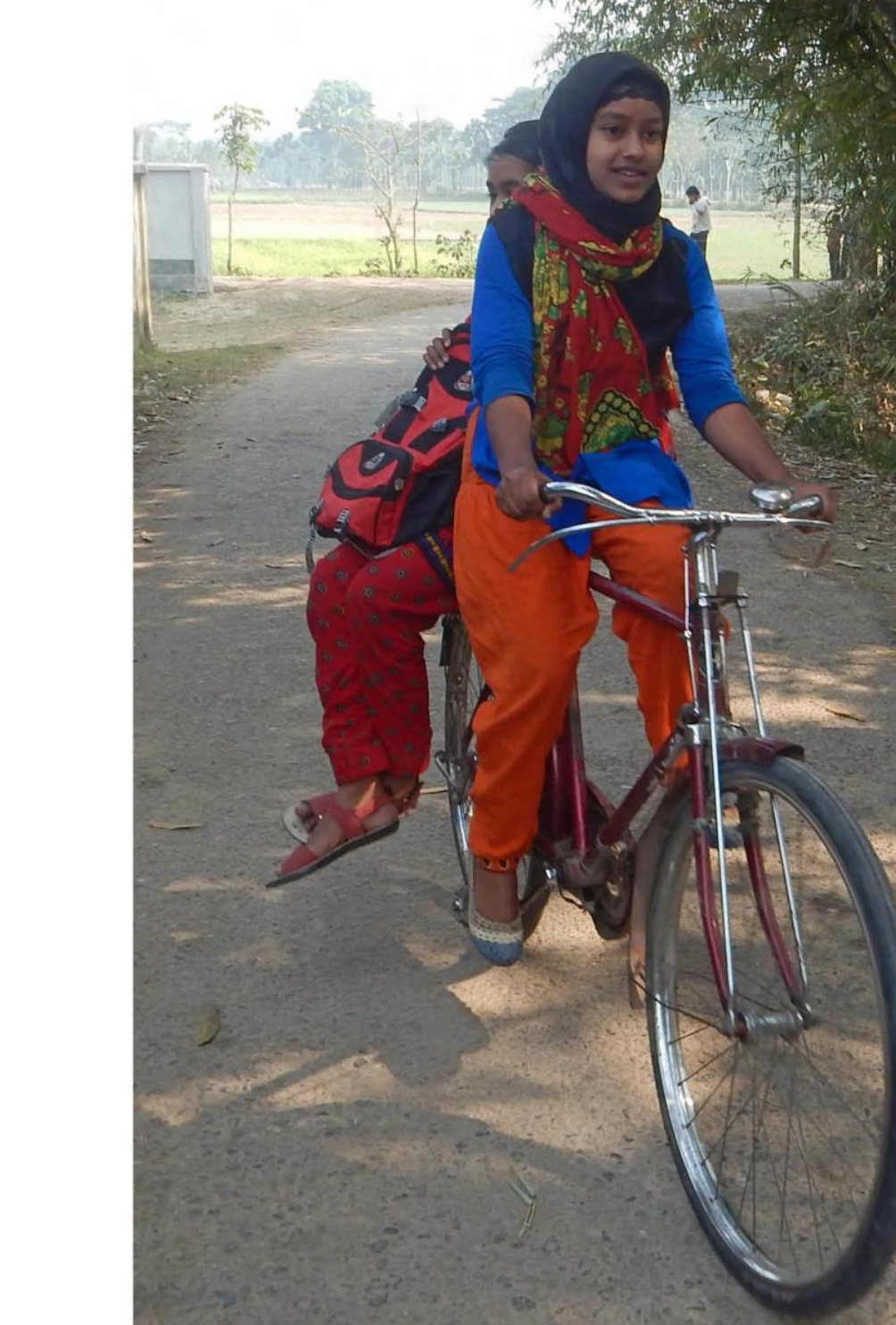

Bangladesthi Association for Life Skills, Income, and Knowledge for Adolescents

\section{COMMUNITY-BASED SKILLS-DEVELOPMENT PROGRAMS FOR GIRLS \\ RESULTS FROM A RANDOMIZED CONTROLLED STUDY IN RURAL BANGLADESH}

SAJEDA AMIN

JOHANA AHMED JYOTIRMOY SAHA

MD. IRFAN HOSSAIN

EASHITA FARZANA HAQUE 


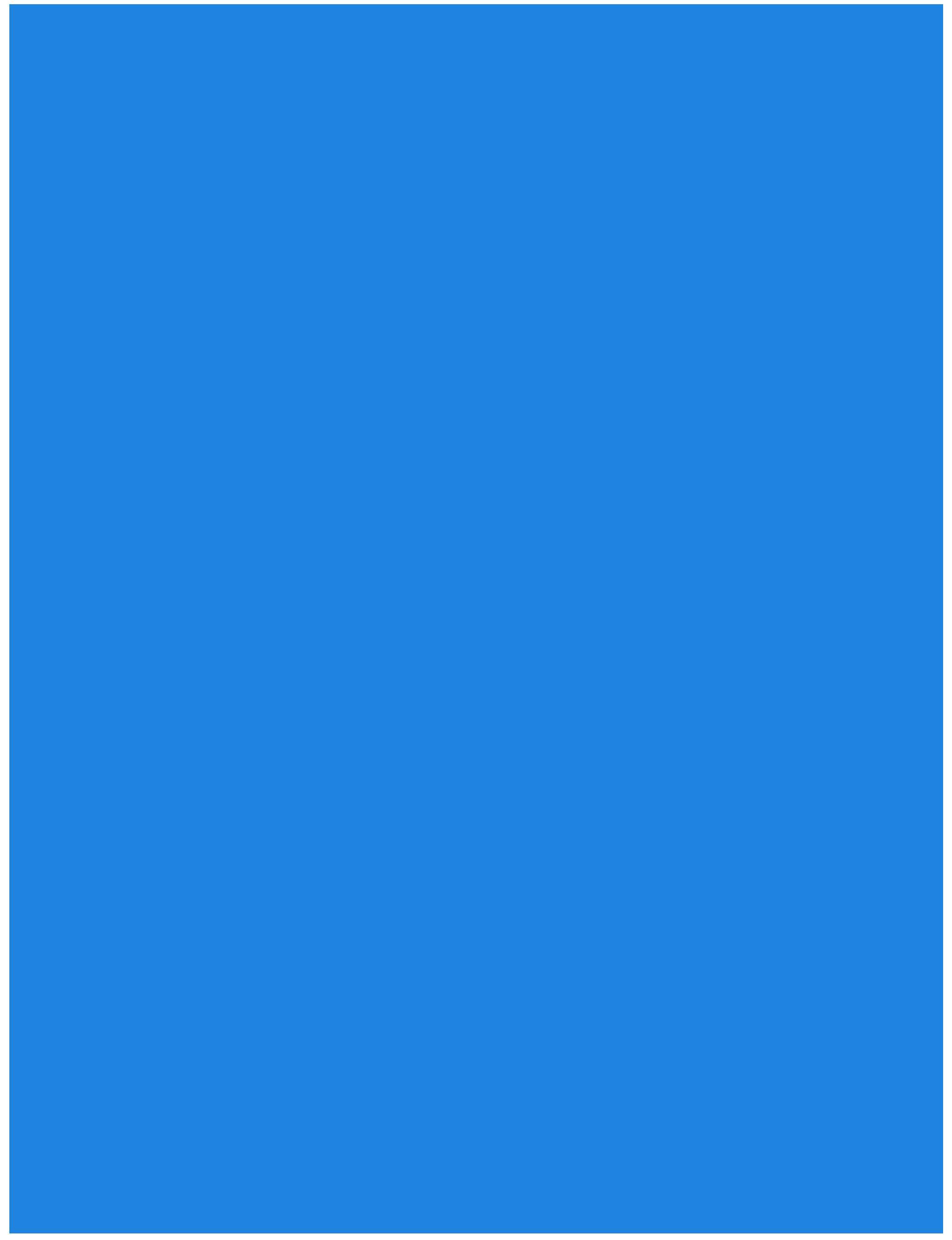




\title{
DELAYING CHILD MARRIAGE THROUGH COMMUNITY-BASED SKILLS-DEVELOPMENT PROGRAMS FOR GIRLS
}

\author{
RESULTS FROM A \\ RANDOMIZED CONTROLLED \\ STUDY IN RURAL BANGLADESH
}

SAJEDA AMIN JOHANA AHMED

JYOTIRMOY SAHA

MD. IRFAN HOSSAIN EASHITA FARZANA HAQUE 


\section{POPULATION COUNCIL}

Ideas. Evidence. Impact.

The Population Council confronts critical health and development issues-from stopping the spread of HIV to improving reproductive health and ensuring that young people lead full and productive lives. Through biomedical, social science, and public health research in 50 countries, we work with our partners to deliver solutions that lead to more effective policies, programs, and technologies that improve lives around the world. Established in 1952 and headquartered in New York, the Council is a nongovernmental, nonprofit organization governed by an international board of trustees.

Population Council

One Dag Hammarskjold Plaza

New York, NY 10017 USA

Population Council-Bangladesh

House \# 15B, Road \# 13

Gulshan, Dhaka

Bangladesh 1212

Tel: +88029842276

Email: info.bangladesh@popcouncil.org

popcouncil.org

The BALIKA project was made possible by generous support to the Population Council from the Embassy of the Kingdom of the Netherlands. The project is also supported by the Ministry of Women and Children Affairs, Department of Women Affairs, Government of the People's Republic of Bangladesh.

Sajeda Amin is Senior Associate, Johana Ahmed is Program Officer and Project Manager, Jyotirmoy Saha is Senior Research Officer, Md. Irfan Hossain is Assistant Program Officer, and Eashita Farzana Haque is Senior Research Officer, Population Council.

Suggested citation: Amin, S., J. Ahmed, J. Saha, M. Hossain, and E. Haque. 2016. "Delaying child marriage through community-based skills-development programs for girls: Results from a randomized controlled study in rural Bangladesh." New York and Dhaka, Bangladesh: Population Council.

Photos:

Cover: Priyanka Rani (Satkhira district); page 1: Ashish Bajracharya, Population Council; page 10: Tonni Mollik, BALIKA member; page 19: Fahmida Bashar Rifa, BALIKA member; page 27: Rani Khatun, BALIKA member; page 32: Shamima, BALIKA member; page 36: Lachmin, BALIKA member.

(C) 2016 The Population Council, Inc. 


\section{Table of Contents}

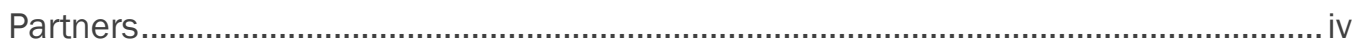

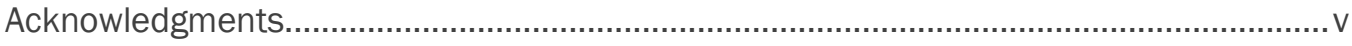

Executive summary....................................................................................................... vi

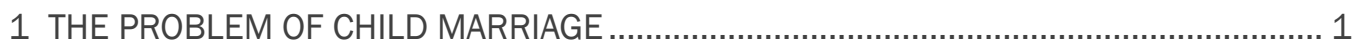

Global examples of programmatic efforts that delay marriage ................................... 2

Efforts to delay marriage through program interventions in Bangladesh .................... 4

Research evidence on child marriage determinants ................................................ 5

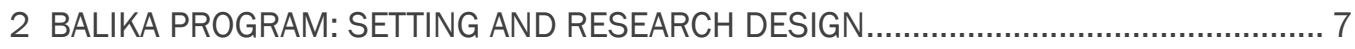

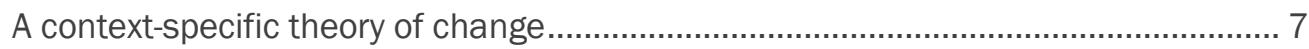

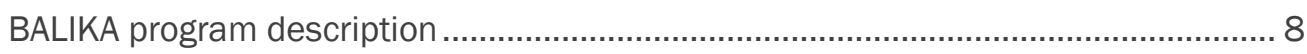

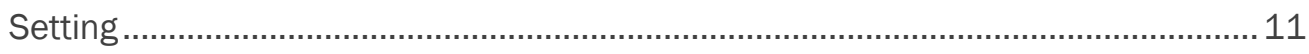

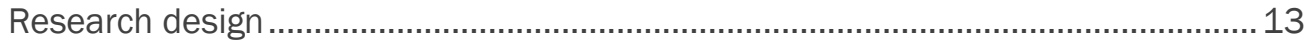

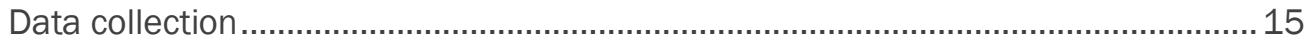

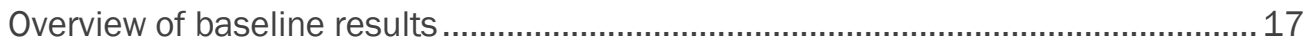

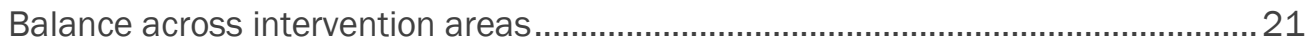

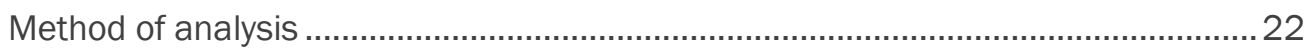

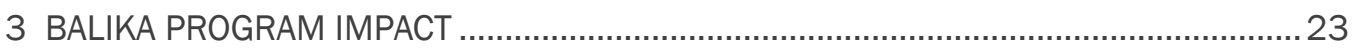

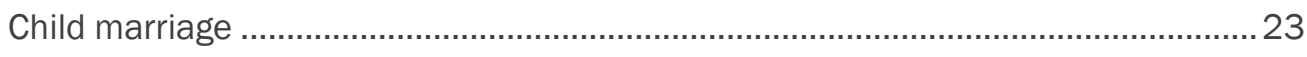

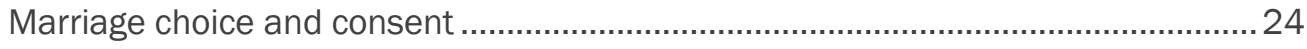

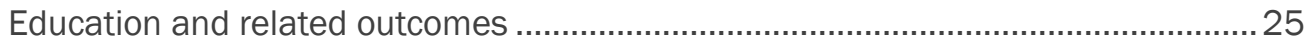

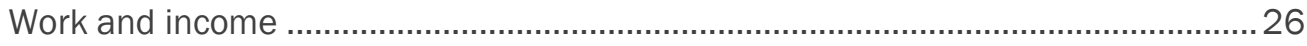

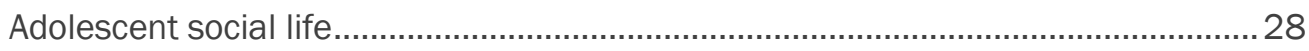

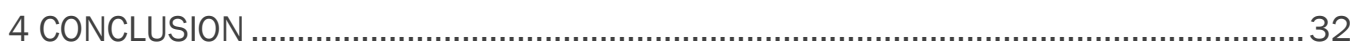

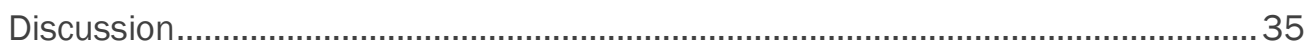

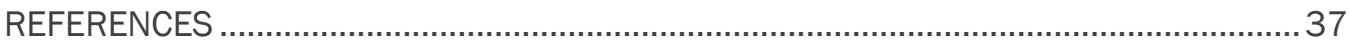

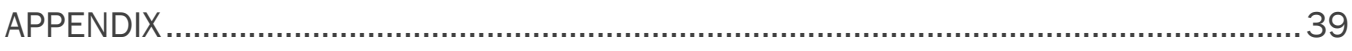




\section{Partners}

BALIKA (Bangladeshi Association for Life Skills, Income, and Knowledge for Adolescents) is a unique collaboration between communities in rural Bangladesh, international NGOs, and the Dutch government.

The Population Council (www.popcouncil.org) confronts critical health and development issues-from stopping the spread of HIV to improving reproductive health and ensuring that young people lead full and productive lives. Through biomedical, social science, and public health research in 50 countries, the Council works with partners to deliver solutions that lead to more effective policies, programs, and technologies that improve lives around the world. The Population Council conducts the world's largest body of research on programs to improve the lives of adolescent girls in the developing world.

Population Services and Training Center (PSTC) (http://infosysbd.com/demo/pstc_final/ index.php/our-projects) is a national nongovernmental and not-for-profit organization working for the improvement of life status of poor and socially disadvantaged people by undertaking various programs and projects for the last 34 years in Bangladesh at the grassroots level. PSTC has extensive experience in the areas of health service delivery; child, adolescent and youth development; governance and rights; and poverty reduction and livelihoods.

Centre for International Development Issues Nijmegen (CIDIN) (www.ru.nl/cidin) is a Netherlands-based interdisciplinary academic research institute that focuses on inequality, poverty, development, and empowerment. It is embedded in the Faculty of Social Sciences of Radboud University Nijmegen. In addition to teaching programs, the organization conducts research on a range of issues including migration, water management, gender, and sexual reproductive health and rights (SRHR). The PopDev Project: Impact of Reproductive Health Services in sub-Saharan Africa and the On Track with Gender initiative are collaborations with the Dutch Ministry of Foreign Affairs and Dutch development NGOs. CIDIN has built up considerable expertise on impact evaluation, covering development interventions implemented by both governmental and nongovernmental actors.

mPower Social Enterprises (www.mpower-social.com) is a global social enterprise, headquartered in Bangladesh, harnessing the power of information and leveraging Information and Communication Technology (ICT) (mobile technologies in particular) to revolutionize the impact of development programs through optimal use of limited resources. With experience in creating technology-supported data collection and decision-support systems for development projects, mPower tracks progress, activities, and outcomes in real time. 


\section{Acknowledgments}

The Population Council, the Population Services and Training Center (PSTC), mPower Social Enterprises (mPower), and the Center for International Development Issues Nijmegen (CIDIN) have worked together on an intervention research study to generate evidence on what works to prevent child marriage in Bangladesh. This report is an integral part of the BALIKA project conducted in three districts in southern Bangladesh, and presents evidence from the endline study. We are grateful to the Embassy of the Kingdom of the Netherlands (EKN) in Bangladesh for their generous support. Key members of the EKN team included Ella de Voogd, First Secretary, Sexual and Reproductive Health and Rights and Gender, and Mushfiqua Z. Satiar, Adviser, SRHR and Gender. Additional funding was provided by the Population Council, DANIDA, and the MacArthur Foundation.

The authors acknowledge the contributions of many individuals and institutions that made this research possible. We thank the Population Council's field and data management teams for their work on the adolescent household survey, including in-depth interviews, focus group discussions, and key informant interviews. Liton Acharja, Arifur Rahman, and Mashiur Rahman provided overall supervision and field support. Sadia Sultana, Runjuma Akter, and Fatema Akter Jumki conducted qualitative interviews and community assessments as research officers. Field supervisors Amena Khatun Poppy, Siuli Biswas, Islama Khatun, Shahinur Akter, Sajia Afrin, Rubina Akhter Sakina, Sultana Ferdushe Mridul, and Rashida Akter worked with a team of 53 data collectors that spent nearly four months in difficult field situations.

PSTC program managers and team members under the supervision of Kaniz Gofrani Quraishy provided valuable logistical and other support to ensure timely completion of the study. Abu Saeem Arif of mPower developed the software for paperless data entry and created an innovative dashboard to facilitate efficient monitoring and coordination of the datacollection process under the supervision of Bidhan Chandra Pal, also of mPower. We are grateful to Sahin Mahmud of mPower who provided both technical assistance regarding data input and troubleshooting of Android systems in the field.

The Population Council's Institutional Review Board reviewed and approved this project and provided ethical clearance. We thank the Ministry of Women and Children Affairs (MoWCA) of Bangladesh and local government representatives for their support of this research.

A special thanks also goes to Population Council colleagues who made important contributions to this study and report. Ann Blanc and Sarah Engebretsen reviewed the report and offered valuable input. We thank Dipak Kumar Shil and Mamun or Rashid of the Dhaka office and Barry Ravitch, Mary Elmoor, and Elizabeth Cottrell of the New York office who managed study funding, subawards, and vendor payments. Joyce Altman and Michael Vosika in the Council's Publishing and Creative Services department edited and designed the report.

Finally, we express our gratitude to the adolescent girls and their families in nine upazilas under three districts who shared their experiences and perspectives by participating in the household surveys and interviews, without whom this study would not have been possible. 


\title{
Executive summary
}

\author{
Two out of three girls in Bangladesh are married before the legal \\ age of 18. Most become mothers while they themselves are still \\ children.
}

Child marriage forces girls into sexual relationships for which they are not physically or emotionally prepared. It can cause them to drop out of school and it limits their opportunities for community participation, including employment. A delayed marriage greatly improves a girl's chances for a healthy, happy, productive life. And the benefits of a later marriage go beyond the girl: her children, family, community, and country experience better health, economic, and social outcomes.

Programs that elevate girls' visibility and status in their families and communities, and build their skills and knowledge, have been shown to delay marriage in different parts of the world. However, in Bangladesh, where efforts to prevent child marriage have focused on the enforcement of laws and policies, little research exists on what approaches work best to delay marriage and why.

To help fill this evidence gap, in 2012 the Population Council and partners embarked on a four-year study to understand whether skills-building approaches to empower girls can delay marriage in Bangladesh communities where child marriage rates are highest in three districts in southern Bangladesh: Khulna, Satkhira, and Narail.

The BALIKA project implemented a randomized controlled trial involving more than 9,000 girls aged 12-18 in 72 intervention communities and 24 control communities within three districts of Bangladesh to determine what works to delay child marriage. This is the first rigorously evaluated study to provide evidence on approaches to delay child marriage in Bangladesh.

Communities were assigned to receive one of three intervention strategies in the trial for 18 months.

- EDUCATION: Girls received tutoring in mathematics and English (in-school girls), and computing or financial training (out-of-school girls).

- GENDER-RIGHTS AWARENESS TRAINING: Girls received life skills training on gender rights and negotiation, critical thinking, and decision-making.

- LIVELIHOODS SKILLS TRAINING: Girls received training in computers, entrepreneurship, mobile phone servicing, photography, and basic first aid. 
In the 24 communities that served as the control group of the study no program services were provided. This group was necessary to determine whether girls receiving services had a benefit compared with girls who received no services.

To measure the impact of each intervention strategy in relation to the others and to the control group, a baseline survey was conducted before the project was implemented, and an endline survey was conducted after the project had been in place for 18 months.

All girls participating in the BALIKA program met weekly with mentors and peers in safe, girlonly locations called BALIKA centers, which helped girls develop friendships, receive training on new technologies, borrow books, and acquire the skills they need to navigate the transition from girlhood to adulthood. Girls used these skills within their communities, which helped build confidence, demonstrate their achievements, and elevate their profiles.

BALIKA results show that programs that educate girls, build their skills for modern livelihoods, and engage their communities can reduce the likelihood of child marriage by onethird and produce better health, educational, and social outcomes for girls. Girls living in BALIKA communities were one-third less likely to be married as children (0.69-0.77 relative odds adjusted for age, religion, and family wealth status) than girls living in communities not reached by the BALIKA program.

Girls who were single at the beginning of the study were one-fourth less likely to be married by the end of the study (0.76-0.78 relative odds adjusted for age, religion, and family wealth status). Each intervention showed that it was possible to significantly delay child marriage:

- In BALIKA communities where girls received educational support, girls were $31 \%$ less likely to be married as children at endline than girls in the control communities.

- In communities where girls received life skills training on gender rights and negotiation, critical thinking, and decision-making, girls were $31 \%$ less likely to be married as children at endline than girls in the control communities.

- In communities where girls received livelihoods training in entrepreneurship, mobile phone servicing, photography, and basic first aid, girls were $23 \%$ less likely to be married as children at endline than girls in the control communities.

In addition to delaying child marriage, the evaluation studied the impact of its three intervention approaches on a range of other indicators that affect education, health, and social outcomes later in life. All three interventions had similarly successful outcomes. Compared to girls outside BALIKA communities, the study found that girls participating in the program were:

- more likely to be attending school.

- $20 \%$ more likely to have improved mathematical skills if they received education support and gender-rights awareness training.

- one-third more likely to be earning an income if they received gender-rights awareness or livelihoods-skills training.

These results are from an intent-to-treat analysis, in which the impact of each intervention strategy on child marriage is measured among all girls who live in the community, not just those girls who participated in the BALIKA program. 
Results summary of the impact of the interventions on child marriage, sexual and reproductive health and rights, schooling, and gender-awareness indicators

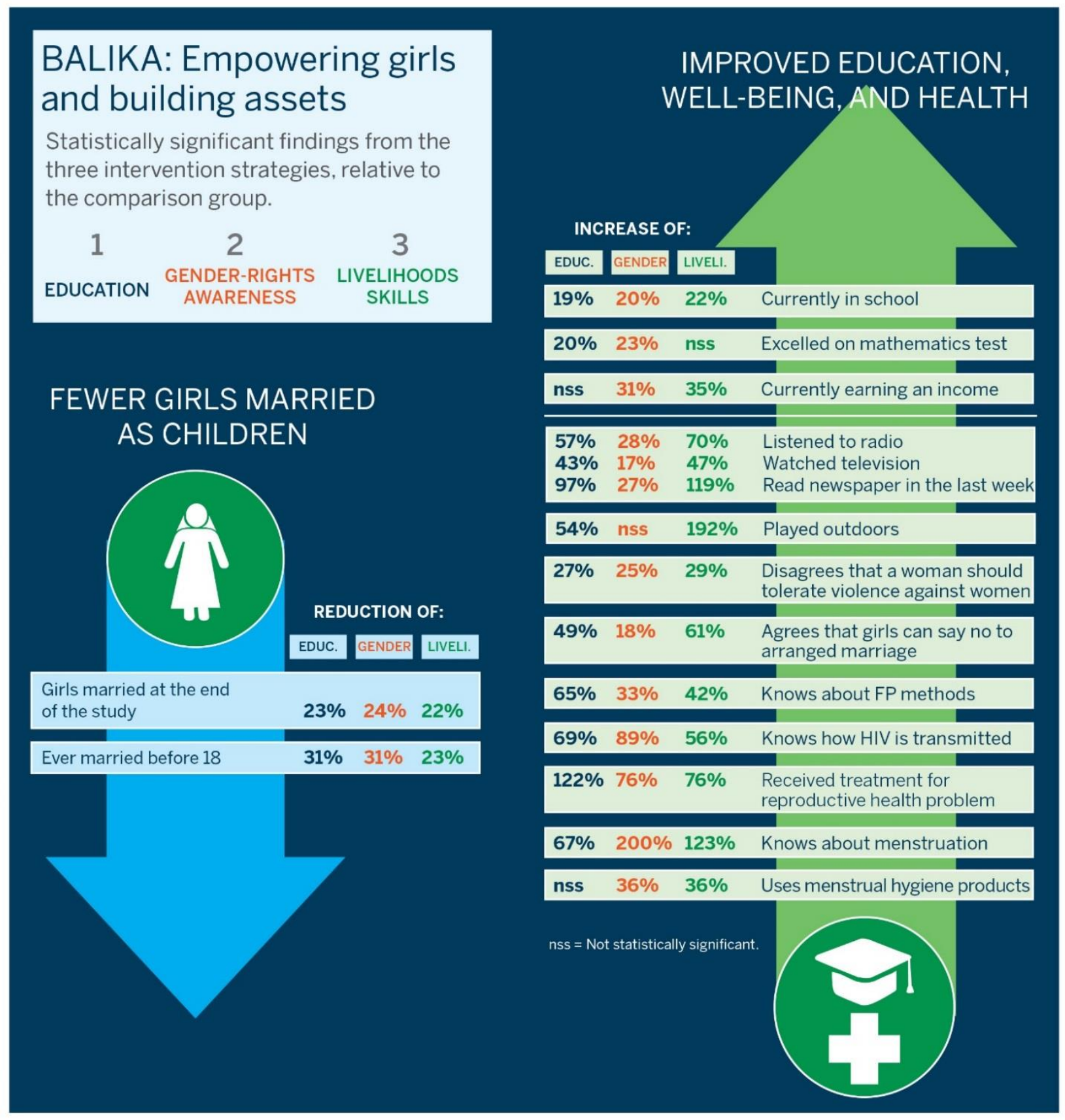




\section{THE PROBLEM OF CHILD MARRIAGE}

Bangladesh has achieved significant success on many gender and reproductive health issues since its emergence as an independent country in 1971. Schooling is nearly universal with girls and boys equally likely to complete primary school; life expectancy at birth has increased from an average of 50 years to more than 70; and fertility has declined from 6.5 births per woman to 2.3. However, these social successes stand in sharp contrast to the persistent high rates of child marriage. Most girls in Bangladesh are married and bear children while they are still children. An estimated two out of every three girls are married before the legal age of 18 , and little improvement has taken place in the pattern of child marriage in recent decades. Marriage effectively ends schooling and prevents girls from achieving their full economic potential. Educating girls and promoting their sexual and reproductive health and rights, including child-marriage prevention, can contribute to population- and poverty-reduction goals by empowering girls and women to have greater control over their productive and reproductive lives.

The practice of child marriage is influenced by community norms and beliefs, household poverty, and a lack of individual opportunities for girls and women. Norms and beliefs may support and be supported by poor access to positive alternatives, such as schooling and work for young girls. Girls who marry early are at a disadvantage because of their social isolation, poverty, and poor education, and because of their young age relative to their partners. These factors result in the limitation of knowledge and skills needed to negotiate adult roles. The lack of power within the marital relationship can compromise a woman's ability to exercise her reproductive rights, including decisions related to family planning, childbearing, and maternal and child health services.

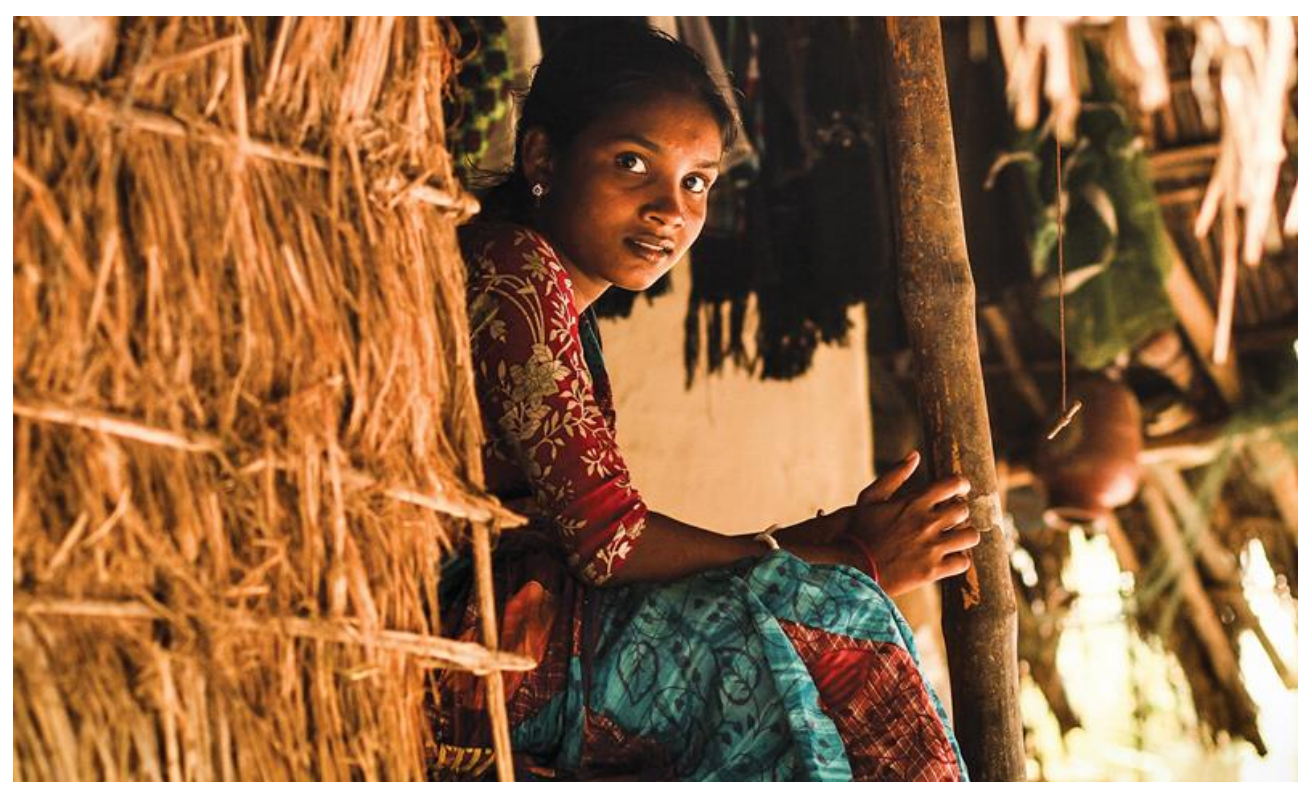

Photo Credit: Ashish Bajracharya, Population Council 
Child marriage is associated with high maternal mortality and increased total fertility. Demographic and Health Survey data from around the world suggest that marriage rather than unwed motherhood is a driver of early childbearing (Haberland et al. 2005). Ninety percent of first births to mothers under the age of 18 take place within the context of marriage. Pregnancy and delivery complications are the main causes of death among girls aged 15-19, and girls who bear children before the age of 15 are five times more likely to die of pregnancy-related causes compared to older mothers (Murphy and Carr 2007).

More recently, evidence has emerged indicating that girls who marry early are at increased risk of gender-based violence, likely due to large spousal age differences and girls' limited power within these marriages (USAID 2009). Delaying marriage may delay initiation of child-bearing and result in lower overall fertility, higher education levels, reduced maternal mortality, and a decrease in gender-based violence.

Research on the initiation of childbearing and determinants of child marriage suggest that relatively little is known about scalable programs that can empower girls to delay marriage. The objective of the BALIKA (Bangladeshi Association for Life Skills, Income, and Knowledge for Adolescents) project (2012-16) was to generate evidence about what works to delay marriage in Bangladesh. We implemented skill-development programs for girls at highest risk, i.e., between 12 and 18 years of age and living in impoverished areas with the highest child-marriage prevalence (hotspots), to explore the potential benefits of such investments in delaying marriage.

\section{Global examples of programmatic efforts that delay marriage}

The main programmatic strategies used to increase age at marriage have been: (1) awareness-raising and education subsidies at the individual and community level, (2) promoting schooling success through interventions such as tutoring/mentoring, school supplies, and uniforms, (3) promoting girls' livelihoods, and (4) gender-rights awareness. Most programs use a combination of strategies and include awareness raising and education at the community level in combination with other approaches, such as promotion of education or livelihoods.

\section{Stipend and subsidy}

In Ethiopia, Berhane Hewan (Light for Eve) is a project of the Ethiopia Ministry of Youth and Sports and the Population Council, and is one of the few programs in sub-Saharan Africa to systematically measure the impact of an intervention to increase age at marriage (Erulkar and Muthengi 2009). Based on formative research, the program combines community mobilization and sensitization, safe spaces, and incentives/asset transfers to keep girls in school and unmarried. The evaluation of the program found significant delays in marriage for girls aged 10-14 and significant increases in school enrollment. In addition, sexually active girls in the intervention site were three times more likely to use family planning compared with girls in the control site. Partners at the Ministry of Youth and Sports consider Berhane Hewan a best practice, and the program has been scaled up. However, concerns remain that it may not be feasible to upscale all components of the intervention, and providing incentives to the families of girls in the form of goats has been difficult to scale up. 
A seven-year follow-up of an education-subsidy program in Kenya showed that stipends for male and female students reduced school dropout, marriage, and teen pregnancy rates (Dulfo, Dupas, and Kremer 2014). In a program that offered students in Kenya merit scholarships (full or partial tuition coverage) through a competitive process, rewarding those with good performance, test scores for the entire pool of competitors increased in the randomly selected schools. The study concludes that providing competitive merit-scholarship incentives is arguably the most cost-effective way to improve test scores (Kremer, Miguel, and Thornton 2009).

Baird and colleagues (2012) conducted a randomized evaluation of cash-transfer programs in Malawi and demonstrated the impact of such programs on a range of sexual and reproductive health indicators, including child marriage. A study that offered stipend support to orphans in Zimbabwe schools using a randomized controlled trial found that interventions that offered school-based meals to all children and stipend support to orphans resulted in a school dropout rate reduction of 82 percent and child marriage reduction of 63 percent after two years of intervention (Hallfors et al. 2011).

\section{Tutoring}

Berhane Hewan also provided basic literacy and numeracy support through tutoring. It helped to improve contraceptive use, and expanded friendship networks to girls who were previously isolated. However, the project offered other components, such as incentives and community engagement to change behavior, so change cannot be attributed to tutoring support alone (Erulkar and Muthengi 2009). In India, the Balsakhi program, run by the education-support organization Pratham, supports recent secondary-school graduates in mentoring young students who are falling behind in third and fourth grade. A second program implemented by Pratham supported computer-assisted learning provided by the school to students. Both programs were rigorously evaluated and found to significantly improve test scores. However, the programs were not able to document any impact on dropout rates (Banerjee et al. 2007).

\section{Opportunities for employment}

Jensen (2012) demonstrated the potential importance of providing information about transformational job opportunities in an intervention research study where randomly selected communities were given information by industry recruitment agents about employment possibilities in a nearby urban center. This informational intervention brought about considerable change in the behavior of parents, who increased their investment in schooling and nutrition for their daughters, and delayed their marriage. Relative to control villages, women in treatment villages were more likely to have higher career aspirations, to want to work outside the home, and to want fewer children in their lifetime. A quasi-experimental study by Heath and Mobarak (2015) comparing Bangladesh villages near an export-oriented industrial zone where factories employed young women in villages farther away found that the prospect of jobs in factories significantly increased schooling and lowered the risk of child marriage and childbirth for girls. The authors argued that girls' delaying of marriage availed them of opportunities for work (Heath and Mobarak 2015). 


\section{Gender-rights awareness}

A recent comprehensive review of curriculum or group-based education programs on sexuality and HIV prevention found that programs that included content on gender and power matters were considerably more likely to be effective in bringing about positive health and gender outcomes than programs that did not include such material. While the studies reviewed were primarily focused on sexuality and health outcomes, and many were conducted in areas with high HIV prevalence, the review suggests that including content on gender and power may have positive gender outcomes that are relevant to schooling and marriage (Haberland 2015).

\section{Efforts to delay marriage through program interventions in Bangladesh}

The need to change child-marriage practices is well recognized and there have been a number of initiatives toward that end. In general, the evidence of an association between child marriage and girls' education is strong (Lloyd 2005). In most of the world, marriage is delayed as educational attainment increases. However, it is less clear which specific programmatic interventions to ensure schooling are likely to be most effective-school quality, economic support, or conditional cash transfers are all plausible interventions that may work in pilot projects, but programmatic scaled up experiences of cost-effective and sustainable strategies are limited. Rigorous evaluations of the impact of these interventions are even more uncommon. Most programs either lack an evaluation framework or employ an extremely weak one (ICRW 2007; IntraHealth 2008), effectively limiting their potential influence on policy. For example, a project entitled "Raising the Age of Marriage for Young Girls in Bangladesh" was implemented including scholarships, skills training, and community awareness/advocacy (Burket et al. 2006). However, the project lacked a rigorous evaluation component and merely tracked the number of beneficiaries and conducted qualitative interviews. Similarly, a national female secondary-school scholarship scheme in Bangladesh that has been in place since 1994, and was designed as a conditional cash transfer to delay marriage, was never rigorously evaluated. This scholarship program has been in place for more than 20 years, but the proportion of girls dropping out well before age 18 in Bangladesh remains among the highest in the world suggesting the program did not have the intended impact.

Programs that have been rigorously evaluated either showed promise or made valuable suggestions for improving program design. A project in Bangladesh entitled Kishori Abhijan (Adolescent Girls' Adventure) utilized livelihoods and life-skills training (Amin 2011). The evaluation showed increased participation in economic activities among participants compared with nonparticipants, and increases in reproductive health knowledge. However, change was detected in marriage age only for a subset of those in the program, the youngest and poorest girls in the poorest communities. Project researchers recommended additional programmatic attention to the economic drivers of marriage, especially dowry payments. Components of the Kishori Abhijan program have been scaled up by various institutions in the country, but the impact of the scale-up has not been evaluated (Amin 2011).

BRAC experimented with a combined micro-finance and life-skills program on a smaller scale and found combined interventions to have important synergistic effects on outcomes 
such as financial literacy and knowledge, but did not document any detectable change in age at marriage or reproductive outcomes (Hossain, Akter, and Das 2012).

Save the Children USA is currently implementing a program in Bangladesh called Kishoree Kontho (Adolescent Girls' Voices) (www.povertyactionlab.org/evaluation/empowering-girlsrural-bangladesh) that experiments with life skills, financial education, and incentives (in the form of cooking oil) to delay marriage. Many of the above-mentioned programs rely on some kind of a safe-space platform that varies in terms of the skills enhanced through the program. In addition to concerns about scale that such programs are likely to face (it is not clear how feasible it is to do transfers in oil rather than cash on a large enough scale to make a difference), the projects do not target the communities or girls most at risk, namely the youngest and poorest girls in communities at highest risk of child marriage.

\section{Research evidence on child marriage determinants}

The literature on determinants of timing of marriage suggests that poverty in combination with cultural/social/religious norms are important structural drivers of child marriage. Several studies have documented the pathways of influence from poverty to child marriage (Erulkar 2006; Amin and Bajracharya 2011). In South Asia, being able to afford dowry and avoid paying the higher dowries associated with increased age at marriage is widely perceived as an underlying explanation for the often observed higher rates of child marriage among the poor (Amin, Mahmud, and Huq 2002).

A recent review of laws pertaining to child marriage-their enforcement and effectivenesssuggests there is little evidence of the effectiveness of legal approaches (Kenny and Dykstra 2015).

Studies among garment workers that explore attitudes toward marriage delays and dowry suggest that structural factors affecting women's opportunities for work and workforce participation that offer meaningful alternatives to marriage have an important influence on the timing of marriage. While garment workers do not reject marriage altogether, girls from poor families that work in factories often describe the need to earn and pay for their own dowry as the motivation for work. As they engage in work, their perception of their own worth, and by association the logic of paying a dowry, can change. When women expect to work after marriage, they may argue that the value of their future income stream should be taken into account when bargaining about dowry negotiations with future grooms. Migration to access new work opportunities is an adaptation strategy that has important consequences regarding decisions about the timing of marriage (Naved, Newby, and Amin 2001).

By far the most directly intentional policy implemented in Bangladesh seeking to delay marriage is a stipend program to keep girls in school. This program has been in place since 1994. The program initially provided support to all girls regardless of economic status, but in recent years has taken a means-tested approach. While the program is credited for increasing girls' schooling, there is relatively little evidence to suggest that it has been consequential for marriage timing (World Bank 2006). 
Normative influences act as structural drivers of child marriage in a variety of ways. The influence of dowry was mentioned earlier. Although dowry was not traditionally paid in Muslim marriages, the practice of demanding dowry at marriage was first noted in Bangladesh in the early 1960s and has now become an established practice despite its illegality. Another normative influence is the pressure on parents who are obligated to marry their daughters, often citing religious doctrine. It is possible that short life expectancies and the costs associated with a daughter's marriage combines to create a strong incentive to marry off a daughter early. Providing for their daughters through marriage is a sentiment often voiced and quoted in qualitative studies (Aziz and Maloney 1985; Muna 2005). Although Bangladesh has seen very rapid increases in life expectancy from an average of about 50 years (in 1990) to more than 70 years (in 2014), perceptions about longevity have been slow to change (Amin and Basu 2004). 


\section{BALIKA PROGRAM: SETTING AND RESEARCH DESIGN}

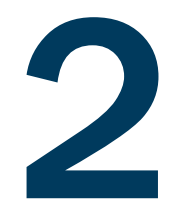

\section{A context-specific theory of change}

An extensive global and local literature review, and data from the BALIKA baseline survey (Amin et al. 2014), allows us to articulate the general theory of change shown in Figure 1. Our theory of change recognizes the important role of cultural norms, economic drivers, and institutional context in influencing the processes that result in child marriage. The overall approach in the program and its components are shown in the panel labeled "Change." Our approach is to engage communities by working with local institutions and supportive adults to create a favorable environment to invest in girls. These investments include creating safe spaces, supportive networks, and a common platform that can bring girls together, as well as various skill-building activities. The objective of the program is to bring about change in girls' lives and their status in the community so that they are perceived as assets rather than as burdens and liabilities to their families and to society.

FIGURE 1 A theory of change regarding child marriage

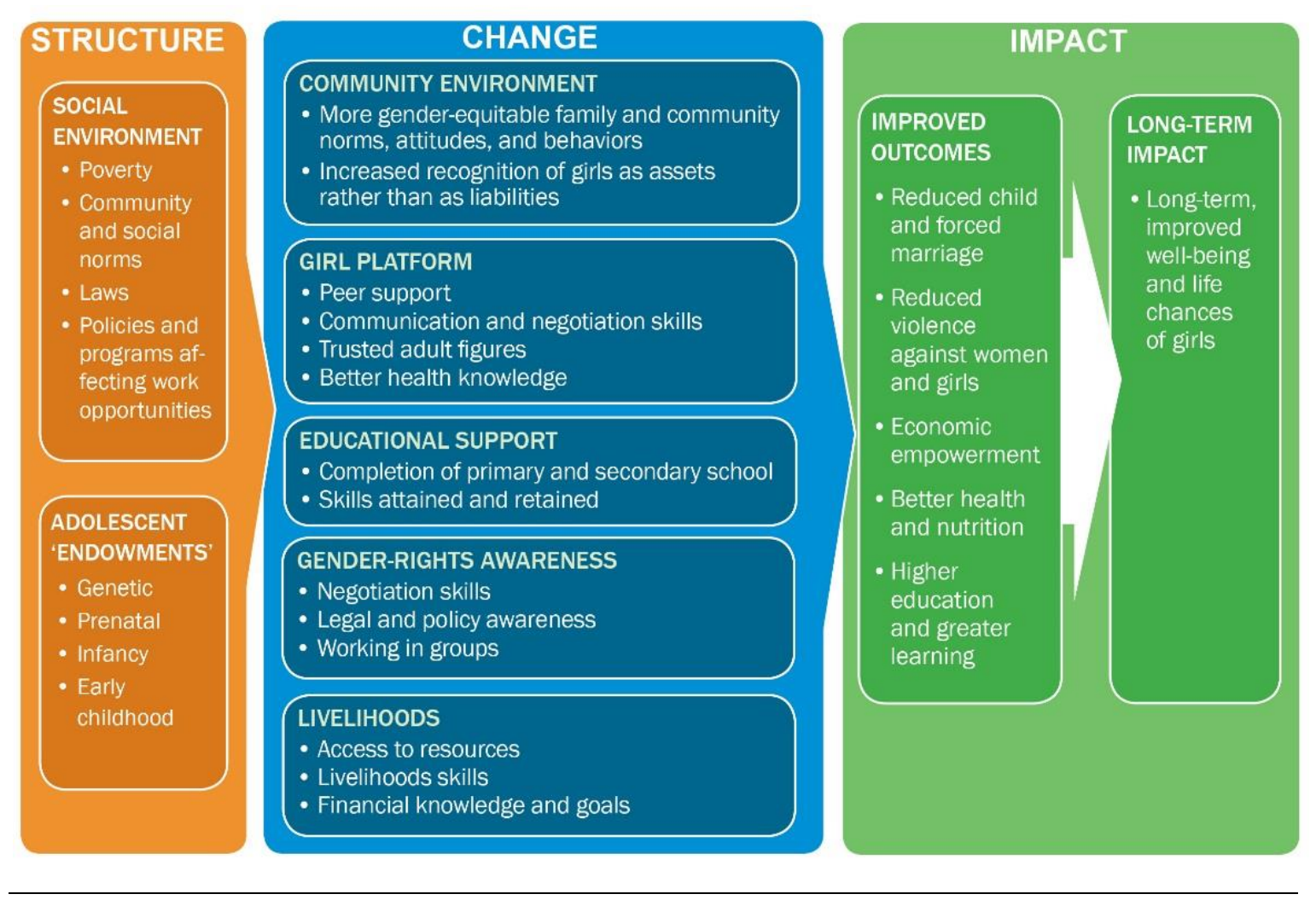


As reviewed earlier, the body of evidence on what works to delay marriage suggests the importance of educational support, gender-rights awareness, and livelihoods skills as being alternative approaches to building skills to empower girls through improved education, gender relations, and livelihoods activities. The acquisition of skills can operate through increasing girls' confidence in their own abilities, serving as credentials valued for their own sake, and as a means of improving future success in the job market.

\section{BALIKA program description}

BALIKA, a skill-building program for rural adolescent girls in communities having a high prevalence of child marriage, is designed to empower girls to delay marriage. A consortium comprising Population Services and Training Center (PSTC), mPower Social Enterprises (mPower), Center for International Development Issues Nijmegen (CIDIN), and the Population Council partnered on the project. PSTC, a national nongovernmental organization that has widespread experience in adolescent and youth development, health-service delivery, and livelihoods, implemented the program. PSTC's expertise in working with the community, acceptance in the locality, and networking capability with the local government and at the national level made the organization the right partner for implementation.

"In our village, girls are not given much priority. They are not allowed to go outside and face many obstacles. Even today, they are confined to their own houses. BALIKA will help them avoid these obstacles. As far as I know, the project will help them to learn how to use computers, will enlighten them about all the problems they face during adolescence." - Boy from focus group, Shovna
Technology played a critical role in this project. mPower developed information and communication technology-based tools and digital learning materials for the girls. The Center for International Development Issues Nijmegen (CIDIN), a Netherlandsbased academic research institute that focuses on poverty, inequality, development, and empowerment, worked with Population Council researchers on quantitative and qualitative research design and analysis.

All BALIKA centers were run by locally recruited young women (mentors) with the assistance of a teacher affiliated with the school that housed the center and worked part-time with the project after school hours. Center teachers and mentors recruited girls, liaised with families and communities, ran center activities, and engaged with the community support groups.

The teachers and mentors were the primary link between the program and the community and were important role models and mentors for adolescent girls.

Mentors were often only slightly older than the adolescents themselves and they reported the experiences of working in BALIKA to be transformative.

Assessing some specific characteristics of girls' schooling in rural Bangladesh, the BALIKA program has taken an approach that attempts to improve school performance with supplementary educational support-rather than an incentive-based approach such as Berhane Hewan or Kishori Kontho, which offer incentives to families for delaying marriage. Even though incentives have proven to have the desired positive impact in Berhane Hewan in Ethiopia, they would not have a similar positive impact in the context of Bangladesh as there is a national program in Bangladesh under which conditional cash transfer is provided in the form of scholarships to girls in secondary school. The incentive offered by the Bangladesh government is higher than the incentive offered in the Berhane Hewan program, which is equivalent to US\$6 per girl. Through BALIKA's education intervention, the study seeks to 
provide specific help to improve school success through improving learning outcomes, as the girls who perform poorly in school are more likely to drop out and be given in marriage.

The BALIKA program offered educational support in safe spaces (BALIKA centers are situated within primary schools to provide access to mentors who function as tutors and provide educational assistance to girls beyond their regular school hours). The Balsakhi program conducted by Pratham and evaluated by JPAL in India, shows that with extra tutoring support low-cost improvement in schooling outcomes at the primary level can be attained. From the experience of this study, BALIKA also provided educational tutoring beyond school hours to girls who attended education intervention sessions. Similar to the Balsakhi program, the BALIKA program recruited young women locally to mentor adolescent girls in the BALIKA centers.

The gender-rights awareness intervention strategy is primarily influenced by the experience of implementing the Population Council's "It's All One Curriculum," which incorporates strategies of promoting critical thinking, negotiation skills, and rights awareness in life-skills programs.

The livelihoods interventions were inspired from studies in India that emphasized the role of changing aspirations through work opportunities. The aim of the interventions was to change gender attitudes that undervalue girls in the South Asian cultural context. The livelihoods arm provided generic skills as well as specific exposure to a variety of income-earning activities with a view toward changing aspirations and inculcating career aspirations from a young age.

The BALIKA program began implementation in February 2014. The interventions took place in 72 out of 96 study unions while the remaining 24 unions served as controls. The interventions took place over an 18-month period. A "safe spaces" component is at the core of the BALIKA program. Girls' group meetings were organized in these safe spaces under the guidance of a female mentor from the community and were critical to the building of social assets among vulnerable girls. The designated safe spaces offered different types of training. Basic life-skills training totaling 44 hours was given to all girls. One of three additional skill trainings (livelihood, education, gender rights) was offered to each girl, totaling 100 hours, according to the randomization of villages.

The program offered skills training to around 9,000 girls aged 12-18 across three districts (Khulna, Satkhira, and Narail) in Bangladesh. The interventions aimed to increase girls' skills, self-confidence, self-awareness, and strategies for advocating for themselves to delay marriage. In the education intervention, in-school girls received educational tutoring in mathematics and English, and out-of-school girls received financial skills and communicative English learning sessions. In the gender-rights intervention, girls received information on sexual and reproductive health, gender rights, negotiation, critical thinking, decision-making skills, and gender-based violence. Participants were educated about gender rights and awareness, and sexual and reproductive health rights-related issues, to change values regarding gender roles by changing power dynamics and gender-based division of labor. In 
the livelihoods intervention, girls received training on computers, and learned about possible income-earning options using mobile-based applications, ${ }^{1}$ photography, health, and entrepreneurship.

BALIKA centers are located in the heart of communities, at primary schools, to offer safe learning environments where girls receive mentoring and peer support and are offered various types of skills and livelihoods training. BALIKA has taken a different approach to delaying child marriage-putting girls and their communities at the center of efforts. BALIKA has engaged community members, local leaders, parents, teachers, and others in solving the issues that make girls most vulnerable, while offering educational support and training skills to build girls' livelihood skills so that they (and the community) see themselves as assets rather than liabilities.

Participants in all three interventions met with the same regularity and were exposed to using computers and tablets with digital contents to acquire varied skills. Project activities in all interventions included community engagement activities, and participants were offered basic life skills. The centers are equipped with a kiosk, tablets, laptop, modem, mouse, and speaker. They have a small library with books that all BALIKA members can borrow on a weekly basis, to encourage girls to develop a reading habit and enhance their knowledge on different subjects.

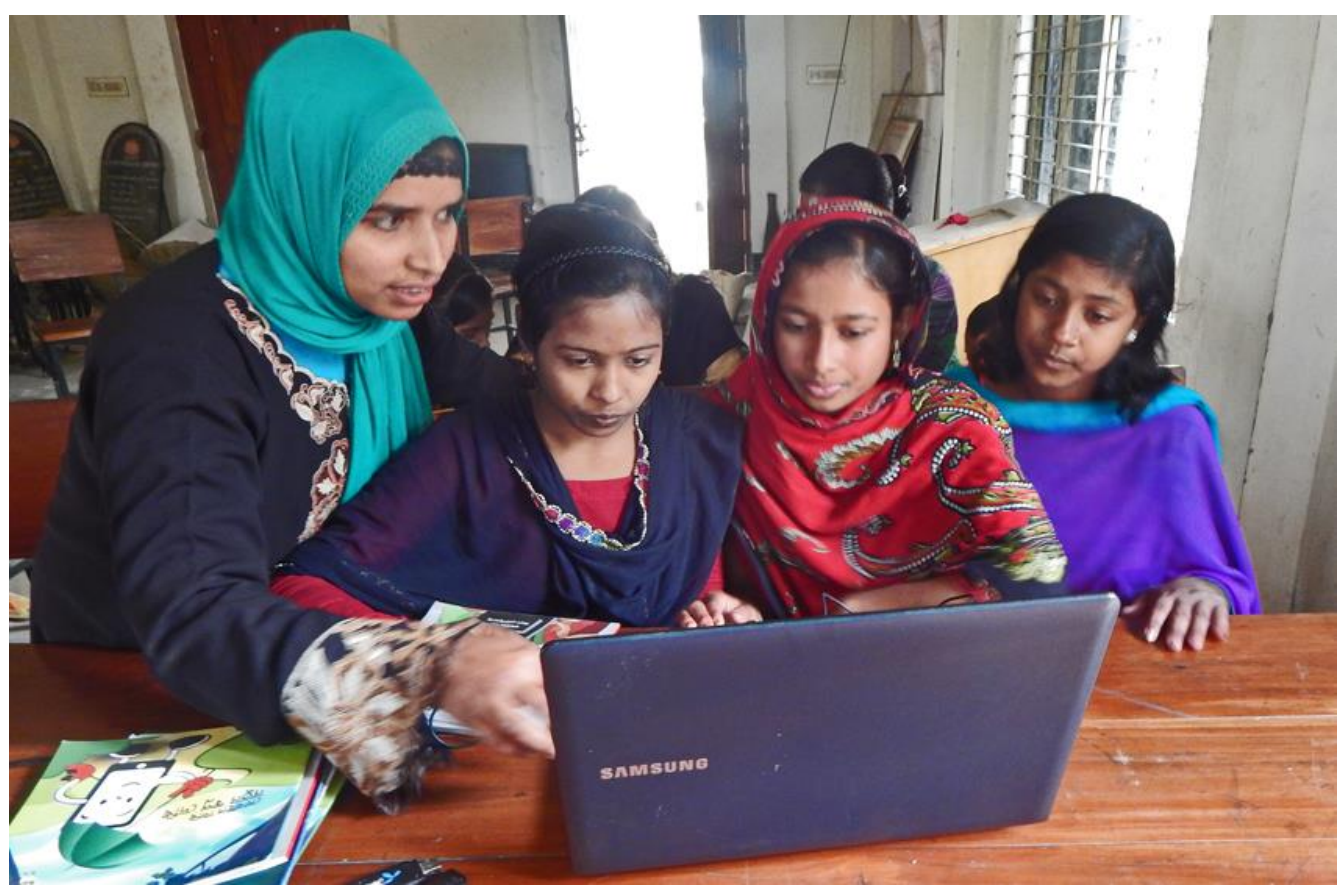

Photo Credit: Tonni Mollik, BALIKA member, Dumuria, Khulna

1 Girls were taught how applications can be used in mobile phones. They learned to download ringtones, recharge talk time on phones, and download information on various topics through mobile apps as well as basic mobile servicing. They also learned about mobile banking using bKash, a safe and convenient way to make payments and use money-transfer services via mobile phones. 


\section{Setting}

BALIKA has been implemented in districts in southwestern Bangladesh. To select our area of work, we analyzed secondary data from existing national data sources on the prevalence of child marriage to identify suitable study districts. Because the BALIKA project was planned as an intervention research project, we avoided selecting areas that were likely to be the site of other programs that might lead to declines in child marriage, which could potentially confound the study design. As such, we excluded districts in the north and northwest where several largescale programs were recently implemented to address child marriage. For example, we received information that BRAC's adolescent program has expanded in the north and hence we avoided those regions even though they include early-marriage areas.

We selected the three districts of Khulna, Satkhira, and Narail. Our formative research and further analysis of secondary data allowed us to characterize the study area in terms of social and environmental characteristics. The southernmost parts of our selected study area experience regular coastal flooding and increased salinity associated with both land topography and river activity. An analysis of local-level variability in child marriage associated with environmental features found that while there were no statistically significant differences by salinity or river erosion, communities that hosted large displaced populations had higher rates of child marriage, while villages that were hit by devastating cyclones in the past decade had lower rates of child marriage (Ainul and Amin 2015). Our analysis concluded that patterns of migration and displacement are important to take into account in an analysis of factors affecting child marriage. Two major cyclones, Aila and Sidr, hit part of the study area within the decade prior to the study. In total, an initial assessment of environmental vulnerability in the 96 study communities showed that 35 out of 96 were vulnerable to water logging, salinity, or river erosion, or had been directly affected by the cyclones.

Coastal villages, even ones that were not directly in the path of these devastating cyclones, are vulnerable to a variety of environmental risks related to sealevel rise. A detailed description of one such community, Pankhali union, is provided in the box entitled "Pankhali Union: BALIKA's Southernmost Center" as an example of the kind of risk environment that characterizes the study setting.

FIGURE 2 Map of study area

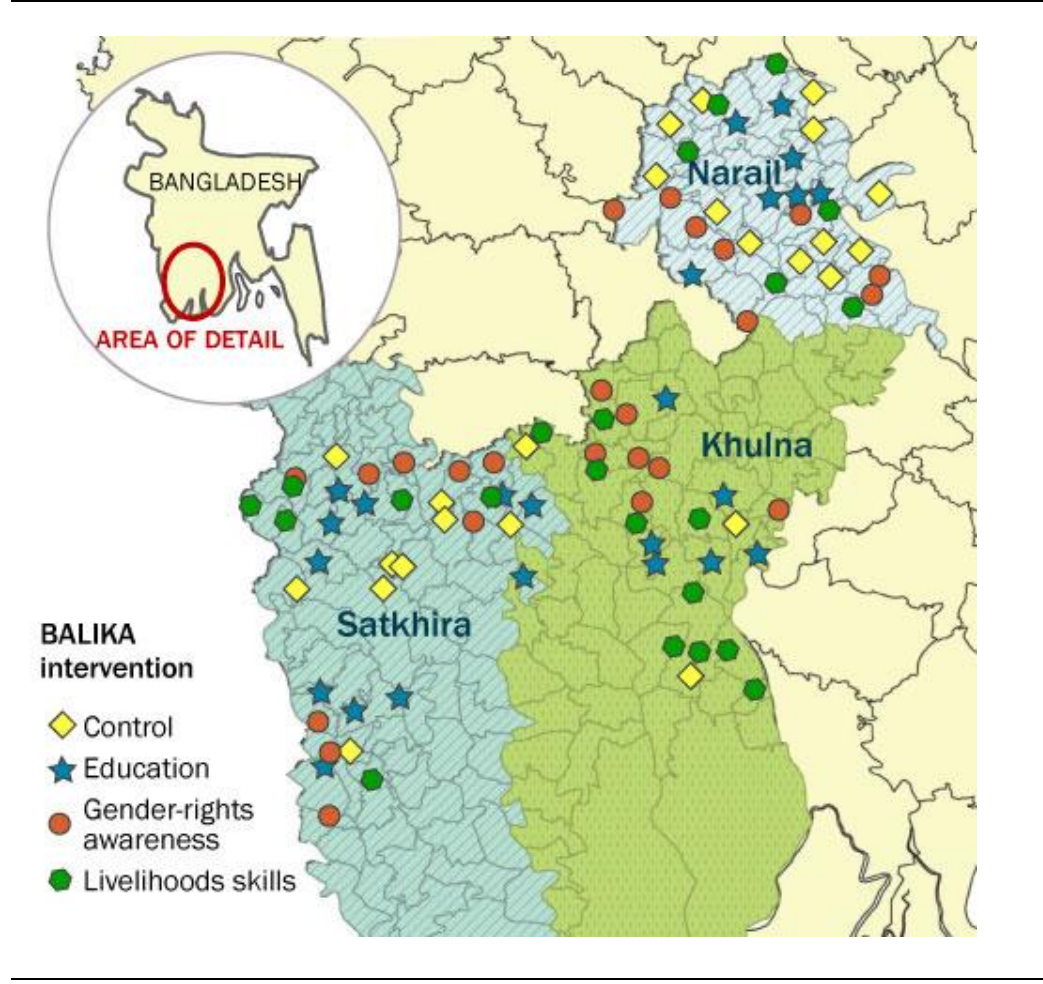


Despite these challenges, the three districts stand out in several positive ways. All three are part of the greater Khulna division, a region shown to have the lowest overall fertility in the country according to the most recent Demographic and Health Survey-1.9 births per woman versus the national average of 2.3 (NIPORT, Mitra and Associates, and ICF International 2016). Age patterns of fertility for women suggest that Bangladesh continues to have a very early pattern of childbearing. For the country as a whole, 25 percent of all births in the three years prior to the survey were to mothers who were under the age of 20 . In Khulna region, 30 percent of all births were to mothers under the age of 20. Child mortality is lower in Khulna than in the rest of Bangladesh. The overall level of education is high, and relatively high rates of girls and boys complete primary school. However, due to child marriage for girls, overall educational achievement is lower for girls than boys.

Although national development organizations such as BRAC and Grameen are not very active in these three districts, perhaps because of the districts' relative inaccessibility, several important local NGOs have emerged since the two major cyclones to conduct relief, rehabilitation, and post-disaster programs. Among these local initiatives are Rupantar and SusheeIon. There are also several longer-standing older institutions that work in a more localized manner. Bnachte Shekha works intensively in Satkhira and nearby areas within our study area and operates out of the nearby town of Jessore. Rishilpi also works in Satkhira, but mostly among a disadvantaged community of the same name.

\section{Pankhali Union: BALIKA's Southernmost Center}

Pankhali union in Dacope upazila, Khulna district is one of the more remote unions of our study area, located near a vast mangrove forest that covers the southwestern coast of Bangladesh. Dacope has many rivers and canals, with few roads to connect it to urban centers. According to the most recent census, the population of 17,000 live in eight villages. The union has 11 primary schools, 4 high schools, and 19 madrassas. The area was connected to the national power grid in 2014. Before that, 70 percent of households used solar power. Interviews with educated local and political leaders suggest that the presence of embankments protects the area from sea-level rise and other environmental hazards. However, the villages were adversely affected during two recent cyclones, Aila and Sidr, because of a breached embankment, which was repaired under a local initiative to allow displaced families to return. Safe drinking water is a problem because of salinity and high iron content. A rainwater-harvesting project is underway. Muslims are only a slight majority-the population is 55 percent Muslim and 45 percent Hindu. Schooling is universal; about 25 percent of girls are enrolled in a madrassa.

Most families rely on agriculture for their livelihood. About 25 percent of the population earns some part of its livelihood collecting and trading in crab in the Sundarbans forest area that covers about 75 percent of the upazila. Few women work in professional jobs; the only jobs available to women are employment in development organizations. Several development organizations have long-term and disaster-related programs. ASA, BRAC, and Grameen are prominent microfinance organizations that work in the area. 
The proportion of the population that is Hindu or Christian is higher in the three districts relative to national levels, but religious composition varies within the region. In Khulna, 40 percent of the population is Hindu, significantly higher than in Narail and Satkhira (more than 20 percent), but even in Narail and Satkhira the proportion belonging to Hindu or other minority religions is more than double the national average, which is about 10 percent. During the baseline survey, there were reports of political and social unrest in Satkhira district associated with elections, resulting in several months of transport strikes and disruption that delayed the start of program activities. These were eventually resolved with a heavy security presence.

All three districts are close to the Indian border or have a longstanding tradition of migration to India. Among Hindus, marriage markets in particular appear to be fluid across borders and it is common for Bangladeshi Hindu women to be married to men in India. However, it is uncommon for Indian women to be married to Bangladeshi men. The extent of such marriage-related migration is difficult to assess. There are also concerns about trafficking of young women for sex work, but it is difficult to assess the extent of such migration. Throughout the period of work of our study we were able to track migration practices, and our efforts at tracking baseline respondents allowed us to provide some estimates of the likelihood of young women leaving the area, by destination, that documented some migration to India but also showed that migration to Dhaka and other urban areas in Bangladesh is more common than migration to India. A key informant interviewed in the qualitative study described migration to India (see box on right).

Data generated from the baseline survey documents that the study area represents the southern region in terms of child marriage, high levels of educational attainment among young people, and low fertility among young women. There is also evidence of high levels of out-migration from the study area.

\section{Research design}

To build an evidence base on initiatives that work to delay marriage, we tested alternative strategies for implementing skill-building programs. We offered three distinct programs and assessed their impact relative to one another and to a set of control communities where no intervention took place. The skill-building approaches are differentiated in terms of their relative substantive emphasis and are best described as: (1) education, (2) gender-rights awareness training, and (3) livelihoods-skills training. A fourth set of communities serve as the control area. All three intervention approaches had many common characteristics: considerable community engagement, a common girl platform and a safe place to meet, basic life-skills training, and access to mentors. In addition, all of the centers were equipped with a computer, a tablet, and a set of books that members could borrow. The activities at the center were organized by a parttime teacher and a full-time mentor recruited from the same community.

Using a cluster randomized controlled research design, we tested different skill-building approaches to delay marriage, examining their effect on a range of related changes in skills, behaviors, and attitudes, in addition to measures related to child marriage and childbearing. Thus, 
the BALIKA evaluation is a four-arm cluster randomized trial where the clusters are comprised of the community surrounding one primary school selected per union. The choice of center location ensured sufficient distance between contiguous unions to avoid contamination of intervention effects. The three intervention strategies evaluated are education, gender-rights awareness, and livelihoods skills. All interventions included 44 hours of basic lifeskills training and 100 hours of skills training based on the specific intervention strategy.

FIGURE 3 BALIKA evaluation: A cluster randomized controlled research design with three intervention strategies and a control group
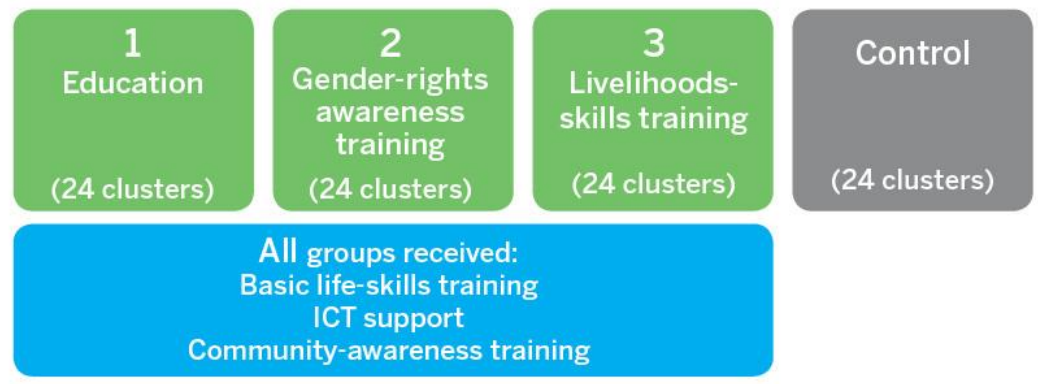

Intervention Strategy 1: In-school girls received tutoring in mathematics and English and out-of-school girls received lessons in communicative English and financial-skills training.

Intervention Strategy 2: All girls received enhanced life-skills training, including information, projects, and exercises about gender rights and negotiation, critical thinking, and decisionmaking skills following the "Its All One Curriculum" (http://www.popcouncil.org/research/itsall-one-curriculum-guidelines-and-activities-for-a-unified-approach-to-).

Intervention Strategy 3: All girls received livelihood training in computers, mobile phone applications and servicing, photography, basic health screening, and entrepreneurship.

Girls in the control group received no services. This group was necessary because we could not be sure that any of the study's three experimental interventions would offer any benefit over no services. No existing services were withheld from the control villages and to that extent they capture the impact of whatever provisions are available to the average community in the region. In recent years, activities included campaigns to raise awareness about the harmful effects of child marriage and services to enforce child-marriage laws. Local communities have been mobilized to increase birth and marriage registration, the latter being common for Muslims but not Hindus or Christians whose marriages are regulated by religion-specific laws. 


\section{Data collection}

The project expended considerable effort in gathering detailed data to inform program design, to document program implementation, and to assess change in girls' outcomes in a manner that may be attributed to the program. The research effort included large-scale quantitative surveys at baseline and endline, monitoring and evaluation of data that described program activities, qualitative interviews, and community assessments.

\section{Baseline and endline surveys}

To measure the impact of each intervention approach in relation to the others and to the control group, a baseline survey was conducted before the program was implemented, and an endline survey was conducted after the program had been in place for 18 months. The endline survey used the same instrument as the baseline, with an additional module to describe program participation.

The analysis followed an "Intent to treat" protocol, which means the survey was conducted among a random sample of girls who were eligible to join and lived within the catchment area of BALIKA centers, or would-be centers in the case of the control villages.

The research team selected 96 potential centers and randomized them into 4 categories. A population enumeration was conducted in the catchment area of centers, defined as anyone living within a 2-kilometer (1.2-mile) walking distance of the center. The baseline survey was designed to cover an average of 120 adolescents in each of the 96 communities. At baseline, 11,609 respondents were successfully interviewed between March and August 2013. The endline survey began after program implementation was completed and was conducted over a period of four months between August and November 2015, and an attempt was made to interview all adolescents interviewed at baseline. A total of 9,982 interviews were successfully completed, yielding a re-contact rate of 86 percent.

\section{Qualitative studies 2013-2015}

The qualitative research component of BALIKA is a part of the formative research to assess qualitative aspects of the setting and their impact on child marriage. Focus group discussions (FGDs) and key informant interviews (KIIs) were conducted only at the baseline in 6 of the 96 study villages, 2 each from the 3 districts-Khulna, Satkhira, and Narail. Indepth interviews (IDIs) were conducted both at baseline and endline, and the study areas are the same as for the FGDs and KIls.

\section{In-depth interviews}

In total, 24 in- and out-of-school married and unmarried girls were interviewed at baseline to explore their individual life experiences. At endline, the aim was to interview the same girls who were interviewed at baseline to assess the change or transition of their previous life experiences. However, 2 replacement girls were selected for interviews who had matched criteria in the cases where the girls from baseline refused to give interviews at endline.

\section{Focus group discussions}

In total, 18 group discussions were carried out at baseline. Focus group discussions were conducted with adolescent girls, young men, fathers, and mothers to learn about their perceptions of factors affecting marriage, girls' security, and mobility. 
Key informant interviews

A total of 30 key informant interviews were conducted at baseline with knowledgeable community members, including marriage registrars, community leaders, local NGO staff, schoolteachers, and health workers. Key informant interviews were conducted to understand community norms, attitudes, and practices regarding child marriage, girls' involvement in productive work, community attitudes about gender roles and norms, and related factors such as girls' mobility and opportunities for education and community engagement.

Community assessments

Community assessment surveys were conducted in all 96 study communities both at baseline and endline to provide a broad overview of community characteristics, norms, facilities, practices, and environmental vulnerability. The endline assessment also attempted to document any changes that occurred since baseline. The assessment exercise included a transect walk with an observational checklist and short interviews with local informants. Factors such as the influence of migration on marriage, women's livelihoods, restrictions on girls' mobility, private tutoring, harassment in public places ("eve teasing"), and environmental degradation or change were some of the specific factors that the assessment surveys observed and documented.

\section{Tracking migrants}

In order to contact respondents who had left the village where they had lived at baseline, a dedicated and specialized tracking team was responsible for identifying, locating, and interviewing respondents who had moved. Among those who were no longer living in the same village as at baseline, 1,299 respondents were successfully interviewed while 763 were traceable but were not interviewed because they were difficult to locate, refused, or were otherwise unavailable. Based on a question we asked of all respondents about the reason for their move, we assess that about 74 percent moved for marriage, 10 percent moved for further education, 6 percent moved for work, and 2 percent moved out of the country. In addition, 1 percent of baseline respondents who were not reinterviewed had died, and we have no further information on the status or reason for moving for 5 percent. 


\section{Overview of baseline results}

\section{Marriage}

The baseline survey confirmed a high prevalence of child marriage in the study area, and more than two-thirds of girls married by age 19. Unlike other areas where child marriage is prevalent, there was no evidence of high dowry demands in this area. Reports of "own choice" or "love marriage" were surprisingly high. Marriage was given as the primary reason for dropping out of school. Respondents felt that the main reason parents preferred marrying their daughters at early ages, even while they were in school, was because they received a proposal of marriage that was "too good to refuse." Parental concerns and feeling pressure to marry off their daughters was voiced in different ways but indicated that decisions about marriage are ultimately made by parents. Two quotes from the qualitative interviews (in box on right) provide examples of locally perceived drivers of child marriage. The first quote demonstrates that even within communities where child marriage is common, the practice is more common among the poor. The second quote, from an adolescent boy, shows that marriage is a parental decision and seeking the young person's consent is not common.

\section{Schooling}

The baseline survey reported universal school attendance among the study population (only 1 percent of girls aged 12-15 never attended school). School dropout rates accelerate during secondary school, and approximately 40 percent of girls aged $16-18$ and 60 percent of girls aged 19 had discontinued schooling at the time of the baseline survey. Only 20 percent of girls completed a secondary or higher level of education. School discontinuation rates are high despite the fact that girls received stipends and other support at the primary and secondary levels (53 percent and 60 percent, respectively). Fifty-two percent of girls who had dropped out reported marriage as the reason for school discontinuation. Other reported reasons were financial constraints, competing household responsibilities, lack of interest /disliking study, and parental concern about safety commuting to and from school. In terms of school quality, survey responses suggested that while schools are crowded, the majority of girls reported having electricity, a library, a clean compound, and a separate girls' toilet in schools. Approximately 10 percent of the girls were enrolled in government-regulated and approved Islamic schools (Alia Madrasa), and less than 1 percent were enrolled in unregulated schools, or Qoumi Madrasa, which did not follow government-approved curriculum by the Madrasa Board. Learning assessments suggest relatively low reading competency in English (48 percent) compared with Bangla (90 percent). Performance in mathematical competency was poor in general but improved with higher grade completion as long as girls remained in school. Girls from wealthier quintiles were more likely to be in school and more competent in mathematics. In all three study districts, about 81 percent of adolescent girls received private tutoring in English and mathematics. Girls from wealthier backgrounds and whose parents were more educated were more likely to receive tutoring beyond school hours than other girls. 
Apart from formal education, the percentage of girls who received training within the study area was low (only 7 percent), with little variation in training components and source, across the districts. The majority of respondents reported receiving training on tailoring garments. Other types of training were computers, handicrafts, and poultry/livestock.

The considerable improvement in girls' schooling in Bangladesh is attributable to a series of policy initiatives in the 1980s that recognized the gender disparity that existed in education at the time. These initiatives included preferential recruitment of female teachers, establishment of a primary school in every village, public-sector financial support to secondary schools in the form of student-stipend support and financial support to secondary schools, even though the vast majority of secondary schools are nongovernmental. A recent analysis of stipend support favoring girls concluded, however, that while stipends are successful in closing gender-attendance gaps, they are not as effective in closing the attainment gap by socioeconomic status (Behrman 2015). Although girls who receive stipends do better than girls and boys who do not, girls from wealthier and more educated families continue to outperform girls from poorer households.

\section{Livelihoods}

The baseline survey suggests that adolescent girls in the study area had few opportunities to earn-only 10 percent reported ever working for pay and 7 percent said they were currently working to earn money. Among girls who worked, married adolescents worked an average of 20 hours a week and were paid at the rate of Tk. 30 (US $\$ 0.40)$ per hour, whereas unmarried girls worked 15 hours a week and were paid Tk. 20 (US\$0.27) per hour. Thus, those who worked reported low numbers of hours worked weekly. The average of 16.1 hours weekly for the study area was low compared to national rates reported on the basis of child-labor surveys. As may be expected, older and married women were more likely to have ever worked than younger unmarried girls. Girls who worked were involved in farming, cottage industry, or homestead poultry raising, and as day laborers. Married adolescents possessed more assets than unmarried adolescents. Regardless of working status, married ad-

"If a girl is very good in study then she can earn money side by side continuing her study. If anything can be possible like this, then girls can get the opportunity to continue her study and parents will not force them to get married."

-Female teacher, Pankhali (Key informant interview)

"Girls of educated parents tend to be married off late. Girls are also married later if they are good students."

-Boy from a group discussion olescents contributed to their family and saved more than unmarried adolescents. The study found that education level is associated with adolescents' engagement in the workforce as well as their asset-ownership status. Although girls with a higher education were less engaged in work, their hourly rate was higher and they were more likely to be engaged in tutoring.

Thus there were substantial variations in the nature of work, hours worked, and income earned, by education status. Less-educated girls worked longer hours, usually in domestic work or agriculture, and were paid considerably less than educated girls who tended to work in the education sector (mostly as private tutors) and worked half as many hours for considerably higher hourly rates. Labor-force participation rates are considerably lower than rates reported nationally. The National Child Labor Survey (NCLS) 2002-03 reports child labor rates of 26.5 percent among girls 5-17 years of age, using a broad definition of economic activity. A majority (56.4 percent) of working children were found to be involved in agricultural activities. The 2006 Child Domestic Labor in Bangladesh survey by the International Labor Organization (ILO) documented that the average monthly wages of a female child domestic worker is Tk. 89 (US\$1.19) (ILO 2006). Studies among female garment factory workers (Amin et al. 1998; Naved, Newby 
and Amin 2001) suggest that young women enter the workforce at relatively young ages and migrate for work to urban areas.

Although there does not appear to be much by way of livelihood opportunities in the area, the perception that such opportunities are present elsewhere is evident from our qualitative interviews, and is influenced by what is known from the few girls and women who have migrated to the cities or abroad for work. The conversations about work opportunities for women among those who migrate suggest that attitudes are conflicted. While women's working to earn is viewed negatively by society (there seems to be general consensus on this), those who are able to work and earn consider themselves liberated and are among the few who can confidently defy conventions regarding the importance of marriage at a young age.

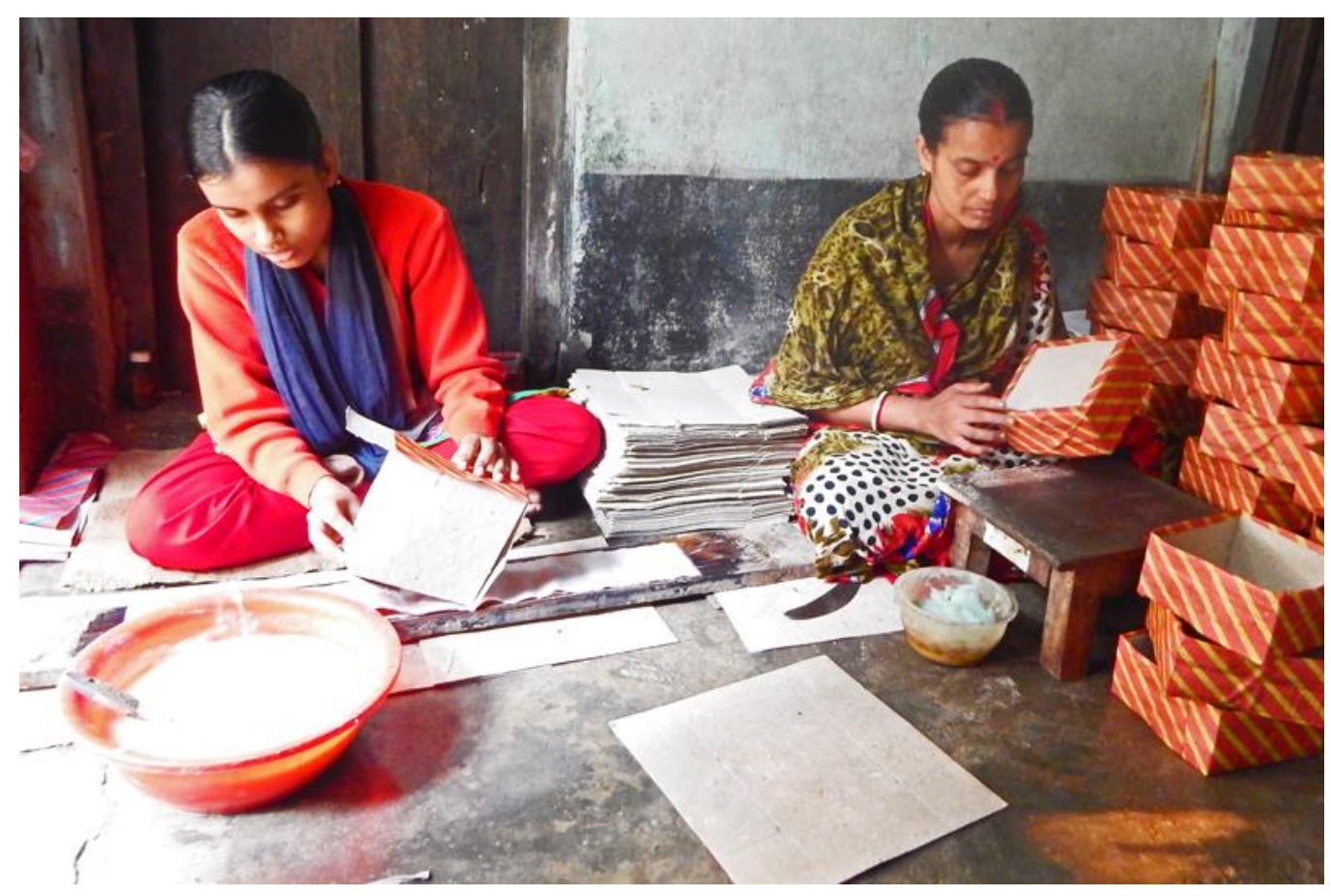

Photo credit: Fahmida Bashar Rifa, BALIKA member, Dumuria, Khulna

\section{Gender norms}

Responses to questions about values and attitudes related to gender-equitable attitudes show substantial differences by schooling and marital status. Those who were married and had lower educational attainment in general held more gender-inequitable values. While differences were observed on a number of indicators, the most striking results were shown in terms of acceptance of gender-based violence and confidence related to respondents' reproductive lives. Almost 50 percent of respondents believe that it is justifiable to beat a woman under specific circumstances, such as if she does not carry out her domestic responsibilities, and married adolescents were more accepting of gender-based violence. Similarly, married women and women with less education were more likely to report that the responsibility of avoiding getting pregnant rested solely on the woman. On other indicators, such as whether women should have the right to divorce, married women and educated 
women were more likely to agree than unmarried and less educated women. Over half of the respondents thought women should have the right to divorce and 38 percent thought a woman had the right to refuse to have sex with her husband. The baseline study affirmed the need to promote gender-rights awareness among all adolescents but with some nuance with respect to age, marital status, and level of schooling. The data suggest that those who were married, not in school, and had lower educational attainment were less aware of gender rights and expressed more inequitable attitudes about gender roles, including about acceptance of gender-based violence and autonomy.

\section{Case Study: A Hostile Social Environment for Young Girls}

At the time of our interview, Amena* had just taken the post Class 10 SSC examinations and was waiting for results. She lives with her father, mother, and grandfather. Her father is a day laborer. He also sells umbrellas in the local bazaar when not on a labor contract. Her brother is 24 years old and works in a garment factory in Dhaka. Her father is the primary wage earner, but her brother also helps them occasionally by sending money.

Amena's parents want to get her married immediately. They think their village is not safe for a young unmarried girl. Girls are often harassed by local boys, and a girl was recently molested by some boys when she was returning home. Amena is afraid to go out of the house. She thinks such attacks on girls are drug related. Several boys are reported to be addicted to cocaine, yabba (methamphetamine), and other hard drugs.

Amena considers herself a good student. She wants to continue her studies but expects she will be married off soon. She received many marriage proposals, which she rejected, because she wanted to take the upcoming exams and her parents supported her. She believes that her father and mother will ultimately be the ones who choose for her, but she is confident that her parents would not force her to get married if she had a strong objection.

Amena's views and expectations of marriage are informed by what she sees around her. She has several female friends her age who are already married. One female friend was married when she was 13 and studying in class 9 , but she had an extramarital relationship that led to divorce. Another friend's marriage at an early age also ended in divorce. The girl was married off again to a different man. Most of the girls in this area get married at the age of 15 to 16 . Amena thinks that girls who have jobs marry later, but the people in her community do not easily accept girls working outside of the area and there are not many decent jobs in the community for women. When a girl continues to study she may not be pressured to marry, but not everyone can afford the cost of higher education. Amena thinks that good-looking girls get married early because they are noticed and harassed more. Parents feel insecure, just as her own father and mother also worry about her security. Parents of girls pay dowry because they believe it will ensure happiness.

We were not able to track Amena for a subsequent interview. She had not joined BALIKA and her entire family could not be located. It is likely that the experience Amena hinted at in terms of feeling insecure led them to migrate out, perhaps to join the brother in Dhaka, a pattern of migration common particularly for families such as Amena's who have limited resources and who are dependent on their labor.

-15-year-old, in-school, unmarried girl, Pankhali, Dacope, Khulna

*Pseudonym used to protect privacy. 


\section{Balance across intervention areas}

The randomization was successful in ensuring balance across interventions for most indicators, such as average age of girls, percent married, mean age at marriage, percent attending school, and educational attainment of parents. There were small differences in birth registration and average number of siblings. There were substantial differences in the proportion nonMuslim and the proportion of households in the poorest quintile.

Participation rates, defined as ever enrolled and attended the program at least once, were similar in the three interventions. In education intervention villages, the participation rate was 39 percent among girls in school and 21 percent among girls not in school; in the genderawareness villages, participation was 43 percent among in-school girls and 23 percent among out-of-school girls; in the livelihoods-skills intervention participation rates were 44 percent for in-school girls and 21 percent for out-of-school girls. Among girls who enrolled but dropped out before completing all sessions, the primary reasons were competing demands from school examinations followed by marriage. Participation in the BALIKA program disaggregated by two-year age groups shows that participation was highest among the youngest adolescents and declined rapidly with age and in a similar manner for all intervention groups (Table 1).

TABLE 1 Baseline socioeconomic and demographic characteristics of survey respondents, by intervention strategy (percent)

\begin{tabular}{|c|c|c|c|c|}
\hline Variable & EDUCATION & GENDER AWARENESS & LIVELIHOODS SKILLS & CONTROL \\
\hline Age (mean) & 15.0 & 15.0 & $14.9 *$ & 15.0 \\
\hline Respondents who were married & 19.7 & 20.5 & 17.5 & 18.5 \\
\hline Age at marriage (mean) & 15.1 & 15.2 & 15.3 & 15.3 \\
\hline \multicolumn{5}{|l|}{ Schooling status } \\
\hline Out of school & $23.6 *$ & 22.2 & 21.1 & 21.3 \\
\hline \multicolumn{5}{|l|}{ Average years in school } \\
\hline Respondent & 7.2 & 7.2 & 7.1 & 7.2 \\
\hline Father & 4.2 & 4.2 & 4.3 & 4.2 \\
\hline Mother & 3.5 & 3.6 & 3.7 & 3.6 \\
\hline Had birth registration card & 92.5 & $90.3 * * *$ & 94.0 & 93.8 \\
\hline Is non-Muslim & $24.8 * * *$ & 19.1 & $32.7 * * *$ & 18.1 \\
\hline Total number of siblings & $2.3 * * *$ & $2.4 * *$ & $2.3 * * *$ & 2.6 \\
\hline In poorest quintile & $22.3 * *$ & 16.7 & $24.3 * *$ & 16.8 \\
\hline$(\mathrm{N})$ & $(2,950)$ & $(2,886)$ & $(2,885)$ & $(2,888)$ \\
\hline \multicolumn{5}{|c|}{$\begin{array}{l}\text { Ever participated in BALIKA (according to } \\
\text { endline survey) }\end{array}$} \\
\hline In-school girls & 39.3 & 43.2 & 43.6 & na \\
\hline Out-of-school girls & 20.8 & 23.1 & 21.4 & na \\
\hline \multicolumn{5}{|l|}{ Age group } \\
\hline $14-15$ & 62.6 & 68.9 & 67.8 & \\
\hline $16-17$ & 33.6 & 35.0 & 34.7 & \\
\hline 18 or older & 12.1 & 13.4 & 12.2 & \\
\hline$(\mathrm{N})$ & $(2,516)$ & $(2,460)$ & $(2,476)$ & $(2,530)$ \\
\hline
\end{tabular}

Significantly different from control group at ${ }^{*} p \leq 0.05 ;{ }^{* *} p \leq 0.01 ;{ }^{* * *} p \leq 0.001 . \quad$ na $=$ Not available. 


\section{Method of analysis}

\section{Difference-in-differences (DiD) model}

To assess the impact of the BALIKA program, we performed a difference-in-differences (DiD) analysis adjusting for three key sociodemographic characteristics: age, religion, and wealth quintile. DiD estimation compares the average changes in key outcomes between baseline $(t=0)$ and endline $(t=1)$ in the intervention groups, compared with average changes in the control groups over time, which provides evidence of program effectiveness (Gertler et al. 2011). The impact of the BALIKA program on an outcome measured for an adolescent "i" assigned to intervention strategy "j" at time-point "t", $\boldsymbol{Y}_{i j t}$ is estimated as follows:

$$
Y_{i j t}=\alpha+\beta X_{i j t}+\beta_{1} \text { Time }_{t}+\beta_{2} \text { Treat }_{j}+\gamma\left(\text { Time }_{t} \times \text { Treat }_{j}\right)+\varepsilon_{i j t}
$$

Where $\mathrm{X}_{\mathrm{ijt}}$ is a vector of the sociodemographic characteristics age, religion, and wealth quintile measured at baseline and endline and $\beta$ measures the effects of the covariates on the outcome for each of the two time points. The indicator variable Time $e_{t}$ equals 1 if the observation is measured at endline and 0 otherwise, which provides estimates of time trend common to control and treatment groups. Treat ${ }_{j}$ equals 1 if respondent is assigned to be in any of the three intervention strategies and 0 for the control group, which captures average differences between interventions and control. $\gamma$ constitutes the coefficient of interest, i.e., the additional change in outcome due to the program. $\varepsilon_{\mathrm{ijt}}$ is the difference between errors at time 1 and time 0 . For continuous outcome we have performed Ordinary Least Square (OLS) estimation and multivariate logistic regression model for dichotomous outcome.

Participation in the program was voluntary and not all eligible girls received the BALIKA intervention, so the focus of our analysis is based on intent-to-treat (ITT) impacts throughout. Randomization of treatment to communities ensures that differences across intervention communities are attributable to the impact of the BALIKA program. The analysis of balance across interventions led us to conclude that there were some differences in wealth distribution and religious composition that had to be taken into account. Accordingly, the difference in impact included controls for covariates. In this setup, covariates serve to reduce the variability of the outcome measures and, hence, increase the power of the statistical tests. If the baseline covariate(s) is moderately correlated with the outcome, differences between the outcome values that can be attributed to differences in the baseline covariate can be removed, leading to a more precise estimate of treatment effect. When, by chance, there is some imbalance in the baseline covariate between groups, the regression model in effect adjusts the outcome values to account for the differences in the baseline covariate between the two groups. To allow for age and differences in religious background in the four arms, we estimated logistic regression that controlled for these factors. 


\section{BALIKA PROGRAM IMPACT}

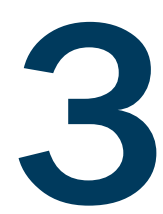

The central aim of the BALIKA project was to contribute to the evidence base on what works to delay marriage. We worked with the community to implement programs according to a randomized design to test the relative impact of three approaches to building assets among adolescent girls. The approaches were tested against each other and in relation to a set of control communities where we conducted research but did not offer programs.

\section{Child marriage}

Overall the probability of child marriages (age at marriage less than 18) declined significantly by about a third in all intervention villages relative to control villages. The probability of child marriage in the education intervention villages was 31 percent lower for the education and gender-rights awareness interventions and 23 percent lower for the livelihoods intervention relative to control villages. The decline in child marriage is attributable to the 18 month-long intervention in all three skill-building strategies. While the change in intervention villages is significantly greater as compared with control villages, the difference between intervention strategies is not statistically significant (Table 2).

TABLE 2 Percentage of respondents by marital status, age at marriage, and age group, by intervention strategy

\begin{tabular}{|c|c|c|c|c|c|c|c|c|c|c|c|c|}
\hline \multirow[b]{2}{*}{ Variable } & \multicolumn{3}{|c|}{ EDUCATION } & \multicolumn{3}{|c|}{ GENDER AWARENESS } & \multicolumn{3}{|c|}{ LIVELIHOODS SKILLS } & \multicolumn{3}{|c|}{ CONTROL } \\
\hline & Baseline & Endline & OR & Baseline & Endline & OR & Baseline & Endline & OR & Baseline & Endline & OR \\
\hline \multicolumn{13}{|c|}{ Marital status/Age at marriage } \\
\hline Married at age $<18$ & 18.4 & 23.6 & $0.693^{* * *}$ & 19.4 & 24.7 & $0.695^{* * *}$ & 16.4 & 23.0 & $0.767^{* *}$ & 17.2 & 28.9 & \\
\hline$<16$ years & 12.1 & 11.5 & $0.694^{* *}$ & 11.7 & 12.8 & 0.810 & 9.9 & 10.6 & $0.760^{*}$ & 10.7 & 13.7 & \\
\hline $16-17$ & 6.3 & 12.1 & 0.803 & 7.7 & 11.9 & $0.651^{* *}$ & 6.5 & 12.5 & 0.810 & 6.5 & 15.2 & \\
\hline $\begin{array}{l}\text { Never married or } \\
\text { married at age 18+ } \\
\text { (N) }\end{array}$ & $\begin{array}{c}81.6 \\
(2,917)\end{array}$ & $\begin{array}{c}76.4 \\
(2,198)\end{array}$ & & $\begin{array}{r}80.6 \\
(2,839)\end{array}$ & $\begin{array}{c}75.3 \\
(2,165)\end{array}$ & & $\begin{array}{c}83.6 \\
(2,837)\end{array}$ & $\begin{array}{c}77 \\
(2,215)\end{array}$ & & $\begin{array}{c}82.8 \\
(2,858)\end{array}$ & $\begin{array}{c}71.1 \\
(2,276)\end{array}$ & \\
\hline $\begin{array}{l}\text { Respondents who } \\
\text { were ever married } \\
\text { (N) }\end{array}$ & $\begin{array}{c}19.8 \\
(2,917)\end{array}$ & $\begin{array}{c}32.0 \\
(2,198)\end{array}$ & $0.77^{\star \star}$ & $\begin{array}{r}20.6 \\
(2,839)\end{array}$ & $\begin{array}{c}33.0 \\
(2,165)\end{array}$ & $0.76^{* *}$ & $\begin{array}{c}17.6 \\
(2,837)\end{array}$ & $\begin{array}{c}30.0 \\
(2,215)\end{array}$ & $0.778^{\star *}$ & $\begin{array}{c}18.7 \\
(2,858)\end{array}$ & $\begin{array}{c}37.4 \\
(2,276)\end{array}$ & $(\mathrm{r})$ \\
\hline $\begin{array}{l}\text { Respondents age }<18 \\
\text { who were ever marriec } \\
\text { (N) }\end{array}$ & d 10.5 & $\begin{array}{c}15.7 \\
(2,198)\end{array}$ & $0.77^{\star \star}$ & $\begin{array}{r}11.3 \\
(2,839)\end{array}$ & $\begin{array}{c}16.3 \\
(2,165)\end{array}$ & $0.73^{* *}$ & $\begin{array}{c}9.0 \\
(2,837)\end{array}$ & $\begin{array}{c}15.1 \\
(2,215)\end{array}$ & 0.86 & 10.0 & 18.5 & $(r)$ \\
\hline \multicolumn{13}{|l|}{ By age group: } \\
\hline $\begin{array}{l}\text { 14-15-year-olds } \\
\text { (n) }\end{array}$ & $\begin{array}{r}11.5 \\
(893)\end{array}$ & $\begin{array}{r}14.6 \\
(639)\end{array}$ & $0.623^{*}$ & $\begin{array}{r}10.0 \\
(830)\end{array}$ & $\begin{array}{r}16.4 \\
(678)\end{array}$ & 0.788 & $\begin{array}{c}8.0 \\
(908)\end{array}$ & $\begin{array}{r}12.4 \\
(683)\end{array}$ & 0.731 & $\begin{array}{r}10.4 \\
(920)\end{array}$ & $\begin{array}{l}18.7 \\
(630)\end{array}$ & $(r)$ \\
\hline $\begin{array}{l}\text { 16-17-year-olds } \\
\text { (n) }\end{array}$ & $\begin{array}{r}28.0 \\
(690)\end{array}$ & $\begin{array}{r}34.4 \\
(724)\end{array}$ & $0.684^{*}$ & $\begin{array}{r}34.6 \\
(667)\end{array}$ & $\begin{array}{r}36.6 \\
(659)\end{array}$ & $0.563^{* * *}$ & $\begin{array}{l}26.4 \\
(666)\end{array}$ & $\begin{array}{r}33.8 \\
(737)\end{array}$ & $0.709^{*}$ & $\begin{array}{r}25.3 \\
(724)\end{array}$ & $\begin{array}{l}39.4 \\
(764)\end{array}$ & \\
\hline $\begin{array}{l}\geq 18 \text { years old } \\
\text { (n) }\end{array}$ & $\begin{array}{r}56.4 \\
(484)\end{array}$ & $\begin{array}{r}47.0 \\
(758)\end{array}$ & 0.917 & $\begin{array}{r}53.6 \\
(491)\end{array}$ & $\begin{array}{r}47.8 \\
(742)\end{array}$ & 1.05 & $\begin{array}{l}58.2 \\
(421)\end{array}$ & $\begin{array}{r}46.1 \\
(709)\end{array}$ & 0.822 & $\begin{array}{r}57.1 \\
(434)\end{array}$ & $\begin{array}{l}50.5 \\
(842)\end{array}$ & $(r)$ \\
\hline
\end{tabular}

Significantly different from control group at ${ }^{*} p \leq 0.05 ;{ }^{* *} p \leq 0.01 ;{ }^{* * *} p \leq 0.001$. OR $=$ Odds ratio. ( $r$ ) = Reference category. NOTE: Odds ratios are based on models exploring change in marital status among those who were unmarried at baseline, controlling for age, wealth, and religion. 
Table 2 suggests that marriage at endline among respondents under the age of 16 was the lowest in the education and livelihoods-skills interventions arms where such marriages were about one-third and one-fourth lower, respectively, than in the control villages. While the impact on the youngest marriages in the gender-awareness arm was not significantly lower than in the control villages, the gender awareness intervention reduced the number of marriages at age $16-17$ by 35 percent.

A slightly different measure of child marriage that measures proportion married disaggregated by age group essentially replicates the same impact results of interventions. Overall all respondents were less likely to be married in the intervention arms relative to control village residents. Among 14-15-year-olds the proportion married was significantly lower in the education arm. Among 16-17-year-olds the proportion married was lower in all arms and girls in the gender arm in this age group were almost half as likely to be married as girls in the control villages.

In-depth interviews suggest that girls gained confidence from the BALIKA centers to voice their opinions in regard to timing of marriage and choice of partner.

\section{Marriage choice and consent}

Table 3 shows changes in a number of marriage characteristics as reported by married respondents who were interviewed at endline. These are based on questions about whether the marriage was registered, a characterization of the nature of marriages (love or arranged), whether girls were consulted and gave consent, and whether there was discussion about dowry practice associated with interventions. All married respondents were asked whether there was a demand for dowry by the husband and whether the families discussed dowry payment.

TABLE 3 Among female respondents married between baseline and endline, type of marriage and responses to dowryand marriage-related indicators, by intervention strategy (percent)

\begin{tabular}{|c|c|c|c|c|c|c|c|c|c|c|c|c|}
\hline \multirow[b]{2}{*}{ Variable } & \multicolumn{3}{|c|}{ EDUCATION } & \multicolumn{3}{|c|}{ GENDER AWARENESS } & \multicolumn{3}{|c|}{ LIVELIHOODS SKILLS } & \multicolumn{2}{|c|}{ CONTROL } & \multirow[b]{2}{*}{ OR } \\
\hline & Baseline & Endline & OR & Baseline & Endline & OR & Baseline & Endline & OR & Baseline & Endline & \\
\hline Love marriage & 21.5 & 19.2 & 0.83 & 26.2 & 19.0 & $0.623^{* *}$ & 22.0 & 22.3 & 0.974 & 21.2 & 22.0 & $(r)$ \\
\hline $\begin{array}{l}\text { Parents asked for girl's } \\
\text { consent before marriage }\end{array}$ & 77.0 & 77.7 & $0.665^{*}$ & 75.8 & 76.8 & $0.685^{*}$ & 71.6 & 79.8 & 1.05 & 70.1 & 78.2 & $(r)$ \\
\hline Girl wanted to marry & 69.5 & 77.7 & 0.784 & 71.0 & 75.7 & $0.664^{*}$ & 72.0 & 79.8 & 0.831 & 68.0 & 80.1 & $(r)$ \\
\hline Dowry demanded & 32.7 & 18.1 & 0.856 & 27.5 & 17.9 & 1.17 & 26.9 & 14.4 & 0.858 & 24.9 & 14.7 & $(r)$ \\
\hline $\begin{array}{l}\text { Average amount of } \\
\text { dowry given (takas) }\end{array}$ & 54,718 & 78,770 & $10,548^{a}$ & 47,143 & 48,237 & $-12,409^{a}$ & 41,746 & 53,974 & $-1,275^{a}$ & 49,486 & 62,989 & \\
\hline $\begin{array}{l}\text { Marriage was } \\
\text { registered }\end{array}$ & 74.2 & 79.6 & $1.82^{*}$ & 80.7 & 83.3 & 1.08 & 73.5 & 76.8 & 1.53 & 84.6 & 84.0 & $(r)$ \\
\hline Proposal was too good & 69.0 & 71.9 & $0.736^{*}$ & 64.8 & 73.6 & 0.97 & 69.5 & 73.7 & 0.791 & 66.5 & 75.4 & $(r)$ \\
\hline $\begin{array}{l}\text { Parents afraid about } \\
\text { sexual security } \\
\text { (N) }\end{array}$ & $\begin{array}{c}7.3 \\
(578)\end{array}$ & $\begin{array}{c}6.1 \\
(626)\end{array}$ & 1.18 & $\begin{array}{c}6.3 \\
(585)\end{array}$ & $\begin{array}{c}5.5 \\
(621)\end{array}$ & 1.223 & $\begin{array}{c}5.6 \\
(499)\end{array}$ & $\begin{array}{c}3.1 \\
(578)\end{array}$ & 0.756 & $\begin{array}{c}5.4 \\
(534)\end{array}$ & $\begin{array}{c}3.8 \\
(736)\end{array}$ & $(r)$ \\
\hline
\end{tabular}

Significantly different from control group at ${ }^{*} p \leq 0.05 ;{ }^{* *} p \leq 0.01 ;{ }^{* *} p \leq 0.001$. OR = Odds ratio. ( $\left.r\right)$ = Reference category.

a These values are coefficients from a linear regression. 
Responses to these questions suggest that the program did not have a positive impact on the nature of the marriages that took place, with the exception that girls in the gender-rights awareness intervention were significantly more likely to say no dowry was demanded. Here, married respondents were more likely to say they were not consulted about their marriage and that the marriage took place because there was no prospect of continuing school. In the livelihoods intervention, respondents were more likely to say that their parents felt pressured to marry them off because they were a burden. In the education and gender interventions, respondents were less likely to have been consulted and in the gender intervention they were also less likely to say they had a love marriage relative to control villages. In these two interventions, respondents were also less likely to say that they were consulted during discussion/negotiations on dowry. Although there was a decline in the proportion of marriages contracted with a dowry, among those who paid a dowry the amounts increased (although not statistically significant).
"I learned from BALIKA that I can say "no" to a marriage proposal. I learned that if a marriage proposal comes and I am too young to marry, I am able to express my opinion to convince my parents. If I couldn't convince them, then I would seek out someone in the family who would understand me or else I would consult with my friends."

- BALIKA member, Pankhali, Dacope

It is possible that child marriages that took place despite the program intervention were among girls in families that were least likely to be influenced by the program. We speculate that the most progressive families were the first to respond to the program and they are represented in the families that responded by delaying marriage. As programs continue and demonstrate the advantages of later marriage for girls, the program's impact may diffuse to families that are more resistant to change.

An alternative explanation is that the emphasis of the program's messages on issues of consent and choice led to a change in the way these matters were perceived in the intervention villages and may have led to an increase in reporting or characterization of marriages as events where they had not given valid consent. In the gender intervention, fewer girls also said that they wanted to marry the man they married.

\section{Education and related outcomes}

At baseline, about 79 percent of girls were currently in school and at endline this percentage decreased to 63 percent as may be expected because the sample is older and school dropout rates are associated with age. Thus it is important to compare enrollment rates relative to control villages. Table 4 shows DiD estimates on school dropout suggesting attendance declined more in the control villages than in the intervention villages and that the programs had a statistically significant and similar impact on school attendance in all three intervention categories.

Respondents were asked if they had received private tutoring beyond school hours. Table 4 shows that the percentage of girls who received private tutoring decreased significantly in the education and livelihoods interventions. The changes were small, however, and similar but not significant in the gender-rights awareness intervention. 
TABLE 4 Key indicators related to respondents' schooling and learning outcomes, by intervention strategy (percent)

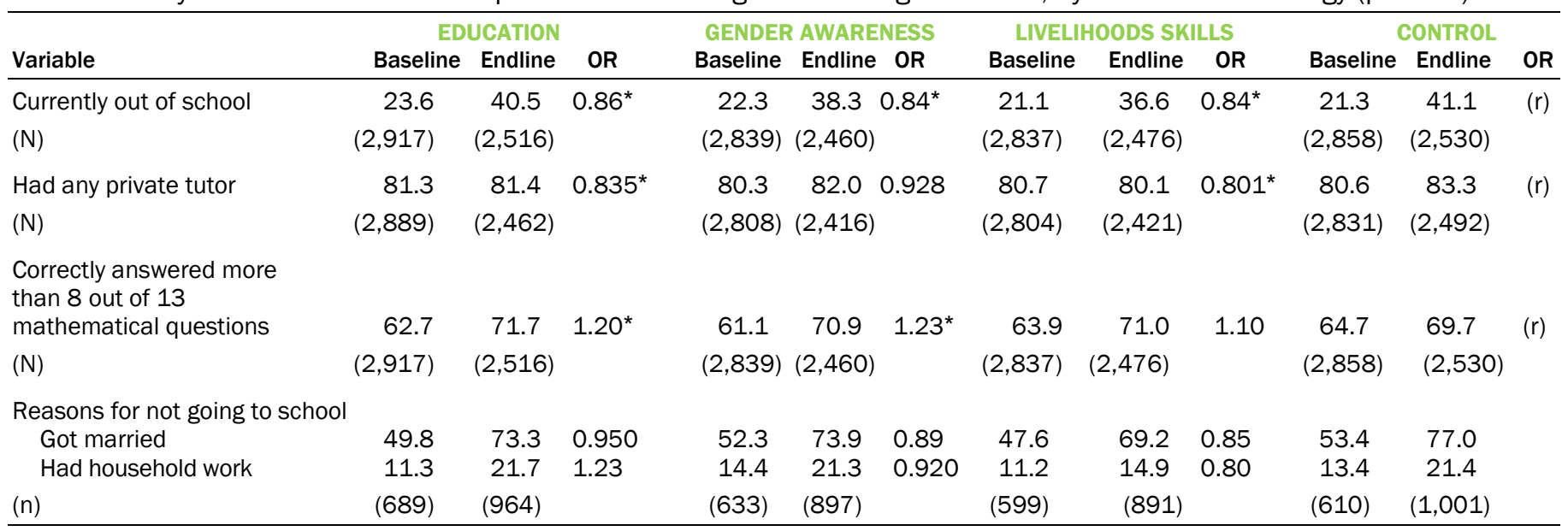

Significantly different from control group at ${ }^{*} \mathrm{p} \leq 0.05 ;{ }^{* *} \mathrm{p} \leq 0.01 ;{ }^{* * *} \mathrm{p} \leq 0.001$. OR $=$ Odds ratio. ( $\mathrm{r}$ ) = Reference category.

The baseline and endline surveys attempted to measure competencies in reading and mathematics and asked about grades in the most recent school examinations. Respondents who were in school were asked about the numbers they scored in their last final exam in English and mathematics. To assess competency in language, respondents were asked to read out four sentences, two in Bangla and two in English. The number of participants who could correctly read all four sentences increased at endline relative to baseline across the three interventions. While at baseline around 44 percent could read the sentences correctly in the education and livelihood interventions, at endline around 54 percent could read the sentences correctly in these two interventions. The gender-rights awareness interventions show a slightly varied number, which is about 45 percent at baseline and 51 percent at endline. However, similar improvement was also observed in the control group, which resulted in a nonsignificant DiD estimate (data not shown).

The mathematics competency measure was comprised of 13 questions on addition, subtraction, multiplication, division, and simple arithmetic and geometry. The table shows improvement in all interventions from baseline to endline (around 60 percent and 70 percent respectively). While at baseline 65 percent of participants in the control group could answer mathematics questions correctly, at endline the number of participants who had given correct answers increased to 69 percent. The improvement in this score in all three interventions was greater in magnitude than in the control group. However the improvement was statistically significant in the education and gender-rights awareness interventions and not in the livelihoods skills interventions.

\section{Work and income}

As reported earlier, the overall workforce participation of adolescent girls is low in the study area. There were small increases in the proportion of girls who reported ever working or who were currently working, but the changes were all significantly greater in the intervention villages compared with the control villages (Table 5). Across the interventions that the baseline survey observed, the proportion of girls ever working was similar (10 percent in the education and gender interventions and 8 percent in the livelihood skills intervention). Only 7 percent of adolescent girls across the interventions were found to be working in the month preceding the baseline survey. The increase was significant only in the gender and livelihood interventions when compared with control villages. 


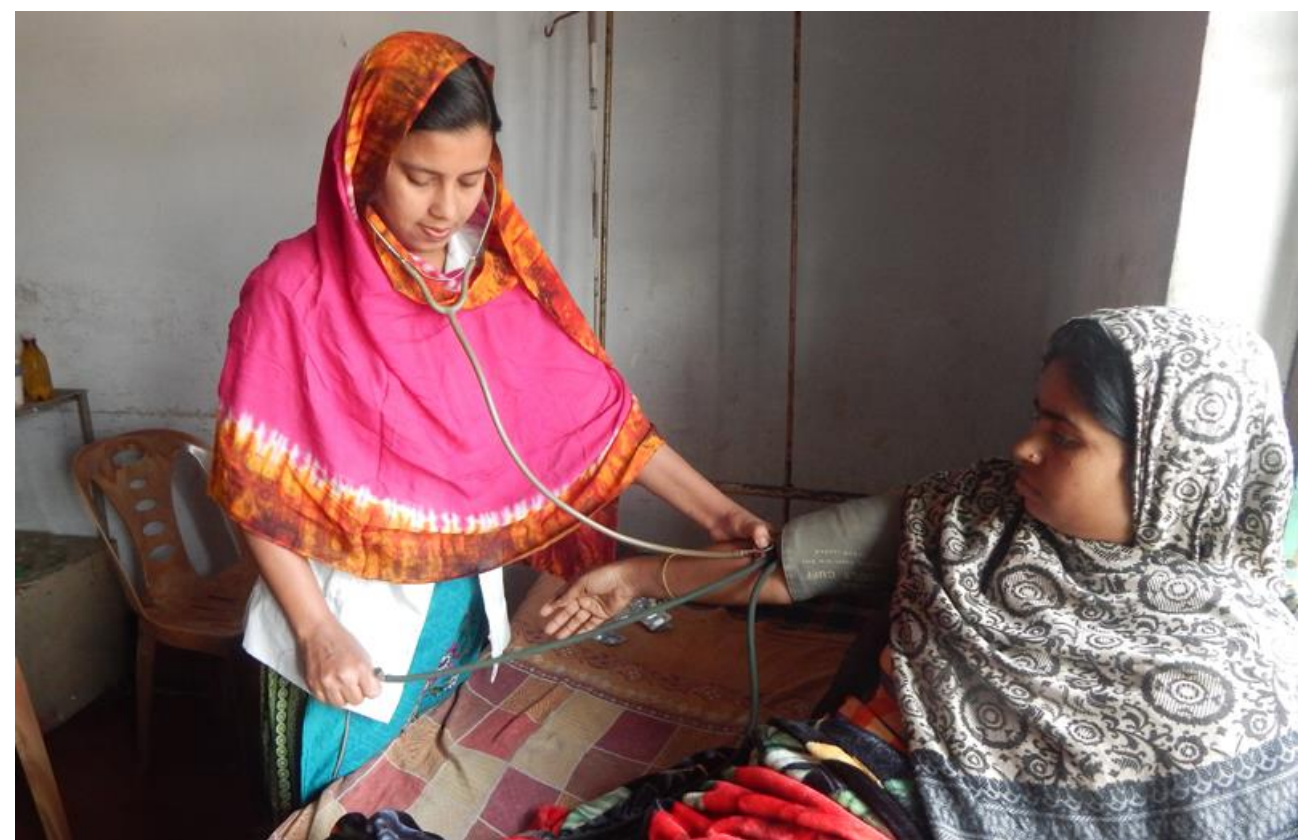

Photo Credit: Rani Khatun, BALIKA member, Dumuria, Khulna

TABLE 5 Work experiences and sector of work among adolescents who work, by intervention strategy (percent)

\begin{tabular}{|c|c|c|c|c|c|c|c|c|c|c|c|c|}
\hline \multirow[b]{2}{*}{ Variable } & \multicolumn{3}{|c|}{ EDUCATION } & \multicolumn{3}{|c|}{ GENDER AWARENESS } & \multicolumn{3}{|c|}{ LIVELIHOODS SKILLS } & \multicolumn{3}{|c|}{ CONTROL } \\
\hline & Baseline & Endline & OR & Baseline & Endline & OR & Baseline & Endline & OR & Baseline & Endline & OR \\
\hline \multicolumn{13}{|l|}{ Work experiences } \\
\hline Ever worked for pay & 10.7 & 12.4 & 1.09 & 10.1 & 15.2 & $1.48^{* * *}$ & 8.4 & 12.4 & $1.43^{* *}$ & 10.2 & 11.0 & $(r)$ \\
\hline $\begin{array}{l}\text { Currently working } \\
\text { (N) }\end{array}$ & $\begin{array}{c}7.4 \\
(2,917)\end{array}$ & $\begin{array}{c}9.5 \\
(2,676)\end{array}$ & 1.05 & $\begin{array}{c}7.5 \\
(2,839)\end{array}$ & $\begin{array}{c}11.8 \\
(2,643)\end{array}$ & $1.31^{*}$ & $\begin{array}{c}5.5 \\
(2,837)\end{array}$ & $\begin{array}{c}9.0 \\
(2,633)\end{array}$ & $1.35^{*}$ & $\begin{array}{c}7.6 \\
(2,858)\end{array}$ & $\begin{array}{c}9.3 \\
(2,739)\end{array}$ & $(r)$ \\
\hline \multicolumn{13}{|l|}{ Out-of-school youth } \\
\hline \multicolumn{13}{|l|}{ In-school youth } \\
\hline $\begin{array}{l}\text { Ever worked for pay } \\
\text { (n) }\end{array}$ & $\begin{array}{c}9.2 \\
(1,498)\end{array}$ & $\begin{array}{c}14.2 \\
(2,228)\end{array}$ & 1.16 & $\begin{array}{r}9.2 \\
(1,519)\end{array}$ & $\begin{array}{c}16.3 \\
(2,206)\end{array}$ & $1.37^{*}$ & $\begin{array}{c}7.5 \\
(1,570)\end{array}$ & $\begin{array}{c}12.3 \\
(2,238)\end{array}$ & 1.23 & $\begin{array}{c}9.0 \\
(1,491)\end{array}$ & $\begin{array}{l}12.1 \\
(2,248)\end{array}$ & $(r)$ \\
\hline \multicolumn{13}{|l|}{ Work sector } \\
\hline Day labor & 6.4 & 2.1 & 1.42 & 5.1 & 2.5 & 1.90 & 10.8 & 2.7 & 0.99 & 4.5 & 1.0 & $(r)$ \\
\hline House maid & 4.9 & 1.8 & 1.33 & 3.2 & 2.2 & 2.52 & 6.6 & 2.4 & 1.27 & 4.8 & 1.3 & $(r)$ \\
\hline Garment worker & 2.4 & 3.3 & 1.04 & 1.3 & 3.5 & 2.06 & 1.9 & 2.7 & 1.04 & 3.8 & 4.8 & $(r)$ \\
\hline Other salary/wage & 5.5 & 6.2 & 0.71 & 2.9 & 7.5 & 1.75 & 7.7 & 10.8 & 0.76 & 5.8 & 6.1 & $(r)$ \\
\hline Other & 14.9 & 6.5 & 0.79 & 9.6 & 6.5 & 1.37 & 6.9 & 6.9 & $2.45^{\star}$ & 8.9 & 4.5 & $(r)$ \\
\hline Total & 100.0 & 100.0 & & 100.0 & 100.0 & & 100.0 & 100.0 & & 100.0 & 100.0 & \\
\hline$(\mathrm{N})$ & (328) & (337) & & (312) & (402) & & (254) & (334) & & (313) & (310) & \\
\hline
\end{tabular}

Significantly different from control group at $* p \leq 0.05 ; * * p \leq 0.01 ; * * * p \leq 0.001 . \quad(r)=$ Reference category. OR $=$ Odds ratio 
At both survey points adolescent girls, currently working or ever worked, were asked about their occupation and over half responded that they were teachers or tutors. Data on hours of work and earnings suggest that while reported hours of work did not change significantly, reported earnings were considerably higher at endline compared with baseline for all interventions including the control villages. Differences across interventions are not significant (data not shown).

Table 5 presents work profiles disaggregated by schooling status. The impact of BALIKA on the proportion who ever worked was found to be significantly higher among out-of-school girls in the gender and livelihoods interventions and among in-school girls in the gender intervention. However, there is variation in the type of work they were engaged in. In general, out-of-school girls were more likely to work in own-farm or home-based production, while in-school respondents were engaged in teaching, tutoring, and other salaried work. Between baseline and endline, there was change in the occupational distribution among those who reported working in jobs such as tutoring, garment work, or other salaried (as opposed to temporary wage) work, and an increase in reporting home-based agricultural and production activities. Girls currently in school and working were teachers or tutors ( 65 percent at baseline and 70 percent at endline). The percentage of girls who worked as day laborers decreased between baseline and endline (data not shown).

\section{Adolescent social life}

"Ever since I turned 12, there has been a restriction on everything I do."

- Baseline respondent, Agardhari, Narail

"I was not allowed to go outside during my menstruation."

- Baseline respondent, Tala, Satkhira
Both baseline and endline surveys asked specific questions about mobility by destination and time of day, phrased as whether the respondent habitually went to or was allowed to go to specific destinations by herself or after dark (Table 6). Most girls (over 60 percent) had permission to go to the market, and positive responses increased in all interventions and in the control group at endline relative to baseline. The increase was statistically significant only for the education intervention relative to the control group. Girls in the education intervention were also significantly more likely to say they were allowed to visit friends relative to girls in control villages. Girls in all interventions were significantly more likely to say they had permission to go to the playground relative to girls in control villages, and girls in the gender-rights awareness intervention were also significantly more likely to say they were allowed to play outdoor games with boys. Responses to other questions, such as permission to go to the cinema or club/association activities (other than BALIKA) were not differentiated by intervention.

TABLE 6 Percentage of adolescent girls permitted to participate in certain social activities, by intervention strategy

\begin{tabular}{|c|c|c|c|c|c|c|c|c|c|c|c|c|}
\hline \multirow[b]{2}{*}{ Variable } & \multicolumn{3}{|c|}{ EDUCATION } & \multicolumn{3}{|c|}{ GENDER AWARENESS } & \multicolumn{3}{|c|}{ LIVELIHOODS SKILLS } & \multicolumn{3}{|c|}{ CONTROL } \\
\hline & Baseline & Endline & OR & Baseline & Endline & OR & Baseline & Endline & OR & Baseline & Endline & OR \\
\hline Going to market & 60.1 & 70.7 & $1.24^{\star *}$ & 64.0 & 71.3 & 1.09 & 62.2 & 69.6 & 1.08 & 61.1 & 66.9 & $(r)$ \\
\hline Going to playground & 19.6 & 15.0 & $1.74^{* * *}$ & 19.2 & 11.7 & $1.32^{* *}$ & 23.2 & 13.6 & $1.25^{*}$ & 20.4 & 9.6 & $(r)$ \\
\hline Visiting friends & 62.9 & 64.0 & $1.27^{* * *}$ & 63.0 & 59.8 & 1.05 & 65.9 & 59.9 & 0.93 & 64.1 & 59.6 & $(r)$ \\
\hline Going to cinema & 1.0 & 1.2 & 0.80 & 1.0 & 1.0 & 0.69 & 0.8 & 1.1 & 0.83 & 0.9 & 1.3 & $(r)$ \\
\hline $\begin{array}{l}\text { Playing outdoor } \\
\text { games with boys }\end{array}$ & 5.4 & 3.1 & 1.26 & 4.6 & 3.5 & $1.69^{* *}$ & 4.9 & 1.7 & 0.74 & 7.0 & 3.2 & $(r)$ \\
\hline $\begin{array}{l}\text { Going outside after } \\
\text { sunset }\end{array}$ & 6.0 & 9.0 & 1.26 & 5.3 & 6.0 & 0.94 & 5.6 & 7.6 & 1.13 & 6.2 & 7.5 & $(r)$ \\
\hline $\begin{array}{l}\text { Going to a club/ } \\
\text { association }\end{array}$ & 1.0 & 0.4 & $0.33^{*}$ & 0.1 & 0.5 & $3.33^{*}$ & 0.8 & 0.6 & 0.59 & 0.4 & 0.5 & $(r)$ \\
\hline $\begin{array}{l}\text { Going to library } \\
\text { (N) }\end{array}$ & $\begin{array}{l}18.5 \\
(2,917)\end{array}$ & $\begin{array}{c}17.7 \\
(2,516)\end{array}$ & 0.99 & $\begin{array}{l}22.4 \\
(2,839)\end{array}$ & $\begin{array}{l}19.6 \\
(2,460)\end{array}$ & $0.68^{* * *}$ & $\begin{array}{c}20.5 \\
(2,837)\end{array}$ & $\begin{array}{l}21.9 \\
(2,476)\end{array}$ & 0.87 & $\begin{array}{c}17.7 \\
(2,858)\end{array}$ & $\begin{array}{c}21.1 \\
(2,530)\end{array}$ & $(r)$ \\
\hline
\end{tabular}

Significantly different from control group at ${ }^{*} \mathrm{p} \leq 0.05 ;{ }^{* *} \mathrm{p} \leq 0.01 ;{ }^{* * *} \mathrm{p} \leq 0.001$. OR $=$ Odds ratio. $\quad(\mathrm{r})=$ Reference category. 
Table 7 reports on responses to a different set of questions about actual activities the respondent engaged in the week prior to the survey. The respondents were asked about whether they listened to the radio, watched television, or read a newspaper. On all three indicators, girls in the interventions were significantly more likely to respond in the affirmative relative to girls in the control arm. Similarly, girls in intervention villages were also more likely to say they had played outdoors in the past week. This increase was significant in the education and livelihood interventions but not in the gender intervention.

Data presented in Table 8 regarding institutional affiliations suggest that girls in the intervention villages were more likely to have an affiliation compared to the control group, and as may be expected given the nature of the program, this change was related to participation in adolescent clubs.

TABLE 7 Percentage of adolescents who reported being exposed to certain mass media and participating in other activities in the past week, by intervention strategy

\begin{tabular}{|c|c|c|c|c|c|c|c|c|c|c|c|c|}
\hline \multirow[b]{2}{*}{ Variable } & \multicolumn{3}{|c|}{ EDUCATION } & \multicolumn{3}{|c|}{ GENDER AWARENESS } & \multicolumn{3}{|c|}{ LIVELIHOODS SKILLS } & \multicolumn{3}{|c|}{$\begin{array}{l}\text { CONTROL } \\
\end{array}$} \\
\hline & Baseline & Endline & OR & Baseline & Endline & OR & Baseline & Endline & OR & Baseline & Endline & OR \\
\hline \multicolumn{13}{|l|}{$\begin{array}{l}\text { Exposure to mass } \\
\text { media (in past week) }\end{array}$} \\
\hline Listened to radio & 12.4 & 9.7 & $1.57^{* \star *}$ & 11.9 & 8.6 & $1.43^{\star *}$ & 11.2 & 10.7 & $1.97^{\star * *}$ & 10.1 & 5.1 & $(r)$ \\
\hline Watched television & 63.3 & 69.1 & $1.28^{* * *}$ & 69.8 & 73.3 & $1.17^{*}$ & 69.1 & 74.1 & $1.27^{\star *}$ & 70.5 & 70.8 & $(r)$ \\
\hline Read newspaper & 9.5 & 11.7 & $1.70^{* *}$ & 11.2 & 12.0 & $1.47^{\star * *}$ & 9.0 & 13.8 & $2.19^{\star * \star}$ & 10.4 & 7.9 & $(r)$ \\
\hline \multicolumn{13}{|l|}{$\begin{array}{l}\text { Other activities } \\
\text { (in past week) }\end{array}$} \\
\hline Performed daily prayer & 35.2 & 35.7 & 0.91 & 33.7 & 38.4 & 1.09 & 36.0 & 38.5 & 0.99 & 27.9 & 30.3 & $(r)$ \\
\hline Played outdoors & 11.8 & 4.3 & $1.54^{* *}$ & 11.4 & 3.0 & 1.11 & 10.9 & 7.1 & $2.92^{\star * *}$ & 10.0 & 2.3 & $(r)$ \\
\hline$(\mathrm{N})$ & $(2,917)$ & $(2,516)$ & & $(2,839)$ & $(2,460)$ & & $(2,837)$ & $(2,476)$ & & $(2,858)$ & $(2,530)$ & \\
\hline
\end{tabular}

Significantly different from control group at ${ }^{*} p \leq 0.05 ;{ }^{* *} p \leq 0.01 ;{ }^{* * *} p \leq 0.001$. OR $=$ Odds ratio. $\quad(r)=$ Reference category.

TABLE 8 Percentage of adolescents reporting affiliation with a social club, by intervention strategy

\begin{tabular}{|c|c|c|c|c|c|c|c|c|c|c|c|c|}
\hline Affiliation & \multicolumn{3}{|c|}{ EDUCATION } & \multicolumn{3}{|c|}{ GENDER AWARENESS } & \multicolumn{3}{|c|}{ LIVELIHOODS SKILLS } & \multicolumn{3}{|c|}{ CONTROL } \\
\hline Adolescent club & 1.6 & 3.8 & $3.33^{* * *}$ & 1.0 & 3.9 & $5.64^{* * *}$ & 3.7 & 4.8 & $1.86^{\star *}$ & 1.8 & 1.3 & $(r)$ \\
\hline $\begin{array}{l}\text { Social/cultural club/ } \\
\text { association }\end{array}$ & 2.1 & 0.7 & 0.52 & 1.0 & 0.6 & 0.91 & 1.3 & 0.7 & 0.86 & 0.8 & 0.5 & $(r)$ \\
\hline$(\mathrm{N})$ & $(2,917)$ & $(2,516)$ & & $(2,839)$ & $(2,460)$ & & $(2,837)$ & $(2,476)$ & & $(2,858)$ & $(2,530)$ & \\
\hline
\end{tabular}

Significantly different from control group at $* p \leq 0.05 ; * * p \leq 0.01 ; * * * p \leq 0.001$. $(r)=$ Reference category. OR=0dds ratio. 
Table 9 presents analysis of responses to questions measuring gendered attitudes among respondents who were asked about their views on whether girls were allowed to refuse an arranged marriage, whether women should tolerate violence, whether men were expected to use force to defend their reputation or to be tough (machismo/masculinity), and about whether men had final say in family matters. Respondents in the intervention villages were much more likely to say girls could say no to marriage and were less likely to condone gender-based violence at the endline survey relative to the control group. However, responses on the masculinity questions were not significantly different.

Table 10 shows responses to questions about the experience of harassment or violence by respondents at home, in public places, or in school. In general, girls in the intervention villages were less likely to say they had experienced harassment relative to control villages at endline. However, the decline relative to baseline was significant only for reports of experiencing violence in public places or at school in the gender-rights awareness intervention.

TABLE 9 Adolescents' change in attitudes regarding statements about gender norms, by intervention strategy (percent)

\begin{tabular}{|c|c|c|c|c|c|c|c|c|c|c|c|c|}
\hline \multirow[b]{2}{*}{ Variable } & \multicolumn{3}{|c|}{ EDUCATION } & \multicolumn{3}{|c|}{ GENDER AWARENESS } & \multicolumn{3}{|c|}{ LIVELIHOODS SKILLS } & \multicolumn{3}{|c|}{ CONTROL } \\
\hline & Baseline & Endline & OR & Baseline & Endline & OR & Baseline & Endline & OR & Baseline & Endline & OR \\
\hline $\begin{array}{l}\text { Agree: "Girls are allowed to say } \\
\text { no to an arranged marriage" }\end{array}$ & 43.7 & 61.7 & $1.49^{* * *}$ & 45.9 & 58.2 & $1.18^{*}$ & 44.2 & 63.9 & $1.61^{* * *}$ & 46.1 & 54.3 & $(r)$ \\
\hline $\begin{array}{l}\text { Disagree: "If someone insults a } \\
\text { man, he should defend his repu- } \\
\text { tation, with force if necessary" }\end{array}$ & 75.7 & 87.5 & 0.90 & 74.7 & 87.8 & 0.98 & 72.4 & 87.0 & 1.02 & 73.0 & 87.0 & (r) \\
\hline $\begin{array}{l}\text { Disagree: "To be a man, one } \\
\text { needs to be tough" }\end{array}$ & 84.9 & 94.6 & 1.10 & 84.3 & 94.0 & 1.03 & 84.7 & 94.3 & 1.05 & 84.6 & 94.0 & $(r)$ \\
\hline $\begin{array}{l}\text { Disagree: "A man should have } \\
\text { final say in all family matters" } \\
\text { (N) }\end{array}$ & $\begin{array}{l}64.3 \\
(2,917)\end{array}$ & $\begin{array}{l}74.5 \\
(2,516)\end{array}$ & 0.91 & $\begin{array}{c}62.3 \\
(2,839)\end{array}$ & $\begin{array}{c}74.1 \\
(2,460)\end{array}$ & 0.97 & $\begin{array}{c}57.4 \\
(2,837)\end{array}$ & $\begin{array}{r}72.0 \\
(2,476)\end{array}$ & 1.07 & $\begin{array}{r}57.4 \\
(2,858)\end{array}$ & $\begin{array}{c}70.6 \\
(2,530)\end{array}$ & $(r)$ \\
\hline
\end{tabular}

Significantly different from control group at $* p \leq 0.05 ; * * p \leq 0.01 ; * * * p \leq 0.001 . \quad(r)=$ Reference category. OR $=$ Odds ratio.

TABLE 10 Percentage of adolescent girls who reported experiencing harassment, according to location of harassment, by intervention strategy

\begin{tabular}{|c|c|c|c|c|c|c|c|c|c|c|c|c|}
\hline \multirow[b]{2}{*}{ Location } & \multicolumn{3}{|c|}{ EDUCATION } & \multicolumn{3}{|c|}{ GENDER AWARENESS } & \multicolumn{3}{|c|}{ LIVELIHOODS SKILLS } & \multicolumn{3}{|c|}{ CONTROL } \\
\hline & Baseline & Endline & OR & Baseline & Endline & OR & Baseline & Endline & OR & Baseline & Endline & OR \\
\hline $\begin{array}{l}\text { At home or with } \\
\text { close relative }\end{array}$ & 11.1 & 7.5 & 1.01 & 11.5 & 7.0 & 0.91 & 10.8 & 6.5 & 0.89 & 11.3 & 7.5 & $(r)$ \\
\hline Outside of home & 33.6 & 32.9 & 0.89 & 35.0 & 30.9 & $0.77^{* * *}$ & 30.2 & 30.7 & 0.94 & 29.2 & 30.9 & $(r)$ \\
\hline $\begin{array}{l}\text { In school or in class } \\
\text { (N) }\end{array}$ & $\begin{array}{l}10.1 \\
(2,917)\end{array}$ & $\begin{array}{c}8.9 \\
(2,516)\end{array}$ & 0.84 & $\begin{array}{c}15.5 \\
(2,839)\end{array}$ & $\begin{array}{l}10.4 \\
(2,460)\end{array}$ & $0.62^{* * *}$ & $\begin{array}{c}10.9 \\
(2,837)\end{array}$ & $\begin{array}{c}9.7 \\
(2,476)\end{array}$ & 0.86 & $\begin{array}{l}10.7 \\
(2,858)\end{array}$ & $\begin{array}{c}11.0 \\
(2,530)\end{array}$ & $(r)$ \\
\hline
\end{tabular}

Significantly different from control group at $* p \leq 0.05 ; * * p \leq 0.01 ; * * * p \leq 0.001 . \quad(r)=$ Reference category. OR $=$ Odds ratio. 
Table 11 reports on a range of sexual and reproductive health indicators that show that specific knowledge about menstruation, sexually transmitted infections, HIV-AIDS transmission routes, and family planning was significantly greater in all interventions compared to the control communities. The table also shows two behavioral indicators, use of sanitary menstrual pads and seeking health services for reproductive health problems, that suggest that girls in the intervention villages were more likely to seek services in comparison to girls in control villages. The response to a question regarding use of sanitary napkins during menstruation (instead of cloth) also improved for the better in the gender and livelihoods interventions.

While girls in the intervention villages were significantly more likely to have heard about family planning, the greater use of methods by married women, which was already high at baseline, did not show significantly greater improvement in the endline intervention villages compared to control villages.

TABLE 11 Adolescents' responses regarding sexual and reproductive health knowledge and practices, by intervention strategy (percent)

\begin{tabular}{|c|c|c|c|c|c|c|c|c|c|c|c|c|}
\hline \multirow[b]{2}{*}{ Variable } & \multicolumn{3}{|c|}{ EDUCATION } & \multicolumn{3}{|c|}{ GENDER AWARENESS } & \multicolumn{3}{|c|}{ LIVELIHOODS SKILLS } & \multicolumn{3}{|c|}{ CONTROL } \\
\hline & Baseline & Endline & OR & Baseline & Endline & OR & Baseline & Endline & OR & Baseline & Endline & OR \\
\hline $\begin{array}{l}\text { Knew about menstruation } \\
\text { (N) }\end{array}$ & $\begin{array}{c}92.5 \\
(2,917)\end{array}$ & $\begin{array}{c}98.8 \\
(2,505)\end{array}$ & $1.67^{*}$ & $\begin{array}{c}93.0 \\
(2,839)\end{array}$ & $\begin{array}{c}99.3 \\
(2,452)\end{array}$ & $3.0^{* *}$ & $\begin{array}{c}91.9 \\
(2,837)\end{array}$ & $\begin{array}{r}99.0 \\
(2,470)\end{array}$ & $2.23^{* *}$ & $\begin{array}{c}93.9 \\
(2,858)\end{array}$ & $\begin{array}{c}98.3 \\
(2,525)\end{array}$ & $(r)$ \\
\hline $\begin{array}{l}\text { Knew about menstruation } \\
\text { before experiencing it } \\
(\mathrm{N})\end{array}$ & $\begin{array}{c}30.6 \\
(2,617)\end{array}$ & $\begin{array}{c}31.2 \\
(2,468)\end{array}$ & 1.01 & $\begin{array}{c}27.6 \\
(2,572)\end{array}$ & $\begin{array}{c}35.3 \\
(2,430)\end{array}$ & $1.40^{* \star *}$ & $\begin{array}{c}35.1 \\
(2,519)\end{array}$ & $\begin{array}{c}36.9 \\
(2,438)\end{array}$ & 1.06 & $\begin{array}{c}33.2 \\
(2,618)\end{array}$ & $\begin{array}{c}33.6 \\
(2,480)\end{array}$ & (r) \\
\hline $\begin{array}{l}\text { Used sanitary pad } \\
\text { (N) }\end{array}$ & $\begin{array}{c}11.2 \\
(2,617)\end{array}$ & $\begin{array}{c}28.7 \\
(2,468)\end{array}$ & 1.11 & $\begin{array}{c}12.8 \\
(2,572)\end{array}$ & $\begin{array}{c}36.4 \\
(2,430)\end{array}$ & $1.36^{* *}$ & $\begin{array}{c}12.7 \\
(2,519)\end{array}$ & $\begin{array}{c}36.1 \\
(2,438)\end{array}$ & $1.36^{* *}$ & $\begin{array}{c}12.8 \\
(2,618)\end{array}$ & $\begin{array}{c}29.6 \\
(2,480)\end{array}$ & $(r)$ \\
\hline $\begin{array}{l}\text { Had correct knowledge } \\
\text { about fertile period } \\
\text { (N) }\end{array}$ & $\begin{array}{c}9.9 \\
(2,699)\end{array}$ & $\begin{array}{c}25.7 \\
(2,474)\end{array}$ & $1.35^{* *}$ & $\begin{array}{c}12.1 \\
(2,639)\end{array}$ & $\begin{array}{c}25.9 \\
(2,436)\end{array}$ & 1.10 & $\begin{array}{c}10.4 \\
(2,607)\end{array}$ & $\begin{array}{c}22.1 \\
(2,445)\end{array}$ & 1.04 & $\begin{array}{c}10.9 \\
(2,683)\end{array}$ & $\begin{array}{c}22.2 \\
(2,483)\end{array}$ & $(r)$ \\
\hline $\begin{array}{l}\text { Had any RH-related problem } \\
\text { (N) }\end{array}$ & $\begin{array}{c}11.8 \\
(2,917)\end{array}$ & $\begin{array}{c}4.5 \\
(2,505)\end{array}$ & 0.99 & $\begin{array}{c}11.3 \\
(2,839)\end{array}$ & $\begin{array}{c}5.3 \\
(2,452)\end{array}$ & 1.24 & $\begin{array}{c}8.8 \\
(2,837)\end{array}$ & $\begin{array}{c}4.9 \\
(2,470)\end{array}$ & $1.48^{* *}$ & $\begin{array}{c}10.2 \\
(2,858)\end{array}$ & $\begin{array}{c}3.9 \\
(2,525)\end{array}$ & $(r)$ \\
\hline $\begin{array}{l}\text { Received treatment for } \\
\mathrm{RH} \text { problem } \\
\text { (n) }\end{array}$ & $\begin{array}{r}38.6 \\
(345)\end{array}$ & $\begin{array}{l}69.0 \\
(113)\end{array}$ & $2.22^{* *}$ & $\begin{array}{r}34.7 \\
(320)\end{array}$ & $\begin{array}{r}60.0 \\
(130)\end{array}$ & $1.76^{*}$ & $\begin{array}{r}40.6 \\
(2,51)\end{array}$ & $\begin{array}{r}65.8 \\
(120)\end{array}$ & $1.76^{*}$ & $\begin{array}{r}47.6 \\
(2,92)\end{array}$ & $\begin{array}{r}59.2 \\
(98)\end{array}$ & $(r)$ \\
\hline $\begin{array}{l}\text { Heard about HIV/AIDS } \\
\text { (N) }\end{array}$ & $\begin{array}{c}79.1 \\
(2,917)\end{array}$ & $\begin{array}{c}91.7 \\
(2,505)\end{array}$ & $1.72^{\star \star \star}$ & $\begin{array}{c}82.1 \\
(2,839)\end{array}$ & $\begin{array}{c}92.6 \\
(2,452)\end{array}$ & $1.61^{* * *}$ & $\begin{array}{c}82.5 \\
(2,837)\end{array}$ & $\begin{array}{c}92.0 \\
(2,470)\end{array}$ & $1.44^{\star * *}$ & $\begin{array}{r}84.9 \\
(2,858)\end{array}$ & $\begin{array}{c}90.5 \\
(2,525)\end{array}$ & $(r)$ \\
\hline $\begin{array}{l}\text { Knew three routes } \\
\text { of HIV transmission } \\
\text { (N) }\end{array}$ & $\begin{array}{c}92.6 \\
(2,305)\end{array}$ & $\begin{array}{c}96.3 \\
(2,296)\end{array}$ & $1.69^{* *}$ & $\begin{array}{c}91.8 \\
(2,330)\end{array}$ & $\begin{array}{c}96.3 \\
(2,270)\end{array}$ & $1.89^{* * *}$ & $\begin{array}{c}93.0 \\
(2,341)\end{array}$ & $\begin{array}{r}96.2 \\
(2,272)\end{array}$ & $1.56^{* *}$ & $\begin{array}{c}92.5 \\
(2,427)\end{array}$ & $\begin{array}{c}93.9 \\
(2,284)\end{array}$ & (r) \\
\hline Heard about syphilis/gonorrhea & 7.7 & 12.9 & $1.55^{* * *}$ & 8.1 & 14.0 & $1.61^{* * *}$ & 10.5 & 16.1 & $2.82^{* *}$ & 9.1 & 10.4 & $(r)$ \\
\hline $\begin{array}{l}\text { Heard about FP } \\
\text { (N) }\end{array}$ & $\begin{array}{c}71.1 \\
(2,917)\end{array}$ & $\begin{array}{c}92.5 \\
(2,505)\end{array}$ & $1.65^{\star * *}$ & $\begin{array}{c}74.1 \\
(2,839)\end{array}$ & $\begin{array}{c}92.1 \\
(2,452)\end{array}$ & $1.33^{* *}$ & $\begin{array}{c}71.1 \\
(2,837)\end{array}$ & $\begin{array}{r}94.3 \\
(2,470)\end{array}$ & $1.42^{* *}$ & $\begin{array}{c}75.5 \\
(2,858)\end{array}$ & $\begin{array}{c}90.4 \\
(2,525)\end{array}$ & $(r)$ \\
\hline $\begin{array}{l}\text { Used FP methods } \\
\text { (among married youth) } \\
\text { (n) }\end{array}$ & $\begin{array}{r}88.8 \\
(573)\end{array}$ & $\begin{array}{c}87.8 \\
(1,075)\end{array}$ & 0.80 & $\begin{array}{r}84.6 \\
(579)\end{array}$ & $\begin{array}{c}88.8 \\
(1,066)\end{array}$ & 1.27 & $\begin{array}{r}82.1 \\
(491)\end{array}$ & $\begin{array}{l}87.9 \\
(982)\end{array}$ & 1.40 & $\begin{array}{r}87.1 \\
(529)\end{array}$ & $\begin{array}{c}88.5 \\
(1,165)\end{array}$ & $(r)$ \\
\hline
\end{tabular}

Significantly different from control group at ${ }^{*} \mathrm{p} \leq 0.05 ;{ }^{* *} \mathrm{p} \leq 0.01 ;{ }^{* *} \mathrm{p} \leq 0.001$. OR $=$ Odds ratio. $(\mathrm{r})=$ Reference category. 


\section{CONCLUSION}

There was significant decline in all intervention villages in the overall probability of child marriage relative to the control villages. The magnitude of decline among the youngest age group was the greatest for the livelihoods-skills intervention. After adjusting for religion and age, the odds of being married in the intervention villages were similar suggesting that the raw differences are attributable to differences in population composition.

The data suggest that the program had an impact on reducing the prevalence of child marriage $(<18)$ regardless of initial conditions. However, age-differentiated patterns of program participation and decline in child marriage as measured in odds ratios suggest that interventions are more successful in delaying marriage among 16- and 17-year-olds and for education interventions for the under age 16 marriages. These age-specific differences in risk of marriage are important to take into account when discussing measurement of program impact.

In addition to child-marriage indicators, Figure 4 summarizes the results reported in Section 3 on the impact of the interventions on schooling, work, gender-awareness, and sexual and reproductive health and rights indicators. These other indicators are important goals of empowerment themselves that may also have later-life impact on marriage and sexual and reproductive health outcomes. On a number of indicators, such as knowledge (and confidence) that girls can say no to marriage, rejection of norms reinforcing gender-based violence, knowledge of STI and HIV transmission, and behaviors seeking reproductive health services, improvements were significantly greater in the villages that participated in the BALIKA program.

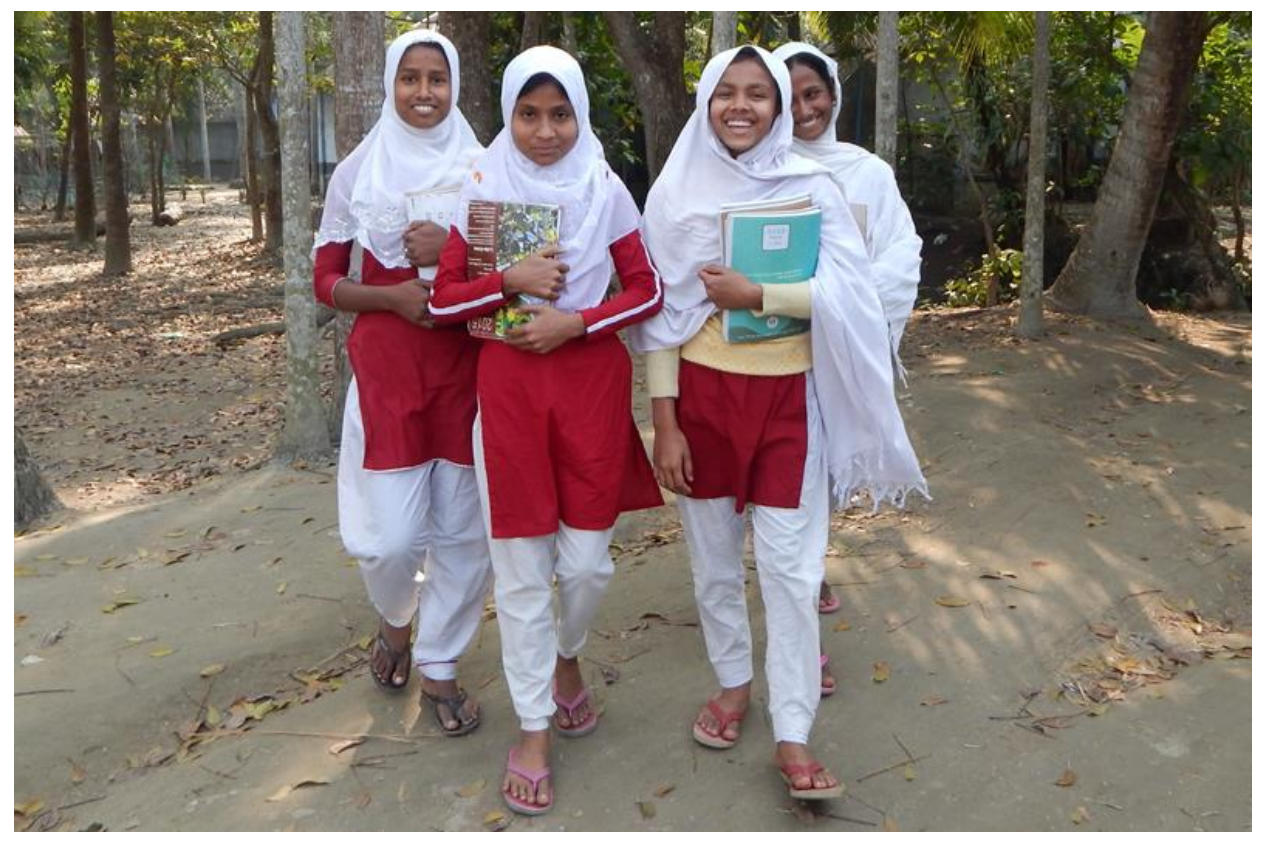

Photo Credit: Shamima, BALIKA member, Purulia, Narail 
FIGURE 4 Results summary of the impact of the interventions on child marriage, sexual and reproductive health and rights, schooling, and gender-awareness indicators

\section{BALIKA: Empowering girls} and building assets

Statistically significant findings from the three intervention strategies, relative to the comparison group.

1

EDUCATION

GENDER-RIGHTS AWARENESS

\section{LIVELIHOODS} SKILLS

\section{FEWER GIRLS MARRIED} AS CHILDREN

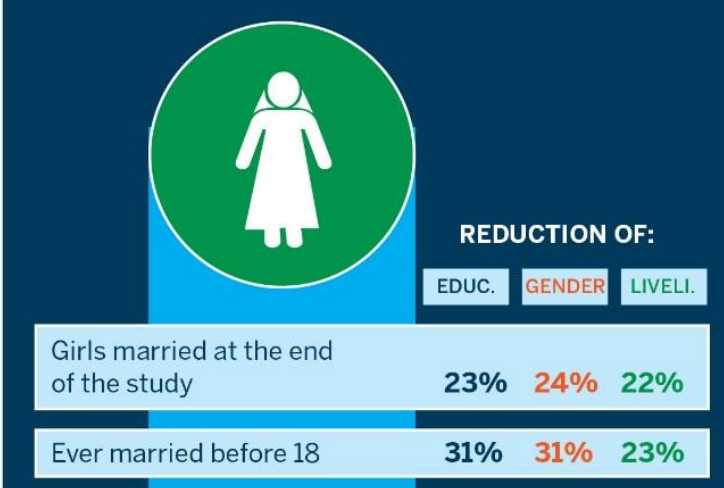

Ever married before 18

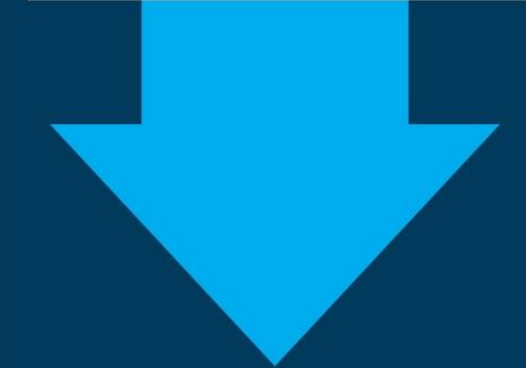

IMPROVED EDUCATION, WELL-BEING, AND HEALTH
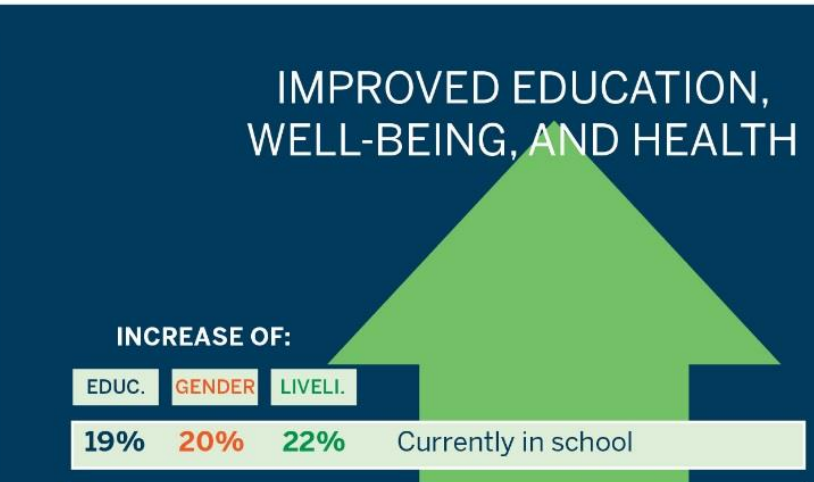

\begin{tabular}{|c|c|c|c|}
\hline $20 \%$ & $23 \%$ & nss & Excelled on mathematics test \\
\hline nss & $31 \%$ & $35 \%$ & Currently earning an income \\
\hline $57 \%$ & $28 \%$ & $70 \%$ & Listened to radio \\
\hline $43 \%$ & $17 \%$ & $47 \%$ & Watched television \\
\hline $97 \%$ & $27 \%$ & $119 \%$ & Read newspaper in the last week \\
\hline $54 \%$ & nss & $192 \%$ & Played outdoors \\
\hline $27 \%$ & $25 \%$ & $29 \%$ & $\begin{array}{l}\text { Disagrees that a womar } \\
\text { tolerate violence agains }\end{array}$ \\
\hline
\end{tabular}

\begin{tabular}{|llll|}
\hline $49 \%$ & $18 \%$ & $61 \%$ & $\begin{array}{l}\text { Agrees that girls can say no to } \\
\text { arranged marriage }\end{array}$ \\
\hline $65 \%$ & $33 \%$ & $42 \%$ & Knows about FP methods \\
\hline $69 \%$ & $89 \%$ & $56 \%$ & Knows how HIV is transmitted \\
\hline $122 \%$ & $76 \%$ & $76 \%$ & $\begin{array}{l}\text { Received treatment for } \\
\text { reproductive health problem }\end{array}$ \\
\hline $67 \%$ & $200 \%$ & $123 \%$ & Knows about menstruation \\
\hline nss & $36 \%$ & $36 \%$ & Uses menstrual hygiene products \\
\hline
\end{tabular}

nss $=$ Not statistically significant.

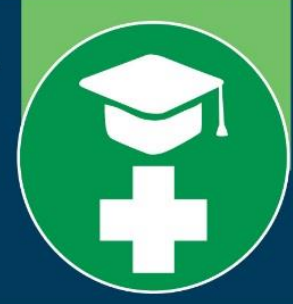


The impact of the programs on several other indicators was somewhat differentiated and suggests that the pathways of change attributable to the program differed according to skill emphasis. It is reassuring that along with the effect on child marriage, all three interventions had an impact on reducing school dropout rates. While we did not detect significant impact on measures of literacy, two of the interventions had a significant impact on mathematical competency. The effect of programs on learning outcomes reflected essentially the same relative impact. A similar pattern of impact was noted in terms of decline in the experience of violence in schools, supporting the general conclusion that both gender-awareness and livelihoods skills improve the experience of schooling and its outcome.

The impact of the program on girls' engagement in livelihood activities was assessed at baseline and endline in intervention villages relative to control villages. As noted in the baseline survey, very few girls were engaged in income-earning activities in the program area. At endline, girls' report of working was similarly low in all villages, but increased significantly in all intervention areas. Relative to baseline, reported income was higher in all intervention arms and there was no differentiation by intervention. There is some change in the sector of work reported. Girls who were in school were more likely to report working in higher-status jobs after the intervention. Apart from this increase, there is little evidence that the program had an impact in terms of changing girls' day-to-day livelihood activities. This is not a surprise to the program designers, since the emphasis in longterm aspirations and skills for livelihoods through exposure to a program that offered short training on a range of skills was designed mainly to enhance knowledge about future livelihood options.

There was some variation in the impact of programs that we are not able to explain in terms of program content, but we note here for completeness. Only the education intervention villages reported a significant decline in the experience of harassment/violence at home, while the other two interventions reported significant reductions of harassment experience at school or in public places. A significant improvement in use of menstrual pads was reported for gender and livelihoods villages. An improvement in adolescents' correct knowledge of the fertile period was reported only for the education intervention, although the same reproductive health curriculum was offered in all interventions. 


\section{Discussion}

The BALIKA program succeeded in delaying marriage in communities where the practice of child marriage is culturally entrenched. The change is attributable to programs characterized by an emphasis on empowering girls through skill-building and involving the community. As an intervention research initiative we chose to offer a package of activities that included the engagement of key actors and mentors from the community and active engagement of a research process to ensure that the effort produced rigorous evidence to inform a learning agenda. Throughout the process, we sought to understand what works and why, with a view to informing future programs. At the outset we made a decision to focus on scalable and sustainable programs, preferably ones that engage the community at all levels and are owned by the community. We also chose to focus on programs that could be taken up on local initiative. As such we did not offer incentives and stipends, despite the fact that similar incentives have been shown to be effective in Bangladesh as well as in other contexts, because a heavy reliance on monetary transfers would add a degree of complexity and expense that might not be sustainable as a local initiative.

We believe that programs need to center around an activity, such as the skill-building component of the program. Other examples of activities offered are access to health or other services, distribution of stipends, sports/cultural activities, or community services. It is unlikely that community engagement alone, even if is focused on changing mindsets, values, and norms specifically related to child marriage, would constitute a sustainable program.

The BALIKA program had several other strategic elements that likely contributed to its success. It deliberately promoted the use of technologies that are not common in the community. The centers thus had all the airs and graces of modern technology centers equipped with computers, tablets, and mobile phones. Members were given identification cards containing bar codes that could be scanned by computers. Surveys used mobile phones to electronically capture and transmit data. Project supervisors and managers used mobile phones to monitor activities and record progress.

The location of centers and the modality of work paid particular attention to the concerns of girls' safety and security. Thus, if families or individual girls felt the center was too far for them to travel to alone, mentors ensured that sessions were organized so that girls in a particular neighborhood could walk together. Program managers tried to avoid choosing locations such as the local union Parishad (village municipal building), because these are often located near markets and would not be considered safe for girls. Instead, almost all centers were housed within a school in the community, and one that the members themselves attended as a child or were cur-
"Earlier I used to have problems with my husband on various issues. At that time he used to stop talking to me [during arguments], and I used to do the same. This problem lingered for a long time. But I was rigid not to compromise. However, from the BALIKA program I came to know about mutual understanding. We are being taught how to come to a common ground even when we are angry." - BALIKA member, Kalia, Narail

"If parents think that girls will earn money, they will give them an opportunity to continue with their studies. Girls should continue their education until they are 22 to 23 years old, then they should have two more years before they get married. They'd get the opportunity to work and also they can get married at the right age [closer to 25]."

- BALIKA member, Pankhali, Dacope 
rently attending. Qualitative data on why child marriage persists shows that sexual safety, harassment in public spaces, and the associated implications for girls' reputations are often important considerations for parents, because they influence marriageability.

The fact that impact on several outcomes of interest improved, including child marriage, attitudes about violence, and specific improvements in knowledge indicators related to reproductive and sexual health, gives us confidence that the common elements in the program, i.e., community engagement, safe spaces, locally recruited mentors and teachers, all contributed toward our common objective, which was to change local perceptions that girls are not liabilities but instead are potentially important assets. Why do interventions work? They elevate the status of girls. The technology used is important for its novelty-to keep girls coming and to ensure attendance-as well as to generate a favorable impression in the community regarding the program. Community engagement is critical, but the interventions are multifaceted in their impact.

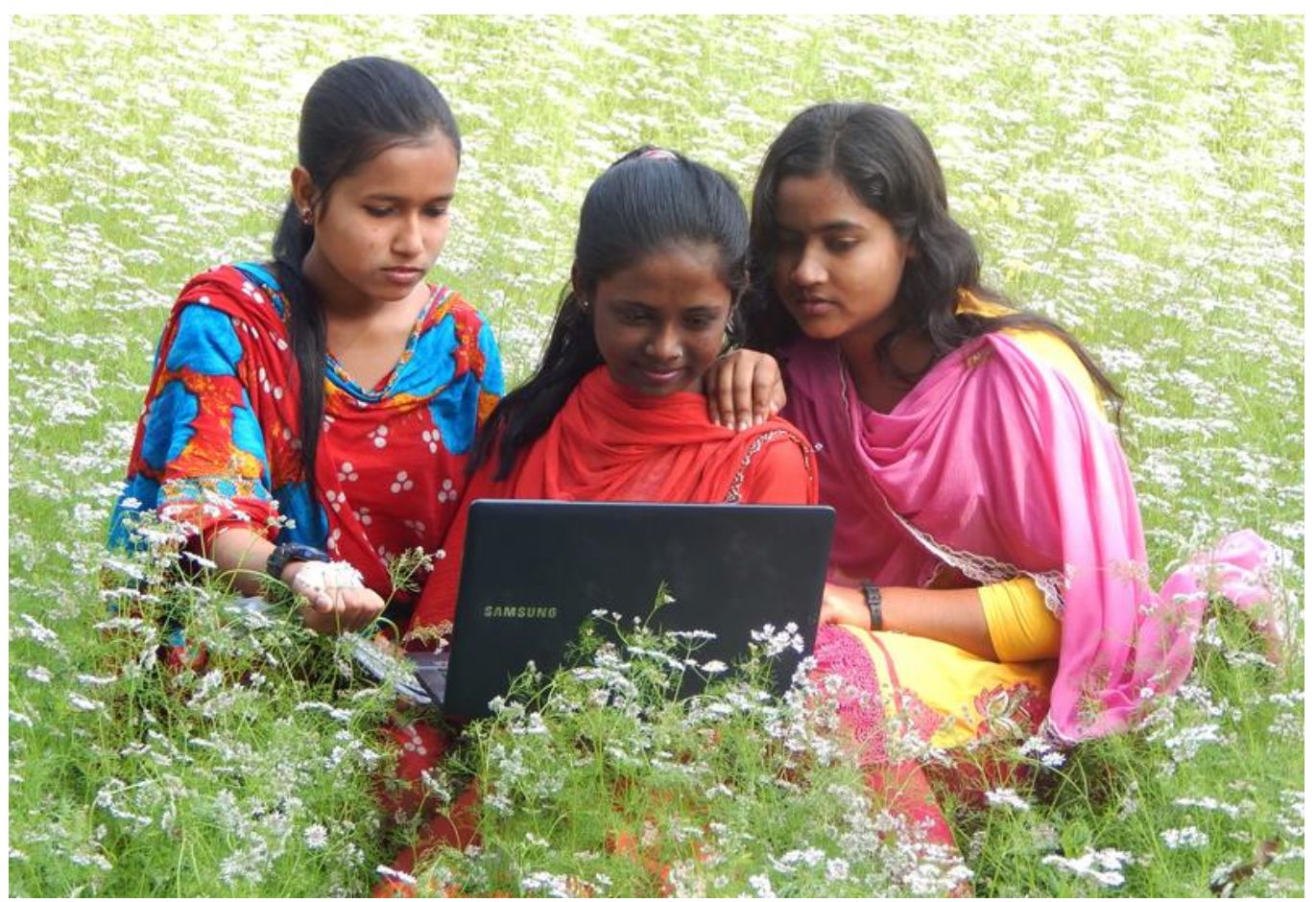

Photo Credit: Lachmin, BALIKA member, Naldi, Narail 


\section{REFERENCES}

Ainul, Sigma and Sajeda Amin. 2015. "Environmental vulnerability and early marriage in southern Bangladesh." Paper presented at the Annual Meeting of the Population Association of America, San Diego, CA.

Amin, S. 2011. "Empowering girls in rural Bangladesh: Kishori Abhijan." Transitions to Adulthood Brief No. 13, updated July 2011. New York: Population Council. http://www.popcouncil.org/pdfs/TABriefs/13_KishoriAbhijan.pdf.

Amin, S., S. Ainul, F. Akter, et al. 2014. "From evidence to action: Results from the 2013 baseline survey for the BALIKA Project." New York: Population Council.

Amin, Sajeda and Ashish Bajracharya. 2011. "Costs of marriage-Marriage transactions in the developing world." Transition to Adulthood Brief No. 35. New York: Population Council. Retrieved from http://www.popcouncil.org/uploads/pdfs/TABriefs/35_MarriageCosts.pdf.

Amin, Sajeda and Alaka M. Basu. 2004. "Popular perceptions of emerging influences on mortality and longevity in Bangladesh and West Bengal," Population Studies 58(3): 357-364.

Amin, Sajeda, Ian Diamond, Ruchira T. Naved, and Margaret Newby. 1998. "Transition to adulthood of female garment-factory workers in Bangladesh," Studies in Family Planning 29(2): 185-200.

Amin, S., S. Mahmud, and L. Huq. 2002. "Kishori Abhijan: Baseline survey report on rural adolescents in Bangladesh." Dhaka: Ministry of Women and Children Affairs, Government of the People's Republic of Bangladesh.

Aziz, K.M. Ashraful and Clarence Maloney. 1988. "Life stages, gender and fertility in Bangladesh," Medical Anthropology Quarterly 2(2).

Baird, S.J., et al. 2012. "Effect of a cash transfer program for schooling on prevalence of HIV and herpes simplex type 2 in Malawi: A cluster randomised trial," The Lancet 379(9823): 1320-1329.

Banerjee, Abhijit, Shawn Cole, Esther Duflo, and Leigh Linden. 2007. "Remedying education: Evidence from two randomized experiments in India," The Quarterly Journal of Economics 122(3): 1235-1264.

Behrman, Julia A. 2015. "Do targeted stipend programs reduce gender and socioeconomic inequalities in schooling attainment? Insights from rural Bangladesh," Demography 52(6): 1917-1927.

Burket, M.K., M. Alauddin, A. Malek, and M. Rahman. 2006. Raising the Age of Marriage for Young Girls in Bangladesh. Watertown, MA: Pathfinder International.

Duflo, Esther, Pascaline Dupas, and Michael Kremer. 2014. "Education, HIV and early fertility: Experimental evidence from Kenya." www.web.stanford.edu/ pdupas/DDK EducFertHIV.pdf.

Erulkar, Annabel S. 2006. "Berhane Hewan: A program to support married and unmarried adolescent girls in rural Amhara, Ethiopia," Program Brief. Accra: Population Council.

Erulkar, Annabel and Eunice Muthengi. 2009. "Evaluation of Berhane Hewan: A program to delay marriage in rural Ethiopia," International Perspectives on Sexual and Reproductive Health 35(1): 6-14.

Gertler, Paul J., Sebastian Martinez, Patrick Premand, Laura B. Rawlings, and Christel M.J. Vermeersch. 2011. "Difference-in-Differences," in Impact Evaluation in Practice. Washington, DC: World Bank, pp. 95-105.

Haberland, Nicole A. 2015. "The case for addressing gender and power in sexuality and HIV education: A comprehensive review of evaluation studies," International Perspectives on Sexual and Reproductive Health 41(1): 31-42. 
Haberland, Nicole, et al. 2005. "Early marriage and adolescent girls," Youthlens on RH and HIV/AIDS, Brief No. 15. Arlington, VA: Youthnet.

Hallfors, Denise, et al. 2011. "Supporting adolescent orphan girls to stay in school as HIV risk prevention: Evidence from a randomized controlled trial in Zimbabwe," American Journal of Public Health 101(6): 1082-1088.

Heath, Rachel and A.M. Mobarak. 2015. "Manufacturing growth and the lives of Bangladeshi women." Research Briefs in Economic Policy No. 10. Washington, DC: CATO Institute.

Hossain, N.Z., A. Akter, and N. Das. 2012. "An early assessment of SoFEA." Dhaka: BRAC, Research and Evaluation Division.

International Center for Research on Women (ICRW). 2007. How to End Child Marriage: Action Strategies for Prevention and Protection. Washington, DC: ICRW

IntraHealth International. 2008. "Community-based interventions to delay age of marriage: A review of evidence in India," Evidence Review Series No. 1. New Delhi: IntraHealth International.

International Labour Organization (ILO). 2006. Baseline survey on child domestic labour (CDL) in Bangladesh. Geneva: ILO.

Jensen, Robert. 2012. "Do labor market opportunities affect young women's work and family decisions? Experimental evidence from India," The Quarterly Journal of Economics 127: $753-792$.

Kenny, Charles and Sarah Dykstra. 2015. "Advancing a gender-based development agenda." White House and the World 2016 Briefing Book. Washington, DC: Centre for Global Development. http://www.cgdev.org/publication/ft/advancing-gender-based-developmentagenda.

Kremer, Michael, Edward Miguel, and Rebecca Thornton. 2009. "Incentives to learn," Review of Economics and Statistics 91(1): 437-456.

Lloyd, Cynthia B. (ed.). 2005. Growing Up Global: The Changing Transitions to Adulthood in Developing Countries. Panel on Transitions to Adulthood in Developing Countries, National Research Council and Institute of Medicine. Washington, DC: National Academies Press.

Muna, Lazeena. 2005. Romance and Pleasure: Understanding the Sexual Conduct of Young People in Dhaka in the Era of HIV/AIDS. Dhaka: The University Press Limited.

Murphy, Elaine and Dara Carr. 2007. “Powerful partners: Adolescent girls' education and delayed childbearing." Population Reference Bureau brief, September. Washington, DC: PRB.

National Institute of Population Research and Training (NIPORT), Mitra and Associates, and ICF International. 2016. Bangladesh Demographic and Health Survey 2014. Dhaka, Bangladesh and Rockville, MD: NIPORT, Mitra and Associates, and ICF International.

Naved, Ruchira T., Margaret Newby, and Sajeda Amin. 2001. "The effects of migration and work on marriage of female garment workers in Bangladesh," International Journal of Population Geography 7(2): 91-104.

USAID. 2009. "Early marriage and youth reproductive health." Fact sheet on Youth RH Policy. Washington, DC: Health Policy Initiative.

World Bank. 2006. "Whispers to voices: Gender and social transformation in Bangladesh." Development Series Paper No. 22. Dhaka, Bangladesh. 


\section{APPENDIX}

\section{BALIKA interventions}

Intervention activities were designed to test the impact of three different approaches to delaying marriage and childbearing using safe spaces to provide basic skills and access to Information and Communication Technology. Community-mobilization activities also provided awareness among community members about the causes and consequences of child marriage. Interventions, delivered for 18 months from February 2014 to August 2015, included:

- Group sessions for skill development

- Community mobilization activities

Interventions were delivered to adolescent girls who were between the ages of 12 and 18, both in school and out of school. Parents (mothers, fathers, guardians, in-laws) of girls and other community leaders from the project areas were targeted through these interventions as important gatekeepers and decision-makers. The BALIKA catchment areas were centered around a primary school in a union and included 72 unions in 9 upazilas and 3 districts in Khulna, Satkhira, and Narail.

\section{BALIKA activities}

Group sessions for girls were offered through village-based BALIKA centers. The BALIKA centers are selected places in primary schools where girls met on a regular basis. The center offered a safe learning environment where girls received mentor and peer support. Girls met weekly for two-hour-long training sessions. The sessions took place after school hours and on weekends to accommodate competing demands on their time for school and afterschool activities. The centers remained in session throughout the year including during breaks in school sessions.

BALIKA program interventions included the use of modern equipment, e.g., laptop, tablets, modem, camera, blood pressure machines, digital content, videos, and so on. Sessions attracted the girls living in villages and remote areas, who can now use equipment that they never had seen or touched before. Sessions were highly interactive and lively due to the use of digital content and videos. BALIKA centers can be used to continue sessions after completion of the project.

\section{Basic life skills}

Learning life skills is a core component of adolescent development. The basic life skills curriculum-which equipped girls with an integrated set of critical thinking, personal, and interpersonal competencies needed to lead productive and fulfilling lives-was delivered across the interventions. All girls were given basic sexual and reproductive health information in a safe space environment. The 44 hours of sessions included knowing yourself and others, creative thinking, decision-making, learning how to say no, learning to compromise, physical and emotional changes in 
adolescence, menstrual hygiene, food and nutrition, reproductive health, HIV/AIDS, child marriage, and family planning. Life-skills topics were discussed for the first hour of weekly two-hour sessions, using interactive learning materials and small-group activities. The life-skills module has step-by-step guidelines for conducting the sessions and includes interactive games and group exercises. It guides the teacher and mentors in generating new ideas and in how to make learning entertaining.

The module was supplemented by cartoons, comic books, and documentaries. The fun and thought-provoking comic book Sathi (Friend) portrays with pictures the story of an adolescent girl named Sathi and the daily struggles of her life. The adolescent girls in the groups were able to relate their own life problems with Sathi and drew motivation and inspiration from her to overcome hurdles. A video documentary Amar Dosh Noi (It Is Not My Fault) on "eve teasing" was created to focus on the issue that presented the ways girls can protect themselves and help those who have been victims of harassment. The aim of this documentary was to create awareness and increase emotional strength among adolescent girls to deal with victim blaming. Another documentary, Akash Chhoyar Sawpno (Reaching the Sky), was created on the topic of self-development for adolescent girls. The objective was to motivate the girls and instill the idea that despite social barriers, with dedication and hard work any goal can be achieved and dreams can be fulfilled.

\section{Education}

It is well recognized that increasing girls' access to, and motivation for, continued schooling is a key intervention strategy for delaying age at marriage. Girls are more likely to control their own destinies and effect change in their communities when they have higher levels of education. The main objective of the education intervention was to improve school performance by providing specific assistance in mathematics and English, the subjects where girls face the most difficulties. Our theory of change suggests that girls who perform poorly in school are most likely to drop out and be at risk of child marriage. Topics were identified and problem areas were prioritized by experts familiar with the Bangladesh national curriculum. Tutoring support was provided through interactive video tutorials. Twenty-four interactive video tutorials were created, each approximately five minutes in length. The flash-based animated contents covered are parts of speech, verbs, prepositions, subject and predicate, sentence-making, tenses, vocabulary, numbers, algebra, and geometry. The materials are intended to assist individual self-learning and increase interest in mathematics and English. The generic materials intended to improve conceptual clarity on these topics are useful for girls in class 6-8. Additionally, existing digital materials from BRAC were used in the sessions to maximize the use of resources. Out-of-school girls were offered a different curriculum, and if needed communicative English. The $B B C$ Janala book, used as a tool for practicing English, contained conversations, grammar, pronunciation, vocabulary, quizzes, and practice tests. At endline, we measured competency in mathematics and English. The out-of-school girls were also taught about financial literacy, including profit, loss, and savings.

\section{Livelihoods}

Providing targeted skills training to encourage new aspirations with regard to future economic opportunities for unmarried girls, especially those who had dropped out of school, can help delay marriage. Vocational training programs for girls that build livelihoods skills mainly focus on traditional skills like tailoring and gardening, but women's labor-market participation in the Information and Communication Technology sector has not developed much in rural Bangladesh yet. In BALIKA, adolescent girls were given generic livelihoods skills, such as basic computer literacy, email communication, and Internet search abilities that 
can be useful for a variety of economic activities. These skills equipped them with Information and Communication Technology-based livelihoods skills to help construct a different pathway to a productive adulthood. BALIKA provided five components of livelihoods skills: basic computing ( 25 hours), basic health screening (17 hours), mobile phone applications (13 hours), basic photography (30 hours), and entrepreneurship (15 hours). For each component, the program developed a teachers' guide and students' book. The teachers' guide contained detailed information and was used as a tool to impart entrepreneurship training. The teachers' guide was complemented by a student book, which facilitated learning for the students and re-emphasized concepts communicated during sessions. Initially we thought of offering two skills to girls depending on their interest and potential. Later we decided to offer all five components to all girls in the livelihoods intervention. The idea was to give them a basic knowledge of the various skills, which might inspire them to pursue advanced-level training at a later date. We did not expect that the girls would start earning money with these skills right away, but rather that these skills would eventually generate income-earning opportunities.

\section{Areas of skills development in the livelihoods intervention}

The livelihoods intervention strategy offered generic financial skills and emphasized activities for income generation. These skills gave the girls the confidence to become entrepreneurs and enabled them to earn income for their families. Skill development was offered in activities that include the following.

\section{Basic health screening}

A Basic Health Screening Training Book was designed to inform adolescent girls aged 12 to 18 about the importance of good health and well-being, to equip them with basic knowledge on primary health care and nutrition, and on maternal, child, and reproductive health. The curriculum was designed in such a manner that all interested adolescent girls could use these skills to explore new earning opportunities in their communities. Through specific services, such as measuring temperature and blood pressure, girls can earn small amounts of money from their local communities. The girls were taught about first aid, child immunization and disease prevention, malnutrition and balanced diet, care for pregnant mothers, the five danger signs during pregnancy, and myths about and transmission of HIV/AIDS.

\section{Photography}

A Photography Training Book was developed to teach adolescent girls about the different features of professional photography. The book's attractive graphics and motivating storyline made learning photography easy and interesting. Girls gained confidence learning about this traditionally male-dominated skill and were inspired to use it as a source of income generation. Topics included basic information about digital photography, such as the parts of the digital camera and its use, types of photography, how to compose a good photo, and how to transfer photos to an external device for printing. Students were able to borrow a digital camera with which to practice photography, and photos were analyzed for quality by the mentors. The photography training generated a lot of interest among the girls and some of them have started to earn small amounts from taking passport-size photos used for various purposes in their locality.

\section{Mobile phone applications}

The Mobile Phone Applications Training Book was introduced to familiarize the girls with the huge potential of mobile phones and to teach them various things that can be administered 
through this device apart from talking to people. The girls learned basic features such as setting the date and time, saving contacts, changing the battery, browsing the Internet, and using social media. The book contains information regarding online payment, bKash, flexiload, and other applications that can be used to help the girls become self-reliant.

\section{Basic computing}

The Basic Computing Book gave the girls the opportunity to learn about computers and use them for basic composing, word processing, and browsing purposes. The use of search engine options opened an unlimited learning source. Topics in the training included different hardware parts and their use, operating software and Microsoft Windows, opening email accounts through gmail, opening a skype ID and its use, use of social media, Microsoft Word and Excel, search engines for browsing for information and websites. Girls were very interested in learning computer skills that could be applied to a wide range of activities. They understood that these skills would help them become independent and self-reliant and build overall capacity to shape their future.

\section{Entrepreneurship}

Adolescence is the best stage to acquire basic knowledge about entrepreneurship and to foster a positive attitude toward it. The Entrepreneurship Book introduced the concept of entrepreneurship and the exciting world of business to the adolescent girls through interactive learning and mentoring. The objective was to show how enterprising behavior can have a positive impact on society. The program provided girls with the skills needed to set up and sustain a small business in their own community. The link between market and entrepreneur was stressed in the step-by-step process. The book explains how a girl can create a nonconventional and innovative source of income using only a small amount of capital. Topics include marketing, finance, business-plan development, critical thinking, risk-taking, leadership, and mentorship.

\section{Components of the gender-rights awareness intervention}

The gender-rights awareness intervention strategy, based on the Population Council's It's All One curriculum, is a rights-based approach that introduces the concepts of sex and gender, gender roles, gender equity and equality, gender discrimination, and gender-based violence. It explores how these concepts have been transmitted and gives girls the opportunity to analyze how gender affects sexual and reproductive health and rights. The topics of child marriage and its consequences, dowry, leadership, mentorship, and role models were also included in the sessions. The teacher/mentor's module aimed to change perceptions and beliefs by discussing gender roles, power dynamics, and gender-based division of labor. Topics were discussed by mentors, and interactive techniques were used to promote participatory learning.

\section{Community-mobilization activities}

The Population Services and Training Center conducted community mobilization throughout the intervention period. Community discussions led by mentors promoted participation by local government representatives and local leaders in the implementation process and sensitized community members on the importance of the continuation of girls' education and the risk of marrying girls early. 


\section{Courtyard meetings}

Awareness-raising activities engaged community members and local leaders from the community. Almost 800 courtyard sessions were organized for parents and guardians of the adolescent girls to inform them about BALIKA's objectives and to highlight the importance of improving the skills of young girls. The meetings also provided opportunities to dispel any misunderstandings about the program and to address parents' concerns. The sessions provided an opportunity for community conversations about child marriage. Approximately 20 people (mothers and fathers) attended each meeting. Mentors conducted the sessions in the presence of project managers. The meetings also encouraged discussion of sexual and reproductive health and rights (SRHR) issues, life skills, the right of a young woman to live a free life, and the right to consent and have choice with regard to marriage, sex, and childbirth. Also discussed were the importance of girls' regular attendance in the sessions and ways to increase girls' attendance at BALIKA centers.

\section{Local support group meetings}

Community mobilization included the formation of local support groups with representation from 13 community members, such as community and religious leaders, teachers, elected government members, matchmakers, marriage registrars, parents, and adolescent girls. Seventy-two local support groups were formed at the beginning of the intervention in the 72 project areas. Group members met bimonthly to review activities at the centers, support implementation of project activities, encourage girls to stay in school, and provide support to prevent child marriage. Group members discussed the importance of girls' education; legislation and laws related to child marriage; dowry; violence; and reproductive health and rights. Members visited BALIKA centers periodically and addressed any security concerns that may have arisen.

The BALIKA interventions included broadly targeted advocacy at the community level. Advocacy programs focused not only on women's groups and community leaders within the study area, but also on relevant national and local-level government institutions, NGOs, and stakeholders, and the adoption of girl-friendly policies and best practices.

\section{Advocacy meetings}

A total of 255 advocacy meetings were conducted in the 72 unions to engage communities in discussions about child marriage and to increase awareness of the value of education, life skills, and livelihood opportunities for girls. Project activities were shared by staff and the community. Attending the meetings were upazila chairmen and government officials, union council chairmen, local female ward counselors, kazi (Muslim marriage registrar), purohit (Hindu priest), imam (Muslim religious leader), lawyers, head teachers of primary and secondary schools, matchmakers, NGO workers, and young boys and girls. Discussions centered on the roles and responsibilities of individuals in the society as well as those of local representatives and government officials.

\section{Local events}

Project staff and BALIKA center girls participated jointly with the local government in such observation events as National and International Girl Child Day and National Victory Day. BALIKA members and mentors actively took part in rallies, debate competitions, cultural activities, writing and signing competitions, and more. 


\section{District workshops}

As part of local-level advocacy, three workshops were organized at the district level in Khulna, Satkhira, and Narail to share project updates, monitor strategy, and disseminate baseline survey results to stakeholders and local government officials, to ensure their support and cooperation. These workshops helped to identify the 9 upazilas and 96 unions that were to become the BALIKA study areas. Among these, 72 unions were randomly chosen and designated as locations for BALIKA centers and 24 would serve as control areas.

\section{National advocacy event}

A national-level dissemination and advocacy event was organized to share the findings of the baseline results and engage ideas and expanded opportunities for adolescent girls. Stakeholders from government, nongovernment organizations, donors, and private-sector professionals attended the event. Additionally, BALIKA project staff participated in different national and international forums and presented an overview of the project.

\section{Website}

A website (creativeworldtech.com/balika/) enabled teachers to download the curriculum directly from the Internet. The site also included animation developed by the project. Providing a visual representation of characters and their problems helped students more easily grasp related educational materials. Students learn and absorb material more quickly if it is supported by illustrations, photos, and other graphics.

\section{Training of trainers (ToT) as mentors and teachers}

A comprehensive four-day residential training on basic life skills was imparted to in-school and out-of-school mentors in several batches. The training included the contents of the basic life-skills module, basic class management, and computer and tablet usage. Additionally, mentors received training on gender rights, education, or livelihoods depending on their categories. Training of Trainers on gender rights and awareness consisted of three-day-long intensive trainings with topics including: the difference between sex and gender, gender norms, gender equality, gender discrimination, gender-based violence, "eve teasing," and the consequences of child marriage. The livelihoods intervention offered five different types of training: basic computing, basic health screening, mobile phone-based applications, basic photography, and entrepreneurship. The trainings were based on the resource books that were developed by the project and included the teacher's guide and the session plan. Expert resource persons were hired for photography and health training. The training was made interactive by role play and practical application of materials. Emphasis was on the use of technology, especially computer skills, as the project used various digital contents prepared by mPower. A refresher training was also conducted at the end of the first year for the mentors.

\section{Mock demonstration sessions}

Apart from the yearly training for mentors, weekly practice training sessions were organized to improve the overall session quality and facilitation skills of mentors. Regular session monitoring visits by managers, senior research officers, and monitoring officers suggested that continuous training and feedback would enhance the knowledge and skills of the mentors on topics to be delivered at BALIKA centers. Once a week, mentors from all the unions gathered at the upazila office and participated in mock sessions in the presence of their supervising managers. The mentors demonstrated their preparations for the following week. 
They gave feedback to each other and received suggestions from the managers on content and presentation skills in order to improve the quality of the sessions.

\section{Monitoring}

Project activities were monitored using four different monitoring forms to assess the quality of sessions, track project activity and quality, track girls' attendance, and measure learning outcomes through an assessment of the girls. Project supervisors assessed class management and interaction between mentors and participants during session observations. An Android-based dashboard was developed to visualize data, track attendance at the individual beneficiary level, monitor activity progress, and take corrective action if needed by providing timely feedback to the implementing staff. Assessment questions were developed to periodically assess the learning outcomes of girls coming to the BALIKA centers. During the session visits, monitoring staff randomly selected girls for the assessment module.

Data recorded on a mobile device were sent to a central database. The monitoring data showed that class-management score improved over the time of the intervention. The performance of the livelihoods intervention increased more than the education and genderrights awareness intervention. Among the three districts, the quality of sessions was found to be better in Narail than Khulna and Satkhira. The reason for that may be that the program implementers in Narail had better educational qualifications and other social skills than the others.

A digital attendance system using ID cards with bar codes was introduced to take attendance of girls coming to BALIKA centers. The girls registered attendance by scanning the bar code in their ID card on a tablet that was equipped to read and store attendance infor-

mation and was linked by unique barcodes assigned to each participant. The data were then sent to a central project database using the Internet. Thus the attendance of individual girls was tracked through this process. One challenge of using this system is that if the ID card is lost or stolen, or if a girl forgets to bring her card, her attendance cannot be counted in the system.

Electronic monitoring of project activities was carried out in addition to manual monitoring. Electronic capture by project supervisors using an Android-based platform provided feedback on a systematic sample of approximately one-fourth of the field-level activities. The objective of the system was to provide timely feedback to program implementers so they could take corrective action as needed, as well as to keep a cumulative account of activities for later analysis of program impact. Monitoring was conducted at a variety of management levels.

The overall monitoring data collection system collected information on implementation of activities, quality of implementation using a rating system, utilization by intended beneficiaries in terms of attendance, and assessment of impact through qualitative monitoring of outcomes. The Android-based monitoring system was introduced seven months after the intervention because it took time to develop and train managers on the monitoring software. Selected indicators of the digital monitoring were compared with traditional monitoring data from the field. The auto-generated graphs presented on the dashboard were particularly useful for managers to track project activities at a glance.

The advantage of digital-monitoring software over manual monitoring was that during the monitoring visit the monitor was able to record the location using the Global Position System (GPS) and the time of measurement from start to end, as well as to take a live photo of the event to get an idea of participants present. These three indicators allowed management to 
obtain an overall picture of project activities and ensured greater accountability of field staff. Four different forms were developed as monitoring tools to evaluate and monitor activities at the BALIKA centers and other community-level activities. The four forms were:

- Center-based BALIKA activity monitoring form

- Student attendance register form

- Form to assess BALIKA session quality using four scales

- Assessment questions for participants (assess impact of activities)

The activity monitoring form described all the activities implemented throughout the intervention period of the project. Population Council and Population Services and Training Center (PSTC) program managers from Dhaka monitored the activities through monthly field visits, and field team monitors visited on a weekly basis to record activities. The activities were BALIKA sessions in schools; courtyard, advocacy, partners' coordination, and local supportgroup meetings; and mentors' weekly practice sessions.

The activity monitoring form indicates session participation of in- and out-of-school girls in BALIKA centers. Figure 5 shows that the highest average attendance of the girls was in the month of September 2014 and the average attendance was more or less stable around 12 to 14. Attendance dropped in the months of November and December due to the final exams of the in-school girls. The overall attendance was high during the intervention period, and the rate declined at the end of the intervention period.

FIGURE 5 Average number of program participants, by month and school status

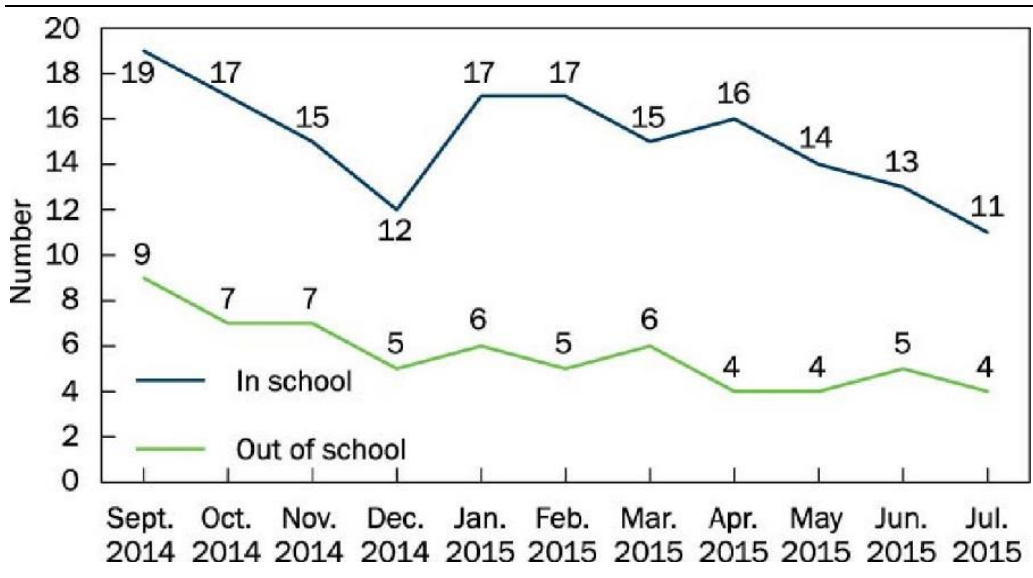


Figure 5 shows the average attendance of in-school and out-of-school girls. The average enrollment for both in and out-of-school sessions was 30 girls in each session. The graph clearly indicates that the attendance rate for in-school girls is higher than out-of-school girls. The highest attendance rate for in-school girls is 19 , while for out-of-school girls it is 9 . The attendance rate for out-of-school girls remains lower, because most of them are married and are busy with household chores or their children and often cannot get permission from their inlaws to attend the BALIKA sessions.

Some differences were found between the manual data that was managed by PSTC, the implementing partner, and the digital data that was developed by mPower, because the time period covered by the dataset is different. However, the trend of attendance is similar for inschool and out-of-school girls. The average scores vary, because the PSTC data were collected from the attendance register and the mPower data were collected by the individual monitor while visiting the session.

Apart from the activity monitoring form, a specific form was developed to assess the quality of the BALIKA sessions. Indicators like class management and interaction between mentors and participants were evaluated by monitors during sessions conducted by mentors. The class-management indicator was divided into six sub-indicators. The sub-indicators were measured using a scale of 1 to 5 , where 1 is the poorest score and 5 is the highest. The six sub-indicators for class management are girls' attentiveness, friendly behavior of teachers and mentors, group work at the session, interactiveness of the session, readiness of logistics, and session start time. Field monitors evaluated quality, scoring from 1 to 5 depending on performance at the respective session. The dashboard presented the overall impression of the quality of class management at a glance for all 72 intervention centers.

The median score of class-management performance was calculated month-wise, and it was found that quality of class management increased from an average score of 3.2 to a score of 3.6 at the end of the intervention. (See Figure 6.) These findings from the dashboard enabled managers to provide feedback on performance to field monitors and respective implementers, so that they could more efficiently carry out sessions with the girls at the BALIKA centers. Another analysis on class-management performance by intervention suggests that the performance of the education and gender-rights awareness interventions was more constant than the livelihoods-skills intervention. Performance in this intervention increased considerably from start to end; there were five different modules which may have

FIGURE 6 Median score on class-management indicators by month and intervention strategy

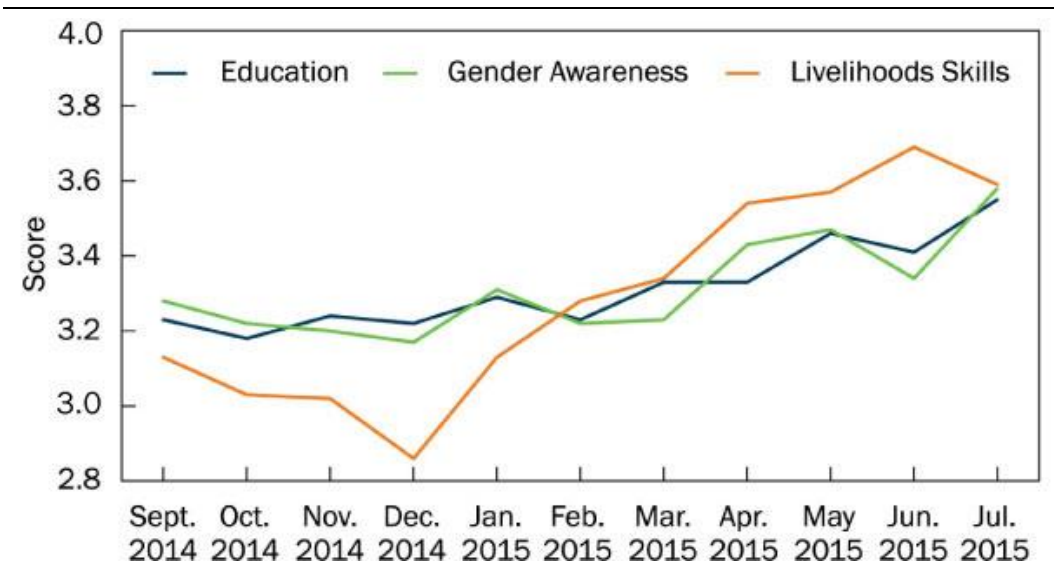

Sub-indicator was measured on scale of $1-5$. 
had different impacts on class-management scores. For example, some girls may have found photography and basic computer sessions more interesting than the other modules. Monthly fluctuations of performances were found as well, which may result from the irregular attendance and dropout of girls from the sessions. However, in all interventions the performance increased from the beginning to the end.

Figure 7 shows class-management scores by district. Narail district centers scored consistently higher than Khulna and Satkhira. The educational qualifications and other skills of Narail mentors are better than in the other two districts, which is why session quality is better in Narail. In Khulna district, there was a high turnover of teachers and mentors in the beginning, and the performance in class management indicates that from December 2014 onward perfomance increased. For Satkhira district, performance remained stable and increased toward the end of the intervention; an increase in performance as the intervention progressed is what all of our findings indicated.

FIGURE 7 Average score on class-management indicators, by month and district

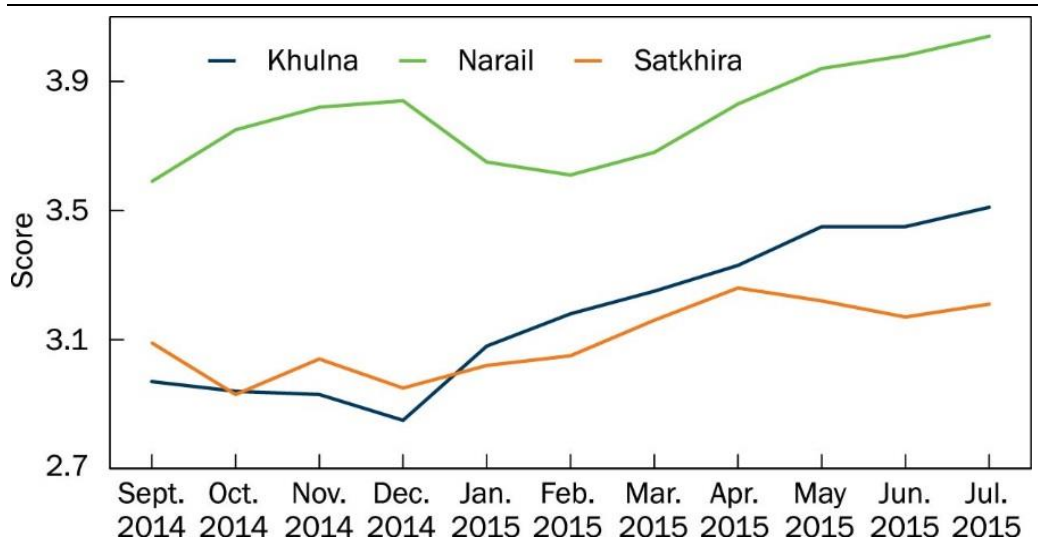

Another session-monitoring indicator was the quality of interaction between mentors and students. The average score was calculated using evaluation of quality on a 1-5 scale as assessed by monitors on several dimensions: cordial and pleasant with girls, ensured session was interactive and participatory, and followed instructions provided in the curriculum. Teacher guides encouraged BALIKA-center mentors and teachers to be creative and informal and to rely on a variety of interactive techniques. There were recommended group activities and games to engage the girls.

Overall performance ratings increased over time. In the month of December 2014, performance ratings and attendance were lowest because the in-schools girls were having their exams. The interaction between participants and facilitators was good, as the average score was 3.7 to 4.0 over the period. Any score above 3.5 out of 5 can be said to be good from the monitoring point of view.

In Figure 8, we can see that performance ratings varied over time in a manner similar to class-management performance. The interaction between mentors/teachers and students was better in the education and gender-rights awareness interventions compared with the livelihoods-skills intervention, where performance also increased from March 2015 toward 
the end of the intervention as the girls showed more interest in photography and computer than other modules.

FIGURE 8 Average performance score (assessing quality of interaction between facilitators and students), by month and intervention strategy

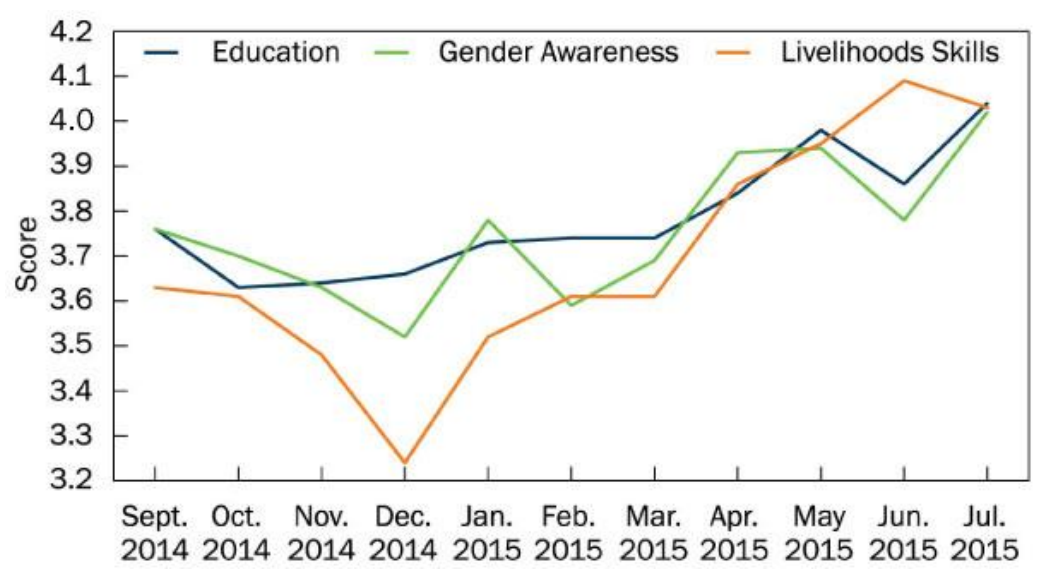

The in-school and out-of-school girls' score for interaction between teacher/mentors and girls shows that the score for out-of-school is less than the score for in-school, because there was inconsistent attendance and more dropout for out-of-school girls than in-school girls. The performance also increased for both groups, and out-of-school girls' performance increased considerably in the latter part of the intervention period (see Figure 9). Similar to class management, the score for Narail district is better than the other two districts. The trend also declined here from November 2014 to January 2015 because of school exams (Figure 10).

FIGURE 9 Average performance score (assessing quality of interaction between facilitators and students), by month and schooling status

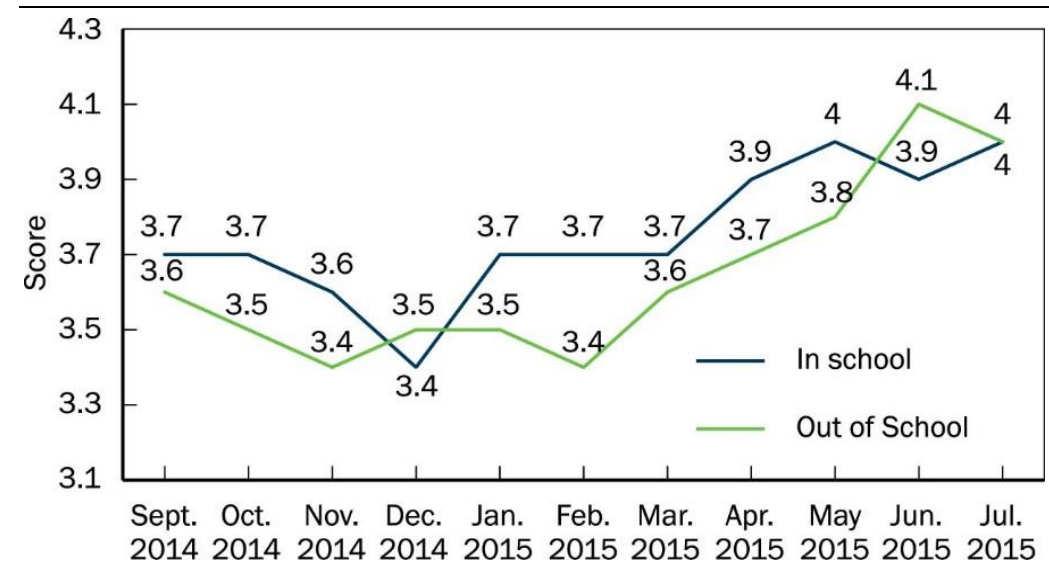


The overall pattern of improvement of session quality as assessed by supervisors, as well as the convergence of quality across interventions, is possibly attributable to the intensity of monitoring activities combined with regular mock demonstration sessions. The regularity of monitoring and close interactions among program mentors and teachers allowed good practices to be diffused among program implementers.

FIGURE 10 Average performance score (assessing quality of interaction between facilitators and students), by month and district

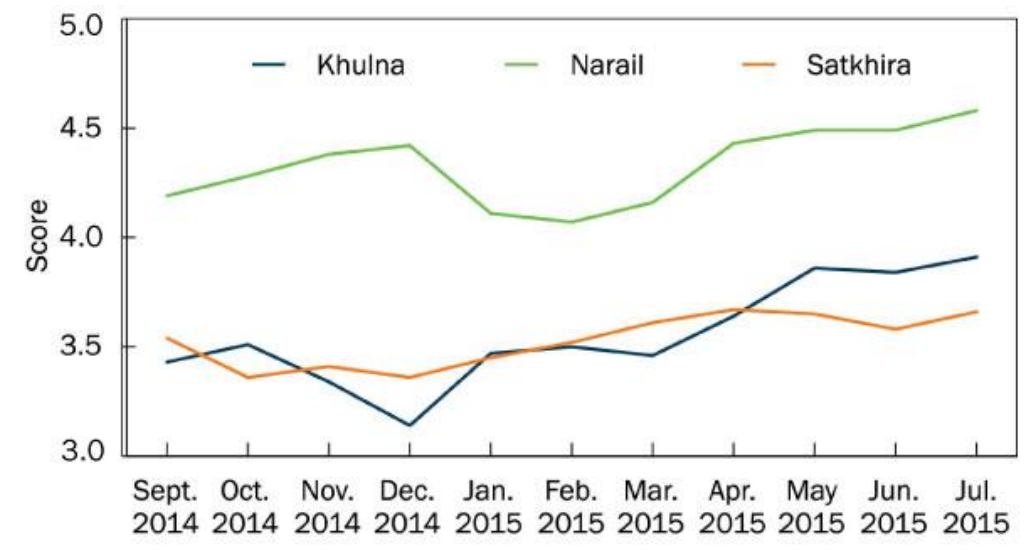





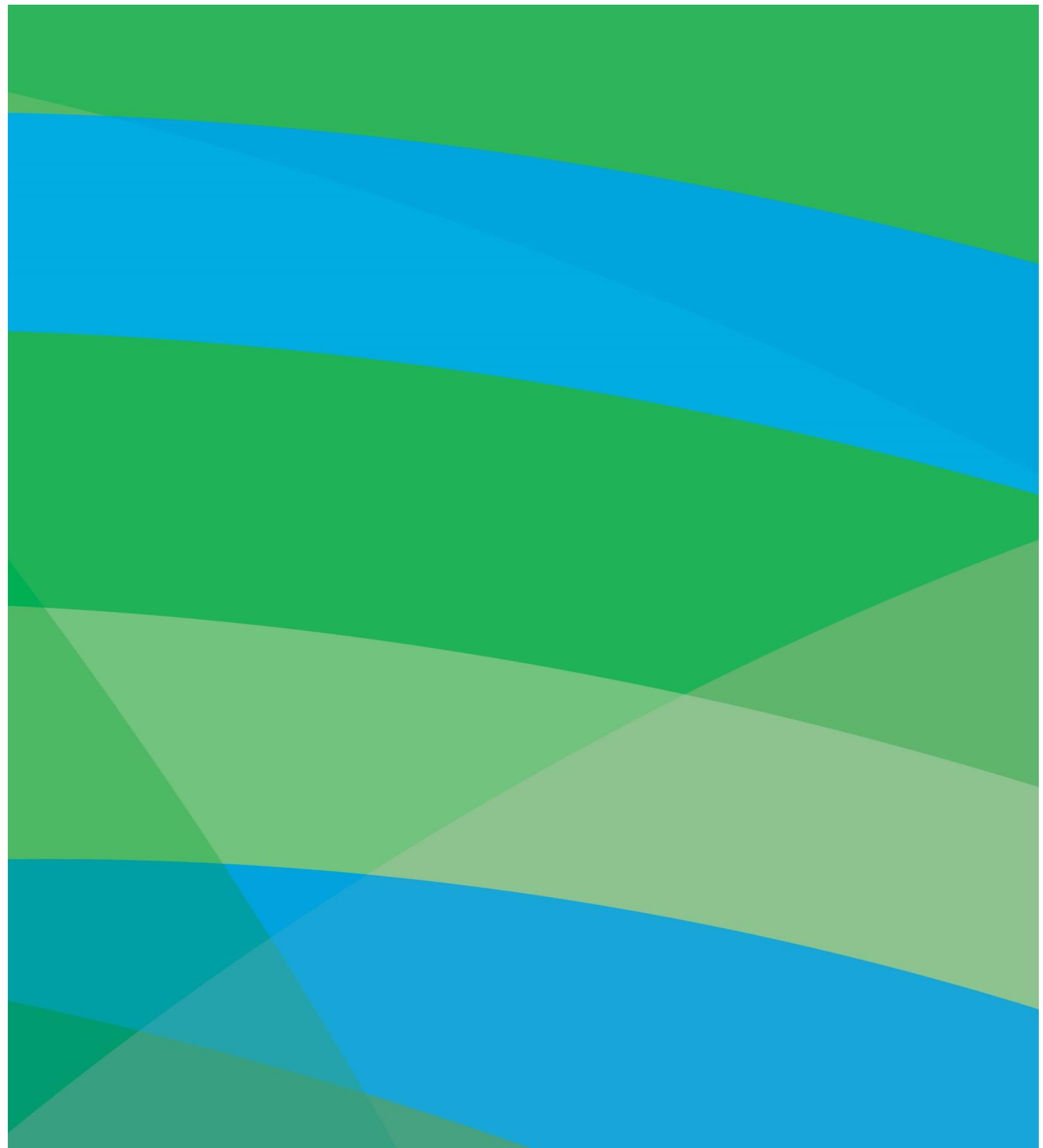

